\title{
IL RE CROATO DEL BASSORILIEVO PROTOROMANICO DI SPALATO
}

\section{IGOR FISKOVIĆ}

UDC: $73.041 .5(497.5)$ "10"

$73.033 .4(497.5)$

Original scientific paper

Manuscript received: 15. 04. 1997.

Revised manuscript accepted: 27. 04. 1997.
I. Fisković

Facolta di lettere

Università di Zagabria

Croazia

Mediante un'analisi trasversale del bassorilievo in marmo raffigurante una scena il cui protagonista è un re assiso al trono e affiancato da altri due personaggi, l'Autore interpreta il significato della composizione, valorizzandolo ampiamente. Vengono respinte le tesi secondo cui la composizione rappresenterebbe il Cristo e vengono offerte argomentazioni di carattere iconografico a sostegno del simbolismo profano e sostanzialmente politico dellopera in oggetto. In questo senso, l'Autore rileva analogie tra il monumento e altre realizzazioni dell'espressività artistica dell'XI secolo nell'ambito dello stile europeo occidentale, ponendo al contempo in risalto il valore antologico e l'esclusività del bassorilievo. L'Autore ne ipotizza la realizzazione per la chiesa e comune di Spalato al tempo del re croato Petar Krešimir IV (1058-1074) - verosimilmente il sogget to principale effigiato nella scena - in base al modello generalizzato del tema del Rex iustus. Vengono quindi analizzate le particolari condizioni di realizzazione del monumento nel contesto della prima fase della riforma ecclesiastica che ebbe luogo all'epoca e che fu appoggiata dall'arcivescovo Lorenzo (Lovro), al quale, come primate della Dalmazia, spetta anche il merito di aver promosso il legame tra la Chiesa regionale e il re croato. Tali argomentazioni sono avvalorate dal riscontro di un atto di damnatio memoriae inflitto al bassorilievo poco dopo la sua installazione originaria; in seguito esso fu trasferito nel battistero del Duomo, in ogni caso prima del Duecento. Riconducendo il senso ideale della scena al suo contesto storico e riallacciando l'opera allo sviluppo del primo romanico nell'Adriatico, vengono cosi sciolti nella maniera finora più esauriente quegli enigmi che da gran tempo erano sorti intorno al pluteo, nelle sue diverse interpretazioni.

Sono pochi i monumenti in Croazia, relativi al periodo preso ad oggetto del nostro Convegno, che hanno dato impulso a tante indagini quanto il bassorilievo marmoreo che si trova nel battistero del Duomo di Spalato e che raffigura un regnante assiso in trono. Il bassorilievo ha destato l'interesse dei primi storici dell'arte medievale dell'Adriatico orientale, sin a partire dalla metà del secolo scorso. ${ }^{3}$ Da allora quest'opera è stata spesso oggetto di dibattiti molto accesi, nel corso dei quali, d'altronde, si è giunti ad accertarne il carattere autonomo, stante la totale mancanza di esemplari analoghi. A partire da interpretazioni del tutto arbitrarie circa il significato del bassorilievo, attraverso titubanze nel riconoscerne lo stile, sino ad affermazioni contraddittorie circa la sua origine, sono state avanzate le ipotesi più disparate.

È così che in una quindicina di saggi pubblicati sull'argomento e in molte più opinioni espresse occasionalmente è possibile riconoscere non solo le incostanti linee di sviluppo della nostra disciplina, ma anche le fragili strutture della realtà culturale nostrana. In un certo senso, il destino di un patrimonio sorto al confine della civiltà europea, si rispecchia nelle analisi che lo concernono, viziate in passato anche da pragmatismo politico e incapaci di emanciparsi da un approccio di tipo non scientifico. ${ }^{2} \mathrm{Ne}$ è risultato che la critica d'arte propriamente detta e la storiografia occidentale nel suo complesso non hanno tenuto conto di una testimonianza di estremo e assoluto valore, nonché di un'opera che non esiterei a definire antologica. Menzionata solo casualmente e di sfuggita in qualche inventario europeo di monumenti tipologicamente affini, quest'opera è rimasta nascosta e oscura. Per di più, sul suo conto è stato detto e scritto negli ultimi tempi il contrario di quanto si riteneva acquisito una volta per tutte. ${ }^{3}$ Tali considerazioni, naturalmente, sono alla radice della mia scelta di riesaminare la questione alla luce delle recenti acquisizioni, affatto diverse da quelle sinora prospettate.
In realtà, è impossibile delineare in questa sede un quadro esauriente dei pareri sinora espressi riguardo il monumento spalatino, di cui stiamo vedendo la fedele riproduzione fotografica, e ciò per via del volume e della complessità del materiale disponibile. Peraltro, ho già affrontato l'argomento in termini piuttosto perspicui in una più ampia pubblicazione in lingua croata,${ }^{4}$ ragion per cui in questa sede mi soffermerò solo sui nodi della controversia che insistentemente si rinnovano come in un circolo vizioso. Da un canto, si è messo in questione a più riprese il contenuto del bassorilievo, contrapponendo alla vecchia tesi che in esso vedeva la raffigurazione di un regnante quella che in esso ravvisava la figura del Cristo. ${ }^{5}$ Esitazioni sono sorte anche circa la datazione dell'opera, che la maggior parte degli studiosi, in base ai suoi caratteri stilistici, situa incontestabilmente nella seconda metà dell'XI secolo, benchè occasionalmente vi siano tentativi di confutarla. ${ }^{6}$ Le indagini sull'origine e sull'ubicazione originaria del bassorilievo restano virtualmente aperte fintantochè si continua a escludere che esso sia stato eseguito a Spalato - dove si trova da gran tempo - ritenendo per contro che provenga dalla località dalmata di Salona. ${ }^{7}$ Dal momento che tali ipotesi non risultano decisive ai fini delle due possibili interpretazioni or ora citate, mi occuperò anzitutto dell'iconografia legata alla morfologia e, per certi aspetti, anche alla datazione. A tale scopo si rende ovviamente indispensabile descrivere l'opera e chiarire le circostanze storiche in cui essa sembra essere stata realizzata. ${ }^{8} \mathrm{~A}$ una migliore comprensione di tali circostanze concorrono anche le modifiche subite dal monumento nel corso dei secoli, alle quali, pertanto, dedicherò l'attenzione dovuta, ritenendole estremamente significative anche per ciò che riguarda il significato el'ubicazione originaria del bassorilievo. Tali modifiche non svalutano tuttavia nè l'identità nè tanto meno l'integrità del monumento, che indubbiamente si situa ai livelli più alti della produzione scultorea coeva in Dalmazia. 


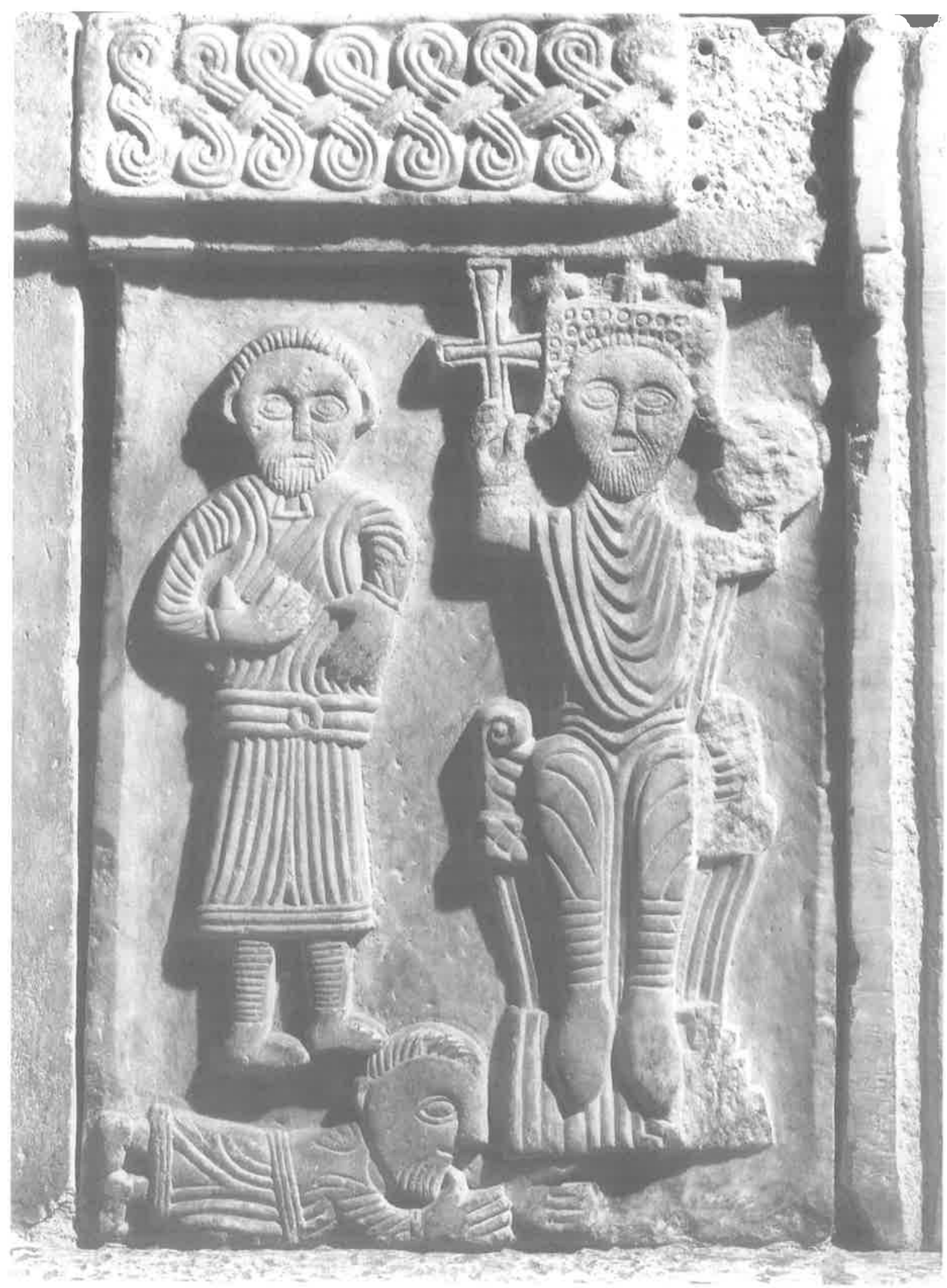

Il rilievo del re e delle due figure nel battistero di Split

Sulla lastra marmorea $(104 \times 63 \times 18 \mathrm{~cm})$, all'interno di una composizione asimmetrica piuttosto densa, ma ciò nondimeno perfettamente leggibile, sono dunque effigiati tre personaggi maschili. Le tre figure emergenti in bassorilievo appaiono fortemente sbalzate dal fondo liscio e scabro, mentre i loro corpi risultano piatti e immobili, ciascuno con il proprio gesto. Prese singolarmente, le tre figure appaiono tuttavia diversamente elaborate, mediante un disegno netto dal tratto marcatamente lineare, che ne sbozza e al con- tempo ne semplifica la fisionomia in una stilizzazione quasi ornamentale. ${ }^{9}$ La misura in cui quest'ultima si affranca dai termini di una scomposizione puramente grafica, vale a dire la misura in cui essa trascende la mera lavorazione a intreccio, risponde palesemente a un canone iconografico orientato alla rappresentazione realistica. La metà sinistra della lastra ospita una figura posta in piedi, frontalmente, con le mani davanti al busto come se recassero un oggetto, mentre le gambe sono viste di profilo. Al di sotto di essa 
giace orizzontalmente un'altra figura, di dimensioni notevolmente ridotte e goffamente appiattita sul margine inferiore della lastra. Anch'essa è raffigurata di profilo, con le braccia protese oltre il capo, proporzionate non già al corpo del personaggio bensì a quello delle due altre figure. Entrambi i personaggi sono a capo scoperto e portano la barba; inoltre sono abbigliati in modo simile, come risulta dalla sommaria lavorazione scultorea dei corpi e dei panneggi. ${ }^{10}$

La figura a destra, la più grande e senza dubbio la principale, è realizzata con una tecnica analoga. Siede in trono e ha il capo cinto da una corona dalla foggia singolare. Le braccia geometricamente alzate e raccorciate recano una croce e un globo, il tutto in un'inalterata posizione frontale, manifestamente dichiarativa del suo status regale. Le sue vesti appaiono più ricche, proprio in quanto plasticamente differenziate, ovvero più accentuate rispetto all'approssimazione tendenzialmente bidimensionale delle altre due figure. Al voluto risalto di questo personaggio contribuisce anche il trono, appena sbozzato ma con raccorciamenti spaziali conformi alle conquiste stilistiche dell'epoca. Nella sintassi dei caratteri formali non è del tutto rimossa la maniera scultorea preromanica, a cui la nostra scena figurale si riallaccia per via della decorazione a intreccio posta nella fascia superiore della lastra e marcata separatamente a mo' di cimasa. ${ }^{11}$ Tuttavia, nel caso delle effigi dei tre personaggi - e in specie nell'intaglio della principale — si è ricorsi all' arrotondamento del rilievo e alla levigatura delle superfici, il che da un canto denota l'adesione al linguaggio plastico del primo romanico e dall'altro la possibile riproduzione di un qualche disegno preparatorio del bassorilievo.

Il bassorilievo fa parte del fonte battesimale posto nel mezzo del monumentale battistero del Duomo di Spalato, ovvero di quello che una volta era il tempio principale del palazzo di Diocleziano, in seguito designato come Santuario di S. Giovanni Battista, conformemente alla sua nuova destinazione. ${ }^{12}$ Il volume del fonte si compone di sottili blocchi marmorei posti in senso verticale a formare ciascuno un lato di dimensioni uguali. L'altezza delle lastre testimonia la prassi del rito battesimale per immersionem; l'insieme viene di solito fatto risalire al XIII secolo (ma su quest'ultimo punto torneremo in seguito). Il dato che invece ci preme subito evidenziare è l'armonia del monumento, determinata tra l'altro dal suo piedistallo quadrangolare, leggermente debordante rispetto al piano dell'elemento sovrastante a croce greca. Le basi del non alto piedistallo in pietra poggiano direttamente sulla sostruzione di epoca antico-romana. Il piedistallo è stato senz'altro realizzato unitamente alla vasca di marmo, ${ }^{13}$ la quale, dal canto suo, risulta dall' assemblaggio di materiali di diversa provenien$\mathrm{za}$, adattati alla forma dell'insieme.

Su due delle lapidi si ravvisano tracce di iscrizioni che ne hanno fatto dedurre la provenienza da sarcofagi pagani. ${ }^{14}$ Diverse lastre del recinto sono completamente lisce, mentre sei di esse conservano tuttora sulla faccia esterna la lavorazione a rilievo, benchè siano state ridotte in larghezza per commetterle e fissarle l'una all'altra. Su ciascuna delle lastre, la composizione decorativa si sviluppa su due piani, di cui l'inferiore è quattro volte più alto del superiore. Il rettangolo verticale è riempito di combinazioni geometriche - in prevalenza di ben noti motivi a intreccio - , mentre quello superiore orizzontale reca una cimasa intrecciata in modo più compatto. ${ }^{15} \mathrm{I}$ due piani sono separati da una sottile fascia scabra, la cui funzione è peraltro di graduare l'aggetto della superficie terminale. Il carattere di quest'ultima è definito anche dal suo contorno, e mentre i lati delle superfici sottostanti si restringono lievemente verso l'alto, le sovrastanti si delineano dritte come pure sopra il bassorilievo figurale di cui in questa sede tratteremo per esteso.

Tutto concorre a dimostrare che questi plutei costituivano una sfarzosa recinzione presbiteriale, che per l'estrema finezza dell'intaglio si inscrive a pieno titolo nell'esperienza preromanica dalmata. ${ }^{16}$ L'elevato grado di maturità del linguaggio stilistico ci è rivelato dall'apparire del pentagramma posizionato in modo molto regolare, con i suoi complementi figurativo-simbolici, al centro di una delle lastre riccamente decorate. ${ }^{17}$ Bisogna tener conto anche di questo dato laddove si voglia esprimere un giudizio più fondato circa il contenuto e l'origine del monumento, a cui tutte le lastre, realizzate secondo un criterio uniforme, appartennero all'origine. Per il momento, comunque, ci basterà evidenziare che la lavorazione delle lastre del fonte è conforme a quella della scena figurale da noi presa in esame, il che comprova inequivocabilmente la loro identicità stilistica e la loro origine comune.

Che il bassorilievo sia stato concepito - e lo è senza alcun dubbio - come elemento dell'arredo del presbiterio, è un dato non trascurabile nell'interpretazione integrale dell'opera, in quanto la riconnette a quell'ampia e articolata tradizione regionale in seno alla quale la realizzazione dei recinti per altari rappresentò per secoli una parte cospicua della produzione scultorea. ${ }^{18} \mathrm{Fu}$ anzi proprio assumendo a modello alcuni esemplari artisticamente eccellenti di questa stessa tipologia di opere, che si aprì la strada al primo romanico dalmata, fatto, questo, che nel resto d'Europa non si verifica in modo così evidente. ${ }^{19} \mathrm{Al}$ fenomeno non è stato dato sufficiente rilievo, mentre si spiega, a mio avviso, con la continuità di una tradizione mantenuta sin dall'epoca tardoantica. In conformità con le influenze dell'Oriente, già le prime chiese cristiane sorte sui litorali dell'Adriatico presentavano spesso setti recanti composizioni figurativosimboliche, ${ }^{20}$ estintesi nel corso del tempo, come è successo ovunque con il prevalere delle concezioni figurative altomedievali e con la generale evasione della scultura nelle astrazioni del linguaggio ornamentale. ${ }^{21}$ Tuttavia, il carattere di standardizzazione prevalso nel processo di consolidamento di un genere di arredo scultoreo comprova molto verosimilmente anche il carattere provinciale delle creazioni artistiche in seno a un ambiente che promuoveva con successo lo stile sulle basi di opere tradizionali e quasi arcaiche. Inoltre, accanto ad altri esempi ugualmente rappresentativi risalenti all'XI secolo e provenienti dalla Croazia meridionale, anche la descritta opera di Spalato può essere assunta a testimonianza di un'aspirazione, generalmente diffusa all'epoca, al rinnovamento nell'arte sacra dello spirito del primo Cristianesimo. ${ }^{22} \mathrm{D}$ 'altro canto, naturalmente, l'assestamento strutturale della liturgia, nonché della forma estetica del punto focale dell'uffizio divino all'interno dello spazio sacro - e probabilmente era questo il compito del monumento - è conforme agli ideali della generale riforma della vita e dell'espressione religiosa.

Tutti questi parametri vanno tenuti a mente poiché contribuiscono - come dimostrerò più avanti — alla formulazione del significato complessivo del monumento in questione; e poiché risultano decisivi anche per la definizione delle qualità formali del monumento, sinora mai valorizzate a sufficienza, nonostante la loro esatta classificazione stilistica. Riconosciuto come prodotto del primo romanico, che nella seconda metà del XI secolo dà nuovo impulso alla figurazione scultorea in Dalmazia, il monumento, insieme 
agli altri affini, provenienti dall'ambito spalatino, viene assegnato al cosiddetto "gruppo zarato-spalatino di sculture altoromaniche". ${ }^{23}$ Al contempo, esso viene fondatamente accostato ai plutei della chiesetta di S. Domenica a Zara - forse più celebri del nostro bassorilievo - mentre dal punto di vista morfologico viene messo in rapporto con il ciborio del proconsole Gregorio, realizzato attorno al 1032 nella stessa città del litorale, situata più a nord di Spalato. ${ }^{24}$

Pur volendo accogliere tali considerazioni, è impossibile non sottolineare il grado stilistico più maturo e probabilmente anche più avanzato del bassorilievo spalatino. In tal senso il primato concesso ai plutei di Zara, ${ }^{25}$ dimensionalmente maggiori ma di composizione più arcaica, non è a mio giudizio sostenibile, risultando l'articolazione plastica del nostro bassorilievo più elaborata e inoltre più compiuta. Oltre al fatto che la composizione asimmetrica del trio figurale denota una spazialità più libera e di felice armonia, è di particolare valore la differenziazione della materia, accanto alla già menzionata illusione di profondità ottenuta con i mezzi di una prospettiva ancora scarna. Ciò è visibile nel raccorciamento geometrico dei contorni e delle superfici del piedistallo su cui poggia il trono, quest'ultimo foggiato con un'attenzione realistica inusitata per l'epoca, e il tutto è reso ancor più suggestivo dallo schiudersi ai lati del manto nell'atto goffo con cui il sovrano alza le braccia. Anche gli arrotondamenti di volume delle calzature nonché la forza persuasiva con cui sono rese le sporgenze all'altezza delle ginocchia che risaltano fra i panneggi spiegati con naturalezza, come anche la forma dell'unica mano conservata, che impugna la croce, rivelano in egual misura la straordinaria abilità dell'artista. In questo senso bisogna salutare i tentativi di individuare l'autore del bassorilievo, pur non potendo condividere la proposta avanzata riguardo il suo nome, trattandosi in questo caso di un'opera superiore alle altre della stessa epoca e della stessa zona. ${ }^{26}$

L'indicazione dei fatti sopra esposti costituisce solo la base di un discorso sui possibili significati del bassorilievo, che vengono discussi, come ho già messo in rilievo nell'introduzione, da molto tempo. Nonostante le varie divagazioni e individuazioni prevalentemete mancate degli elementi essenziali dell'opera, risulta comunque e incontestabilmente che il soggetto principale della scena è un re seduto sul trono, un dato, questo, che va assunto come punto di partenza. A tale constatazione dobbiamo, tuttavia, subito aggiungere un fatto comunemente noto, che, cioè, all'epoca della realizzazione del bassorilievo non vi era una netta distinzione nella rappresentazione di un sovrano celeste o terrestre, ${ }^{27}$ del Cristo o di un imperatore o re. Nell'arte medievale, scene sul genere del nostro bassorilievo (difficilmente enumerabili in questa sede) sono di regola a carattere rituale e rimandano a un simbolismo che allude alla glorificazione dell'uno come dell'altro (Cristo o imperatore) ${ }^{28}$ Esse traggono origine, come si è dimostrato in più occasioni, dalle antiche cerimonie praticate alla corte imperiale, ${ }^{29}$ ovvero dall'immaginario ufficiale in uso sia in Oriente che in Occidente.

Nel processo di acquisizione di usanze e atteggiamenti, tale immaginario - come è ben comprensibile - è stato assunto anche dalla Cristianità. ${ }^{30} \mathrm{E}$ con il progressivo affermarsi dell'ideologia che riconosce nel governante politico l'eletto da Dio e il vicario di Cristo sulla terra, la civiltà cristiana ha definito le formule di identificazione figurativa tra i detentori del potere universale e di quello temporale. ${ }^{31}$

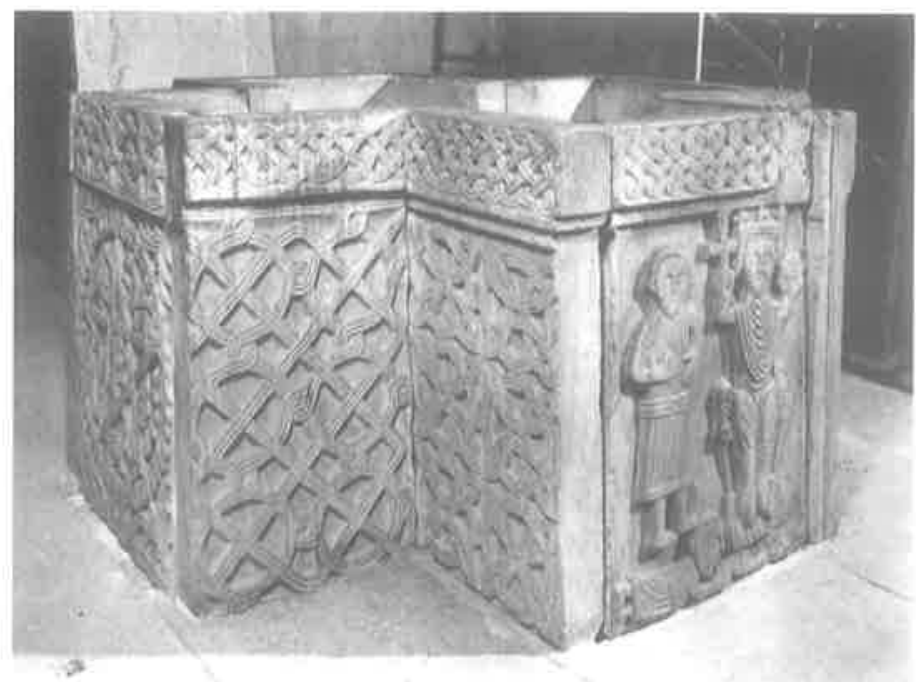

Il fonte battesimale - vista dalla parte sud-orientale

La trasposizione dello schema iconografico della maiestas domini nelle figurazioni dei re cristiani, si fonda sulla visione che riconosce in ciascuno di essi un'emanazione di Cristo tra gli uomini. ${ }^{32} \mathrm{E}$ in questa misura che le rappresentazioni analoghe di questi personaggi appartengono tutte a una routine figurativa che - a seconda della destinazione dell'opera - sapeva tradurre le idee generali in immagini talora storicamente allusive, rivelazioni di stati ideali piuttosto che annotazioni di eventi concreti. ${ }^{33}$ In tal senso, anche il bassorilievo di Spalato viene ad assumere estremo interesse, poiché pur non fornendo riscontri espliciti di sorta, offre comunque punti di appoggio tematici che si prestano a svariate interpretazioni, sinora costantemente offuscate.

Attenendomi a quanto stabilito sul conto del nostro bassorilievo e seguendone l'ordine interpretativo, vorrei menzionare alcune verità di carattere tecnico per nulla trascurabili. Scene analoghe a quella del bassorilievo, con la loro mescolanza di astratto e di reale, nella tradizione europea sono per lo più realizzate in altri ambiti dell'espressione artistica. L'estrema scarsità delle opere realizzate nell'ambito scultoreo si registra persino nell'ambiente culturale mediterraneo, dove le tradizioni ereditate dall'antichità esercitavano maggiore influsso per quanto concerne l'uso dei mezzi espressivi. Un più ampio materiale comparativo proviene principalmente dai generi di espressione non plastica, dove la composizione viene riprodotta mediante l'uso di elementi codificati e dal contenuto prestabilito. ${ }^{34}$ Materiale di questo tipo si riscontra soprattutto in oggetti ad uso liturgico, di lavorazione artistica ad alto livello, vale a dire relativi alle sfere religiose che ne annullano i significati profani, in accordo con la spiritualità medievale.

Le rappresentazioni disponibili a cui in linea di massima il bassorilievo spalatino può essere collegato, riguardano principalmente stirpi di titolari della corona imperiale franca, ma esistono anche rappresentazioni di sovrani di provincia. Tali opere sono tutte di dimensioni minori e figurano per lo più su manufatti di arte applicata. ${ }^{35}$ Stante il carat tere eccezionale del bassorilievo, che è scolpito in pietra, ovvero in marmo, e che fa parte dell'arredo liturgico, quanto appena detto rende incontestabile l'unicità del monumento spalatino. Comunque, per ciò che concerne la prassi di interconnessione dei soggetti che figurano ciascuno su una diversa componente dell' arredo liturgico, il nostro bas- 


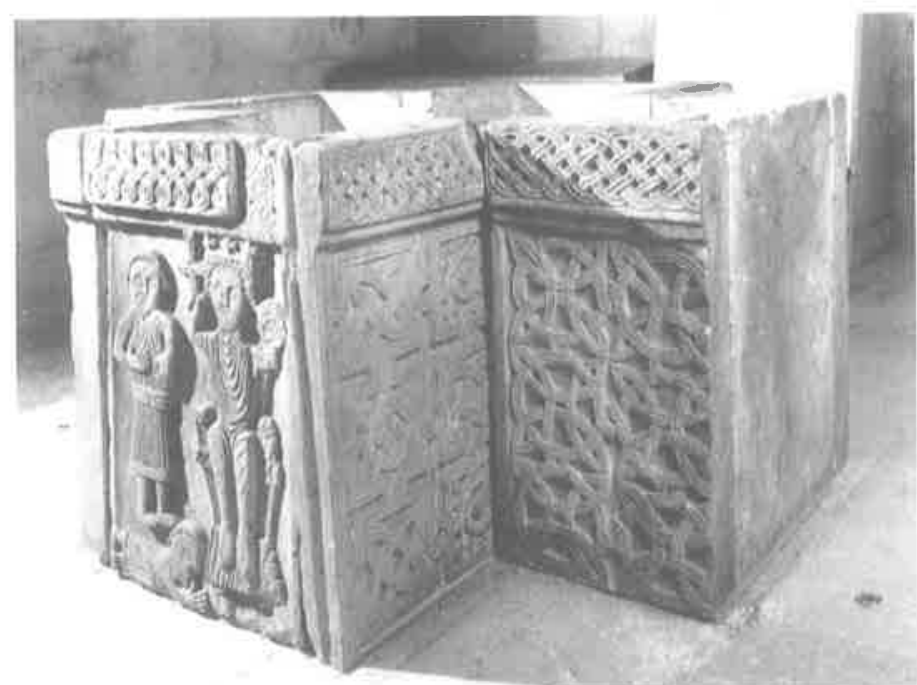

Il fonte battesimale - vista dalla parte nord-orientale

sorilievo ricalca sino a un certo punto certi esempi provenienti dalla Croazia meridionale, il che ci induce a riconoscerne le radici nella tradizione regionale. ${ }^{36}$ Bisogna inoltre rendersi conto di come il valore di questo monumento trascenda le modalità di approccio sinora adottate, richiedendo analisi più comprensive di quelle sinora svolte.

I dilemmi-chiave formulati dagli studiosi circa il significato e la genesi del bassorilievo, ci inducono inevitabilmente alla ricerca di possibili analogie nell'ambito dell'arte altomedievale entro un territorio più vasto, ma della stessa sfera culturale. A tale riguardo vorrei anzitutto respingere la tesi che vede nel soggetto principale del bassorilievo una raffigurazione del Cristo, apportando nuovi argomenti a favore di quella che in esso ravvisa un sovrano secolare, da me sostenuta sin dall'inizio. ${ }^{37}$ A vantaggio di quest'ultima è sufficiente analizzare gli aspetti iconografici dell'opera, in cui, a mio giudizio, il fatto maggiormente significativo è che il sovrano in questione appaia privo di aureola. Raffigurazioni del Figlio di Dio senza aureola sono ignote all'XI secolo nè tanto meno sono ammesse dal dogma, ${ }^{38}$ per cui non possono risultare dall'esame di qualsivoglia opera. Nonostante si tratti prevalentemente di rappresentazioni della gloria di Cristo, dove egli appare come figura autonoma, è sottinteso che anche in altri cicli narrativi, di tipologia diversa, il Figlio di Dio debba figurare sempre con gli stessi attributi. Proprio in ambito croato ciò è confermato dai già citati plutei della chiesetta di S. Domenica a Zara, che del resto vengono comunemente messi in rapporto con il nostro monumento. ${ }^{39} \mathrm{Su}$ ambedue le lastre, cioè, tutta una serie di personaggi che prendono parte al ciclo narrativo sulla vita di Cristo è sprovvista di aureola semplicemente perchè non spetta loro, mentre i santi, viceversa, portano un'aureola a guisa di semplice cerchio, e il protagonista della narrazione reca il nimbo con la croce, di regola anche quando viene rappresentato come bambino.

È pertanto da escludere che il suddetto segno di identificazione del Cristo sia stato tralasciato nella raffigurazione del Signore del Mondo intronizzato su un bassorilievo dello stesso ambito culturale, se non addirittura della stessa cerchia di botteghe scultoree. Per altro, già in realizzazioni europee di data antecedente e della stessa tipologia artistica, Cristo è in genere sormontato un cerchio iscrivente una croce. ${ }^{40} \mathrm{Se}$, da un canto, in Dalmazia opere plastiche di questo tipo sono piuttosto infrequenti, dall'altro l'usanza viene confermata in numismatica, dalle monete in uso prima e dopo l'XI secolo, sulle quali il motivo ricorre ripetutamente. ${ }^{41}$ Lo stesso motivo sta ad indicare la santità del Salvatore ovunque in pittura, sia in quella libraria che in quella murale, nelle miniature come nella pittura monumentale..$^{42}$

Naturalmente, al centro del nostro interesse vi è la rappresentazione del regnante sul trono. Tra numerose raffigurazioni analoghe della gloria di Cristo, egli non appare in alcun luogo - almeno per quanto mi sia stato dato osservare - senza aureola e con la croce e il globo in mano. ${ }^{13}$ Questi oggetti compaiono solo singolarmente nella sinistra di Cristo, e anche in questo caso in via del tutto eccezionale, poiché a simbolo-chiave della sua missione spiriturale e storica prevale di norma il libro dei Vangeli, mentre con la mano destra egli impartisce la benedizione. ${ }^{44}$ Sono proprio questi ultimi i simboli dell'onnipotenza teorica del Figlio di Dio, del suo dominio universale sul mondo, poiché egli è il più elevato degli incoronati e innalzati al trono. Accanto all'assenza dei principali segni distintivi della santità del Cristo, mancano nella composizione asimmetrica del bassorilievo spalatino pure altri motivi che potrebbero giustificare un ulteriore soffermarsi sulle ipotesi che in esso riconoscono la figura del Cristo.

Non resta dunque che un'unica possibilità, ovvero quella di riconoscere nel personaggio incoronato e assiso al trono, in posizione frontale, un sovrano secolare. Per lui parlano anche gli oggetti che tiene nelle mani, poiché la croce e il globo simbolizzano di regola, sin dalla tarda antichità, la dignità e i diritti di diversi sovrani di paesi cristiani. ${ }^{45}$ Benchè sia stato scritto di frequente che non esistono a tale riguardo leggi imprescindibili o norme fisse, ${ }^{46}$ l'identica disposizione della croce nella destra e del globo nella sinistra è testimoniata da una serie di esemplari rappresentazioni pittoriche di sovrani secolari medievali. ${ }^{47} \mathrm{Nel}$ nostro caso, l'importante è che gli esempi bizantini di questo tipo siano tutti posteriori, fatta eccezione per quelli numismatici, il cui ruolo nella trasposizione di modelli figurativi non è da trascurare. ${ }^{48}$ Sono interessanti invece gli scritti che testimoniano la regolarità con cui il fenomeno si verifica nell'ambito dell'iconografia regale occidentale, durante i secoli che videro l'istituirsi del primo Stato croato sulle stesse basi delle altre entità componenti l'Impero franco. Supponiamo che insieme agli orientamenti politici la Croazia

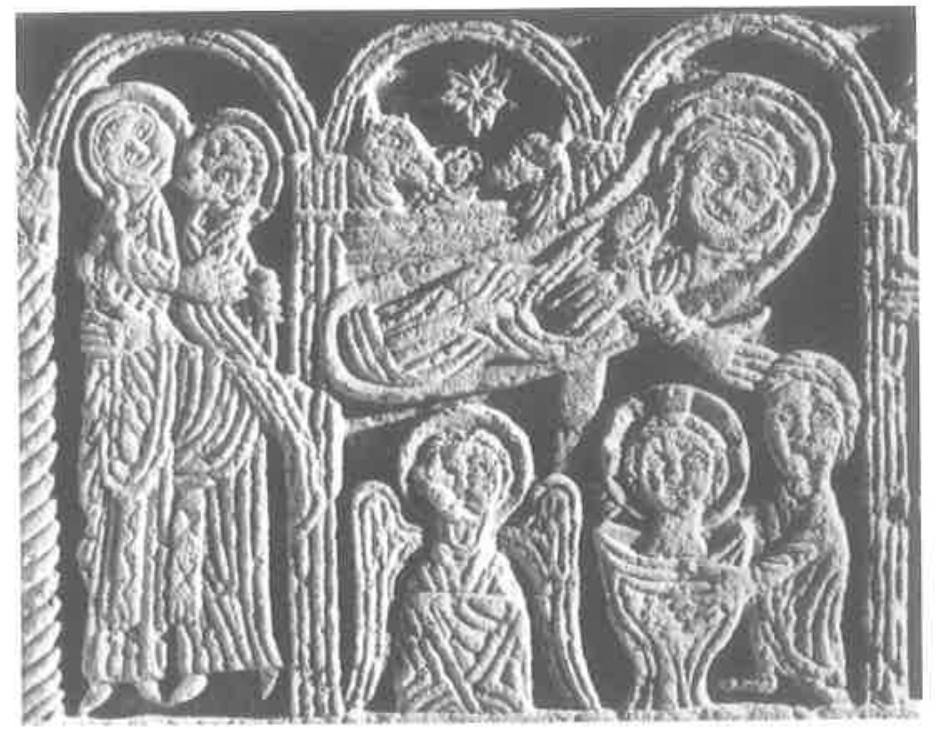

Parte del pluteo di S. Domenica a Zadar-metà del sec. XI 
riprendesse anche le forme occidentali di cerimoniali di corte, di maggiore influsso rispetto a quelle orientali; bisogna però notare che i due tipi di cerimoniale hanno radici comuni che risalgono all'epoca del tardo Impero romano. ${ }^{49}$

Rimanendo nello stesso ambito metodologico, bisognerà dedicare qualche parola all'oggetto posto un po' più in basso rispetto alla croce, nella mano sinistra del sovrano - quella che è stata danneggiata in superficie nella fase di muratura della lastra nel fonte battesimale. Si tratta certamente di un globo che, come è risaputo, rappresenta, in quanto simbolo di potere universale, l'attributo più marcato (secondo la bibliografia disponibile, pare sia più un simbolo convenzionale che non un'insegna imprescindibile) del sovrano secolare. ${ }^{50}$ Nell'idea che l'Alto Medioevo aveva del potere e dell'autorità, il globo occupa un posto speciale, basato su leggi risalenti all'antichità, e viene attribuito in vari modi anche al Cristo, nelle cui mani rappresenta il mondo governato dal Figlio di Dio. Chiaramente, i capi delle maggiori comunità politiche hanno avocato a sè tale diritto, in qualità di vicari di Cristo e volendo anche in questo imitare Roma ${ }^{51} \mathrm{Ma}$ da che la cultura carolingia ha acquisito la sua autonomia, nel mondo latino è stata adottata la forma sferica più semplice: un globo spoglio senza aggiunte in cima e senza applicazioni sulla superficie. ${ }^{52}$ Direi che sul nostro bassorilievo figurava proprio un globo di questo genere, poiché, nonostante sia danneggiato, ne è ancora ravvisabile nitidamente il contorno. Quanto alla croce, che di solito figurava in cima al globo simbolico, essa è contrastata da quella che figura nell'altra mano del sovrano e, quindi, si è voluto evitare una ripetizione illogica. La croce, poi, situata nel centro visivo del nostro bassorilievo, è di forma troppo generica per consentire analisi più dettagliate che comunque non ci porterebbero a sapere molto di più, ma servirebbero soltanto a confermare un uso figurativo verificabile in base a numerose fonti. ${ }^{53}$ Stante il realismo della rappresentazione, la croce non può essere intesa che come una probabile testimonianza dell'aspirazione a raffigurare la concretezza storica di certe situazioni. Certo è che esemplari di croci in metallo simili a quella del nostro bassorilievo, erano in uso lungo le coste dalmate. ${ }^{54}$

Simili tesi vengono rafforzate da altri dettagli della soluzione figurativa del bassorilievo, il cui stile come anche il periodo di realizzazione, può essere stabilito con sicurezza. A questo riguardo si è ormai concluso da diverso tempo il dibattito sulla foggia o sul tipo di corona che, a confronto con la natura generica degli altri attributi considerati in questa sede, ha suscitato un particolare interesse da parte degli studiosi. ${ }^{55}$ In modo sostanzialmente corretto, gran parte degli studiosi è concorde nel ritenere che l'oggetto in questione sia una corona in metallo adorna di perle e foggiata con semplicità a guisa di diadema munito di paraorecchi laterali nonché di una decorazione di tre crocette in cima. ${ }^{56}$ L'importante è che lo stesso tipo di corona appare anche in altre fonti, e che le tre crocette finali (cornetti o fiorellini a seconda delle varianti) indicano convenzionalmente sovrani secolari. ${ }^{57}$ Inoltre, la presenza di corone più o meno simili è accertata anche in monumenti artistici o in figurazioni coeve, non solo in Occidente, ma anche in ambito croato.

Una corona identica è posta infatti sul capo di un sovrano regionale - ripetutamente accertato come tale - effigiato nell'affresco della chiesetta di S. Michele, nei pressi di Stagno (Ston), risalente al tardo XI secolo ${ }^{58}$ Raffigurato con un modellino di edificio ecclesiastico, ben riconosci-

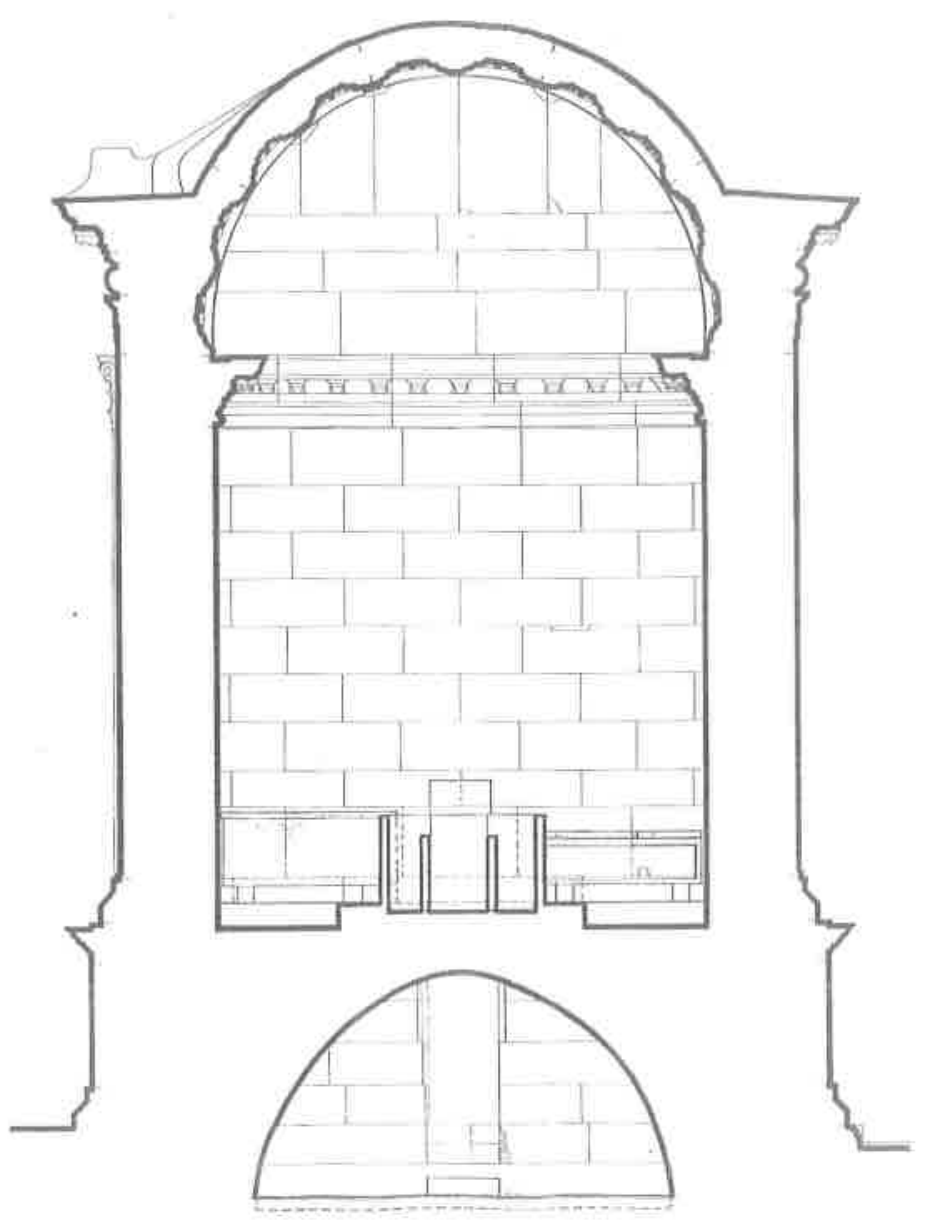

Sezione trasversale del Battistero, originariamente un tempio del secolo IV

bile, tra le mani, nel ruolo di fondatore o donatore del medesimo, questo regnante, storicamente identificato con certezza, viene considerato un analogo da cui si può dedurre l'origine profana del protagonista nel nostro bassorilievo. ${ }^{59}$ Anche i paludamenti dei due personaggi presentano analogie, per quanto sia dato paragonarli vista la schematizzazione quasi geometrica del linguaggio pittorico e scultoreo del primo romanico. Tutti e due, portano un corto mantello gettato sulle spalle, e inoltre calzettoni e una sorta di babbucce. ${ }^{60}$ La tunica indossata dal protagonista dell'affresco non è però così nitidamente visibile sul soggetto principale del bassorilievo, dimensionalmente ridotto rispetto al primo, poiché nell'opera di Spalato i panneggi si fondono con la stilizzazione scultorea del trono. Quest'ultimo segue anch'esso gli stilemi della tradizione europea, per cui può essere considerato un tratto iconografico del sovrano secolare, ${ }^{61} \mathrm{o}$ in ogni caso il marchio distintivo della sua dignità.

Tutte le componenti dell'immagine plastica contribuiscono con ogni evidenza alla costruzione della totalità del suo messaggio, nel rispetto del canone artistico medievale sull'armonia di forma e contenuto. Infatti, nel nostro esempio i fattori di questi due poli di lettura dell'opera sembrano essere, in maniera allusiva, gli elementi più accentuati. Certe sfumature della descrizione plastica si direbbero cioè tutt'altro che casuali, come dimostrano le proporzioni dei singoli elementi, con la particolare accentuazione degli attributi regali: la croce, la corona e il globo. ${ }^{62}$ Oltre a essere alquanto ingranditi e foggiati più dettagliatamente rispetto al resto, essi sono scolpiti entro una rigorosa struttura geo- 


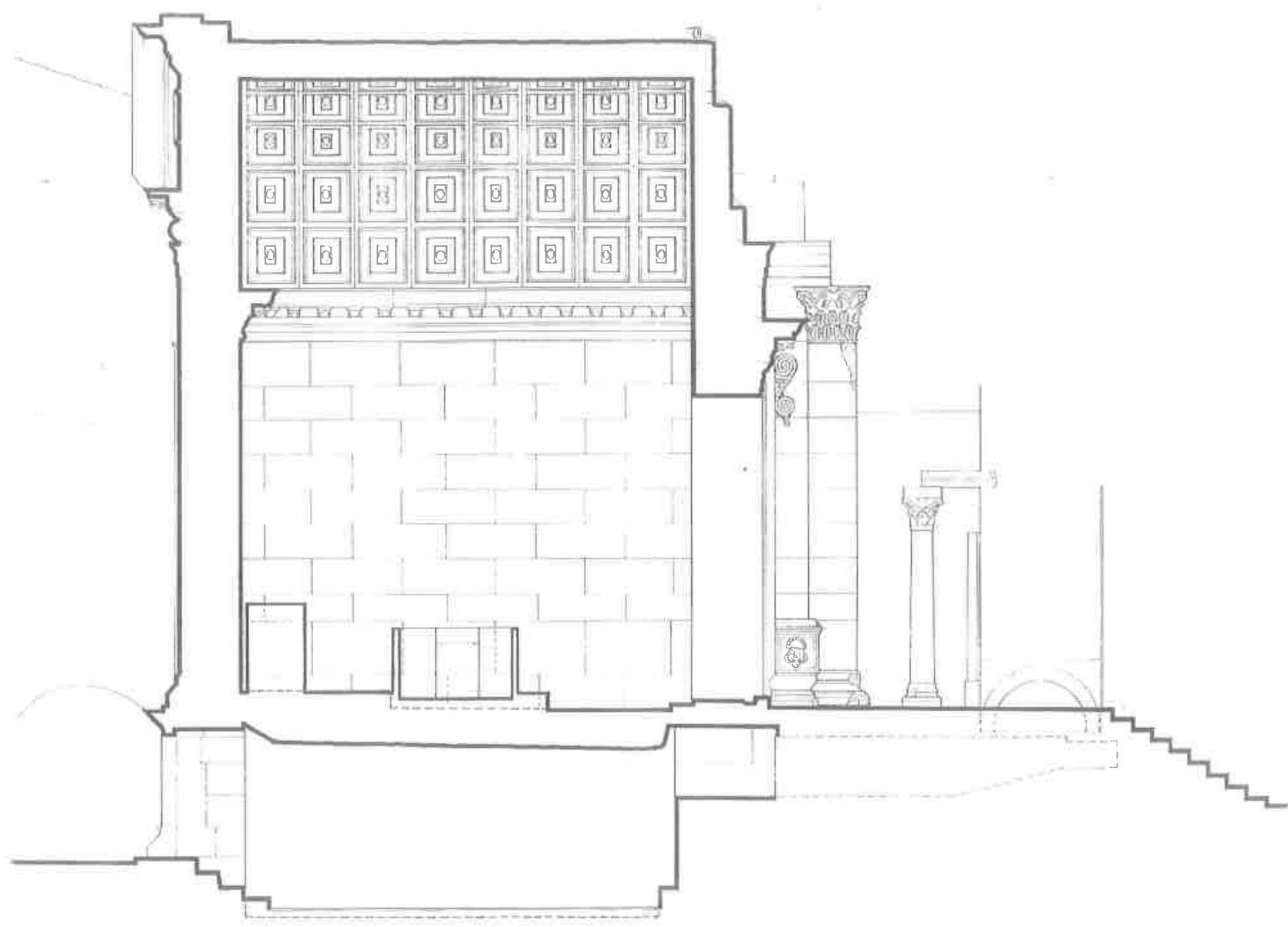

Sezione longitudinale del Battistero - tempio pagano

(Neno Ivanišević, Durđica Barač)

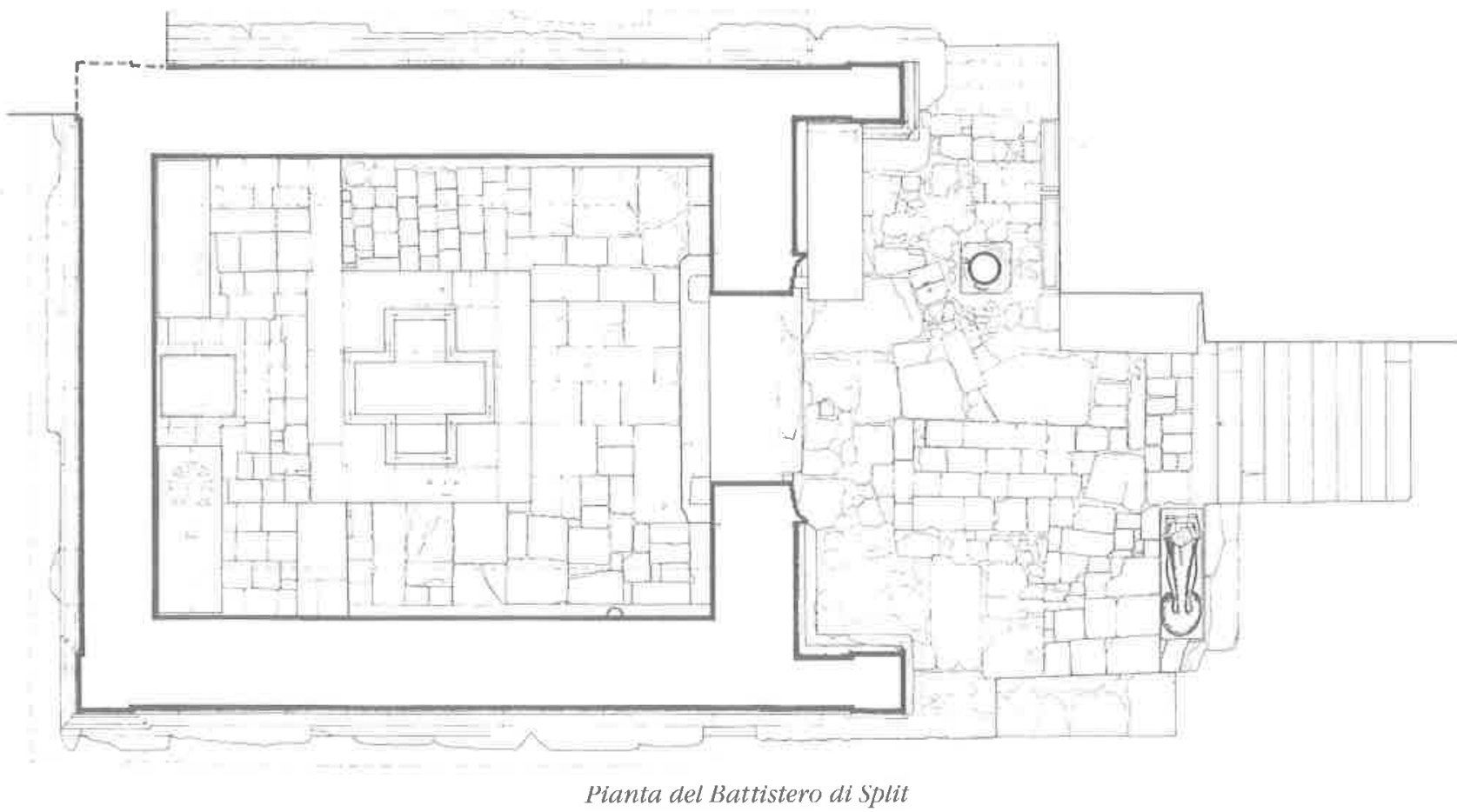

metrica alla cui definizione concorrono anche le braccia che li sorreggono e che finiscono per creare una cornice intorno alla testa recante la corona imponente. Pertanto questi attributi, all'interno del contesto, sono chiaramente guidati dalla volontà di far emergere in modo ieratico qualcosa di molto importante: i segni della dignità regale. A tale scopo, alla complessiva frontalità del bassorilievo, concorre anche il gesto del personaggio che mostra levando le braccia tali attributi, il che esprime letteralmente la volontà che questi ultimi emergano all'interno dell'insieme figurativo. Lo stesso gesto, secondo il canone medievale, indica ostentazione del potere, ${ }^{63}$ e ciò rappresenta un'ulteriore prova del fatto che l'opera reca in sè caratteri profani, ovvero aulici, anziché teologici. 
Per giungere a conclusioni più esaurienti sarà tuttavia necessario chiarire il senso, vale a dire il ruolo dei due personaggi laterali, che non sembrano rispondere a scopi meramente decorativi o formali, dal momento che partecipano alla scena ciascuno con un'azione autonoma. Essi arrivano anzi a riempire l'intera metà della superficie in ordine a una sorta di "prospettiva ieratica", essendo le loro dimensioni lievemente ridotte rispetto a quelle del re. Se ciò rispondesse ai fini di un'inquadratura migliore, ciò risulterebbe senz'altro dalle loro posture nonché dal loro dislocarsi all'interno della cornice. Nella composizione che emana significati rituali, superando a un tempo il principio di struttura centrica, i due personaggi stanno ambedue alla destra di quello principale, conformemente alle regole del cerimoniale cortese, indicato dai vari dettagli iconografici di cui abbiamo detto a suo tempo. ${ }^{64}$

Il personaggio di dimensioni ridotte che giace in basso, è stato solitamente interpretato come un suddito in atto di prostrazione dinanzi al sovrano. ${ }^{65}$ Tale interpretazione ha indotto a riconoscere nella figura assisa al trono un imperatore bizantino, finchè non si è scoperto che anche presso gli imperatori occidentali era in uso la stessa forma di cerimoniale. ${ }^{66}$ Non notando, tuttavia, nulla di prossimo agli imperatori neanche nell'abbigliamento e venendosi al contempo a definire il carattere particolare della corona, ${ }^{67} \mathrm{si}$ fece largo la convinzione che si trattasse di un sovrano regionale. Il personaggio in piedi, alto e barbuto, restava però un enigma, poiché in assenza di attributi marcati non si riusciva a comprenderne l'azione svolta insieme al personaggio sdraiato a terra. Anche se, a differenza di quest'ultimo, esso non è rivolto verso il re, dalla posizione dei piedi è lecito supporre che proprio questa fosse invece l'intenzione, rimasta tuttavia inespressa nella scalpellatura bidimensionale. Con l'esaurirsi delle possibilità di analisi del monumento nel suo complesso e stante l'assoluta mancanza di informazioni dirette sul complesso a cui il bassorilievo apparteneva, tutto ha portato necessariamente a concentrare l'attenzione sulle circostanze storiche inerenti l'ambito indiscusso della sua appartenenza.

Le argomentazioni proposte non sembrano tuttavia approfondite a tal punto da poter essere accolte dalla maggioranza degli studiosi, per cui tutto è rimasto circoscritto entro i limiti delle indicazioni provvisorie. ${ }^{68}$ Nel frattempo, si è cominciato a identificare il re effigiato nel bassorilievo e proveniente dall'ambiente in cuil'opera si trova, con questo o quel sovrano croato della seconda metà dell'XI secolo: da un canto Petar Krešimir IV (regnante dal 1058 al 1074), dall'altro il suo successore Dmitar Zvonimir (titolare della corona dal 1076 al 1089). ${ }^{69}$ Entrambi i re avevano conquistato e mantenuto il dominio per terra e per mare della costa adriatica orientale, legandosi strettamente all'organizzazione ecclesiastica sotto la giurisdizione di Roma ${ }^{70} \mathrm{La}$ Chiesa diventa più forte e influente soprattutto dopo la grande divisione del 1056, già avendo le sue sedi nelle città della costa dalmata sino ad allora facenti parte del tema bizantino. Ma anche l'amministrazione della Dalmazia e i suoi legami con la metropoli si allentano in questo periodo, per via delle lotte dinastiche e di impegno dello Stato nell'impedire l'avanzata del nemico nelle regioni più centrali: ${ }^{71}$ ciò aumentò l'autonomia di quelle città in cui i vescovi godevano di un potere e di un'autorità incontrastabili. Ci si è chiesti dunque quale dei due suddetti re e in quali circostanze potesse essere raffigurato in un monumento così significativo e all'interno di un ambiente il cui punto di riferimento era la sede arcivescovile della provincia. ${ }^{72}$ In gene- re, però, gli studiosi d'arte non si sono impegnati nell'esame di questa materia, mentre gli storici, dal canto loro, non hanno preso in considerazione il bassorilievo quale documento di prima qualità valido nella ricostruzione di un quadro storico da definirsi con maggiore precisione.

I dilemmi sono stati infine aggravati dagli interrogativi circa l'ubicazione originaria del pluteo di cui il bassorilievo fa parte. L'ipotesi che esso provenisse da Spalato è stata seriamente messa in dubbio dal ritrovamento, nella località di Salona (Solin), di frammenti di arredi scultorei dalla morfologia quasi identica. ${ }^{73}$ A differenza di quelli rinvenuti nei pressi del Duomo, affini al nostro pluteo malgrado la natura generica dei loro ornamenti, i reperti di Salona sono a tema figurale e provengono da una chiesa di rilevanza storica, edificata nell'XI secolo. Inoltre, dalle tradizioni regionali veniva trasmessa la storia del trasferimento delle lastre dai ruderi di Salona al battistero di Spalato, come annotano $i$ primi autori che hanno lasciato testimonianze circa il monumento. ${ }^{74}$ Con tutta la complessità del problema e l'incrociarsi delle domande che sorgevano spontaneamente ogni volta che si profilava una nuova ipotesi, l'indagine ha finito praticamente per arenarsi. Neanche i vani tentativi di screditare la tesi della raffigurazione di un sovrano nel contesto storico croato riuscivano più a mettere in stato di agitazione gli animi, poiché tutto era tra l'altro sovrastato da una certa spossatezza. ${ }^{75}$ In questa generale spossatezza, gli archeologi e gli storici dell'arte sono riusciti comunque a mettersi d'accordo circa la datazione approssimativa del bassorilievo.

Importanti novità, rispetto alle molte opinioni accumulatesi senza mai giungere a un corposo risultato finale, sono state introdotte dal compianto prof. Željko Jiroušek, docente nella Cattedra di Arte Medievale di Zagabria. Nel 1993, a un convegno sulla cultura paleocroata, Jiroušek ha presentato una scoperta persuasiva circa un intervento posteriore alla genesi del monumento e quanto mai cosciente, eseguito dallo scultore sul bassorilievo. ${ }^{76}$ Jiroušek è stato il primo a notare giustamente che dalle mani irrigidite del personaggio in piedi a sinistra era stato asportato l'oggetto che questi in origine teneva sul petto. Ritenendo che si trattasse di una spada, Jiroušek ha avanzato l'ipotesi che questi fosse un uomo di corte del seguito regale, offrendo al contempo un'analisi comparativa di scene analoghe. ${ }^{77} \mathrm{Nel} \mathrm{Me-}$ dioevo simili scene non sono infrequenti, ma Jiroušek si riferiva soltanto alle più antiche, riconducendo il bassorilievo all'ambito dell' arte carolingia e datandolo al IX secolo. ${ }^{78}$ Infine - forse indotto al dubbio dal silenzio dei colleghi - lo studioso non ha consegnato il proprio articolo in vista della pubblicazione sugli Atti del convegno: resta il fatto che egli ha saputo illustrare in modo convincente, per lo meno in forma orale, la sua scoperta sulla cancellazione dell'attributo di quel personaggio a prima vista così neutro.

La scoperta è resa tanto più interessante dal fatto che già molto tempo prima ci si era resi conto che anche l'iscrizione posta sullo stesso bassorilievo era stata cancellata, mentre in origine essa figurava all'interno della sottile fascia che sovrasta la scena figurale e che si estende fra questa e la decorazione terminale. I tentativi di leggere l'iscrizione appaiono tuttavia forzati, ed essendo ancor oggi impossibile decifrare in essa una sola parola, non possono in alcun modo essere condivisi. ${ }^{79}$ Senza dubbio l'iscrizione fu asportata con molta cura, levigando la superficie per nasconderne ogni possibile traccia, così come con estrema abilità fu cancellato l'oggetto che il personaggio laterale recava sul petto. Entrambe le mani sono dunque rimaste nel loro stato originale, mentre sulla superficie occupata originaria- 
mente dall'oggetto sono state prolungate le linee dei panneggi della veste, come se prima non fosse mai esistito nulla.

Dopo le prime ipotesi sulla spada, ne sono state avanzate delle altre, tutte egualmente plausibili, sull'originaria presenza di un rotolo ${ }^{80} \mathrm{~A}$ ciò rinviava la posizione delle mani, poste a una certa distanza l'una dall'altra, ma anche le dimensioni della superficie interessata dall'intervento. In ogni caso risulta dimostrabile un atto almeno parziale di damnatio memoriae, finalizzato a cancellare l'azione svolta dal personaggio soggetto al re e ciò nondimeno degno di gran stima a fianco di quest'ultimo ${ }^{81}$ Non v'è dubbio, pertanto, che il contenuto originale della scena fosse sbilanciato e che in una data fase della sua esposizione sia stato intenzionalmente ridotto a un'immagine neutra, o vagamente simbolica, in cui l'unico soggetto ancora riconoscibile restava il re. Con ogni probabilità, la simultanea cancellazione dell'iscrizione che sovrasta la scena figurale servì a rimuovere ogni possibile informazione circa un evento da principio rappresentato con grande rilievo.

Tutto ciò, a mio giudizio, testimonia che l'intervento fu eseguito allor quando il bassorilievo rivestiva ancora la sua funzione originaria, molto probabilmente come elemento del recinto dell'altare in una qualche chiesa importante. Se il bassorilievo avesse avuto un senso e una destinazione a carattere squisitamente religioso, sarebbe difficile giustificare la modifica da esso subita. C'è da supporre che nessuno avrebbe osato farla. Viceversa, con il consolidarsi dell'ipotesi sul significato semi-profano del bassorilievo, si è fatta strada anche una lettura in chiave storico-politica del significato e dell'identià del suo protagonista. ${ }^{82}$ Parallelamente, diventava più importante abbracciare con lo sguardo la totalità della scena, svelandone soprattutto l'idea, piuttosto che l'identità del personaggio principale, la cui effigie non era stata ritoccata. Ho orientato pertanto la mia ricerca all'ipotesi che esistessero simili opere in altri domini figurativi relativamente alla stessa epoca nonché alla stessa area geografica attestate dallo stile del bassorilievo.

Dunque era inevitabile consultare i manoscritti miniati dell'XI secolo, che rappresentano per la nostra disciplina una miniera di modelli figurativi largamente utilizzabili nonché il materiale per il riconoscimento delle aspirazioni spirituali e intellettuali veicolate da altri media espressivi. Fra i tomi dalla celebre abbazia benedettina di Montecassino ho scoperto così una miniatura in cui si ravvisavano elementi riconoscibili della scena raffigurata dal bassorilievo spalatino ${ }^{83}$ Studiando le circostanze in cui era stata eseguita (sui testi degli studiosi che l'avevano indagata in modo approfondito), ho ricavato sufficienti analogie con le circostanze che avrebbero potuto fare da sfondo alla realizzazione del nostro monumento. Ripercorrerò questa mia riflessione, nelle sue linee essenziali, nel testo che segue.

La miniatura, a mio giudizio in larga misura affine al bassorilievo spalatino, si trova dunque nell'Evangeliario di Arrigo II, oggi custodito presso la Biblioteca Vaticana. ${ }^{8.1}$ L'Evangeliario venne eseguito nello scrittorio di Regensburg (che d'altronde esercitò una notevole influenza sullo sviluppo della miniatura europea) in occasione del viaggio del sovrano a Montecassino nel $1022 .{ }^{85}$ Essenziale per gettare luce sui rapporti tra la casa regnante germanica e la maggiore sede dell'ordine benedettino in una fase di lotte per il predominio sull'Italia meridionale all'epoca in cui Bi-

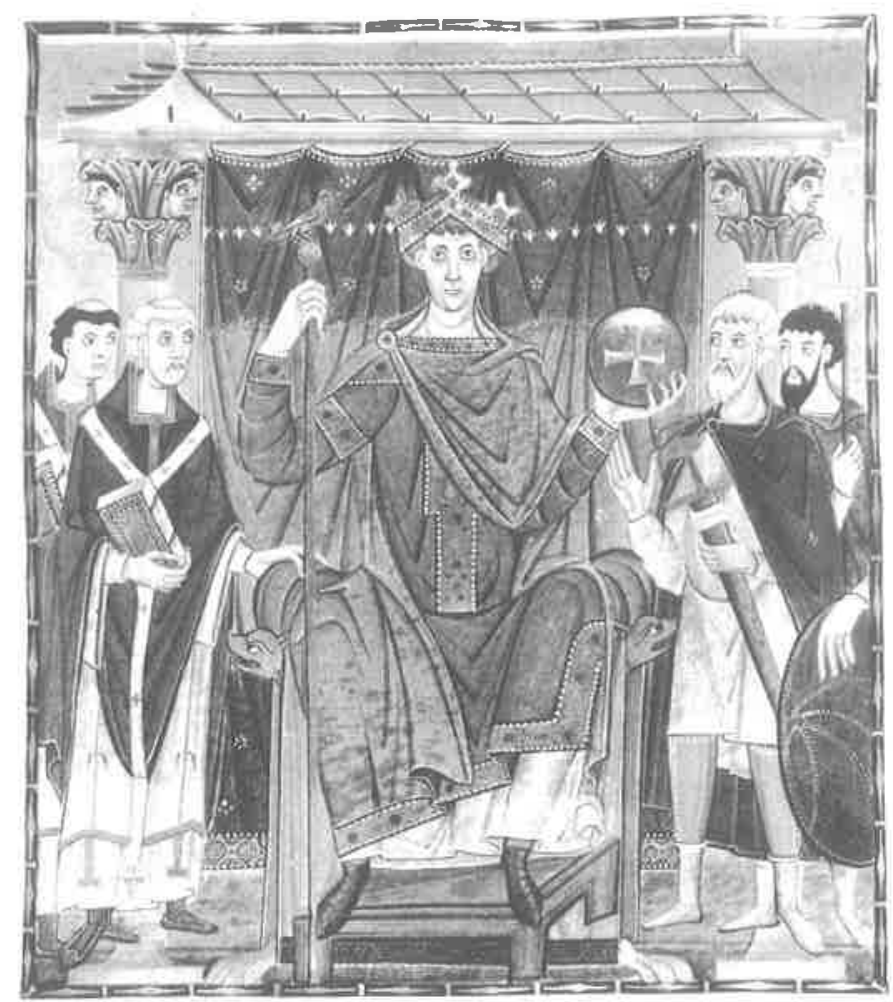

Evangelistario di Ottone III. Fine del secolo X. (München-Bayerische Staatsbibliothek)

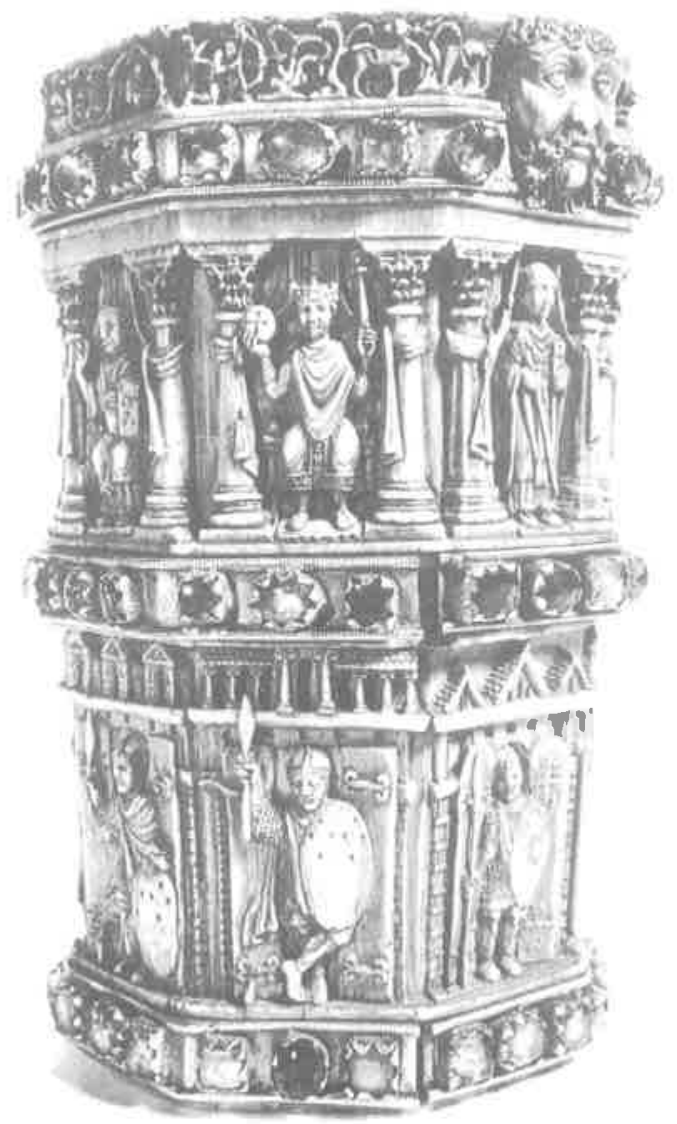

Situla d'avorio di Ottone III o di Enrico II. (Aachen-Münster) 


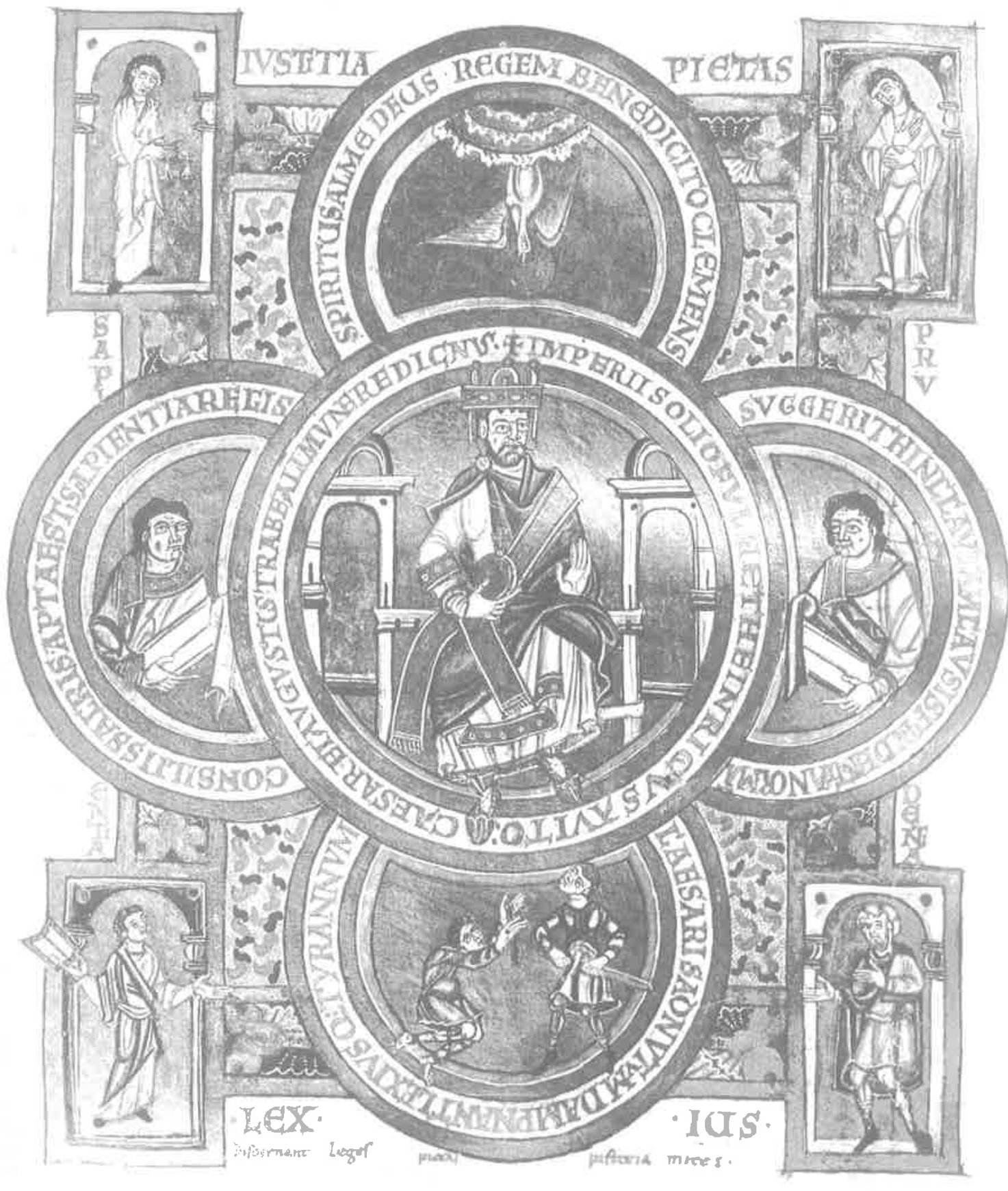

La miniatura del libro di Giovanni dell'Evangelistario di Enrico II, eseguita nel 1022 per Monte Cassino (Cod.Vat. Ottobon. Lat. 74.)

sanzio stava ritirandosi dalla zona, I'Evangeliario ha attratto la nostra attenzione per via di un'immagine posta a illustrare il Vangelo secondo Giovanni. Qui, infatti, in luogo dell'evangelista è raffigurato un sovrano assiso al trono, incorniciato da una preziosa decorazione. ${ }^{86}$ Nei riquadri circostanti, disposti in modo concentrico e accompagnati da varie diciture, si ripartiscono diverse immagini simboliche inerenti il ciclo teologico dell'avvento della giustizia sulla terra. In questo modo, è lo stesso sovrano a proclamarsi Rex iustus, garante dell'emanazione, della salvaguardia e del rispetto delle leggi. ${ }^{87}$
L'insieme si prospetta come una prefigurazione del contributo del regnante all'abolizione della tirannide, secondo la legge inscritta nella volontà dell'Altissimo. La rappresentazione allegorica dell'atto di correggere l'ingiustizia conferisce all'illustrazione, con il sovrano che spicca in posizione centrale, un carattere di propaganda politica, ${ }^{8 /}$ il che trova conferma nella genesi dell'Evangeliario. Quest'ultimo si inserisce infatti in un contesto di opposizione all'influenza che Bisanzio esercitava sul monastero e sull'Italia meridionale. Da notare, inoltre, che la principale ed unica scena a carattere narrativo è costituita nel suo insieme simbolico da un'azi- 
one simile a quella del bassorilievo spalatino da noi descritta: Arrigo II viene rappresentato seduto, con il globo in mano, ${ }^{89}$ mentre in basso, in un riquadro a parte, un personaggio sguaina la spada mentre un altro sta in ginocchio con le mani congiunte nella preghiera. Gli specialisti hanno ampiamente illustrato il contesto di appartenenza di tali figurazioni di concessione di grazia, in ordine sia ai dogmi delle dottrine giuridiche vigenti nel Medioevo, che alla trascrizione di raffinate sentenze latine nella pagina del testo liturgico. ${ }^{90} \mathrm{Si}$ è così individuato come nucleo del messaggio la raffigurazione simbolica di un sovrano storico nelle vesti di esecutore della Provvidenza divina nonché di tutore di un sistema giuridico giusto a beneficio dell'umanità, per la pace fra gli uomini.

Gli storici sono riusciti in particolar modo a collegare l'intento che anima la miniatura, commissionata e donata dall'imperatore in base a un preciso programma politico, con gli eventi che andavano verificandosi nel mondo di allora. ${ }^{91}$ Secondo un parere condiviso, la miniatura trae la sua origine non solo dalla disputa fra l'impero germanico e quello bizantino circa le sorti di quell'abbazia importante per la Sud Europa. Essa fa piuttosto riferimento a uno scontro fra dignitari locali, ovvero fra rappresentanti di opposte fazioni che si contendevano la supremazia politica, conflitto poi risolto da Arrigo II a seguito delle sue imprese storiche. Questa tesi trova sostegno ed è avallata dal ripetersi dello stesso soggetto in un altro volume artisticamente affine: il cosiddetto Evangeliario di Uta, ${ }^{92}$ eseguito nell'ambito dello stesso scrittorio, ovvero nella scuola di miniatura di Regensburg, sotto il governo dello stesso re. Ciò giunge a riprova delle finalità politiche della scena in oggetto, vale a dire del suo concreto carattere storico che al contempo fa richiamo a una generica dottrina religiosa.

Tutto spiega inoltre il ruolo svolto da Montecassino, la cui importanza si accrebbe con l'inizio della grande riforma della spiritualità e delle istituzioni cattoliche che avrebbe raggiunto il proprio apice verso la metà dell'XI secolo. ${ }^{93} \mathrm{Nel}-$ le arti figurative, la riforma trova eco nella tensione a una rappresentazione realistica, che da un canto allude ad eventi reali e dall'altro si ispira a un risvegliato gusto per l'antico che trovava espressione in tutte le attività delle autorità ecclesiastiche e laiche.$^{94}$ Questo, com'è noto, costituisce un filone artistico i cui ideali denotano le prime intuizioni dello stile romanico paneuropeo. Gli effetti dell'incontro di questo filone con il fertile influsso bizantino, di cui condivideva i presupposti spirituali, si propagavano eloquentemente nell'Italia centro-meridionale. I processi spirituali e artistici verificatisi in quest'area furono seguiti nell'Europa settentrionale da un accresciuto numero di opere d'arte che, al servizio della propaganda politica dei diversi sovrani, affrontano il tema della Giustizia. ${ }^{95}$ Questo fatto indica senza ombra di dubbio la diffusione dell'idea in un'area che si ispirava agli ideali e alle conquiste della riforma della Chiesa come alle determinanti dell'espressione artistica nell'XI secolo.

All'interno di questo quadro il suddetto evangeliario di Enrico II di Montecassino, luogo di irradiazione di uno spirito che in seguito si sarebbe diffuso ampiamente, appare indispensabile per l'interpretazione del bassorilievo di Spalato. ${ }^{96}$ Tenendo conto degli elementi di similitudine presenti sia nella scena principale della miniatura che nel bassorilievo in oggetto, sarei a favore di una loro interdipendenza. Assumendo la composizione alquanto conforme delle due opere al punto di partenza, il tipo di approccio che abbiamo adottato ci porta in seguito ad approfondire le conoscenze sulla congruenza di risposte artistiche alle

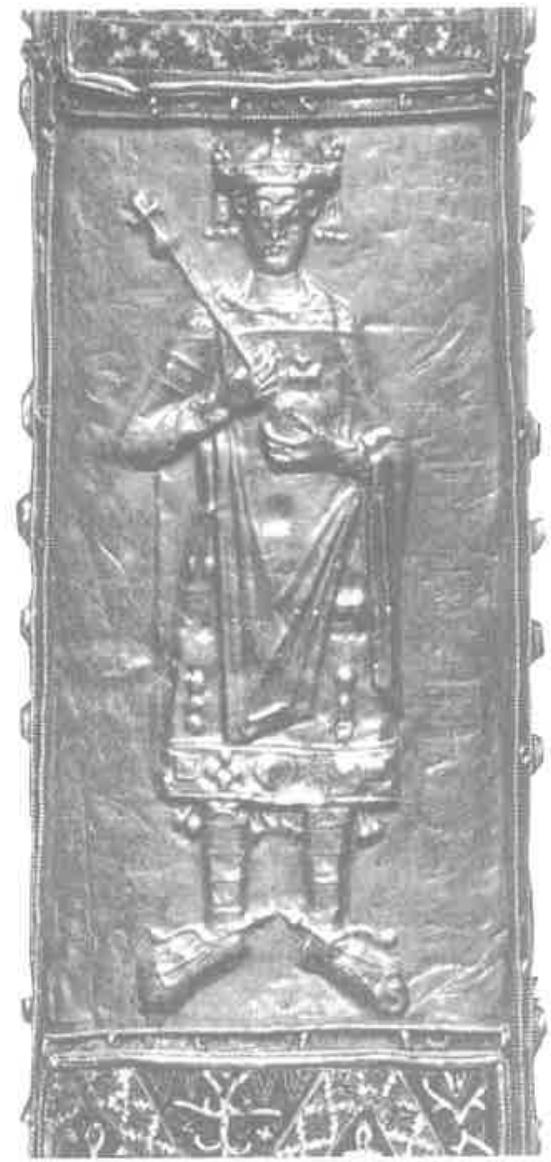

La figura del re sul fodero della spada del secolo XII (Schatzkammer - Wien)

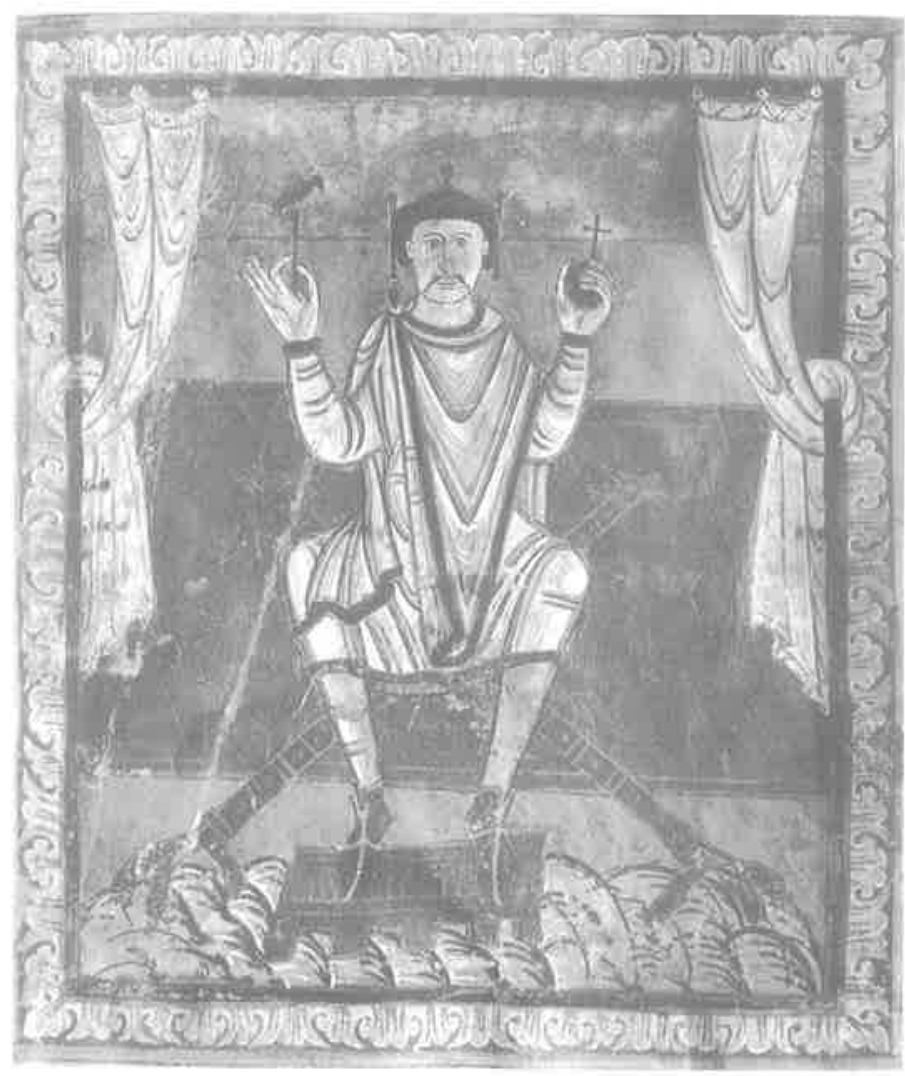

La figura del re dell'Evangelistario di Enrico IV o VRegensburg verso il 1100 
situazioni politiche nell'ambito dell'orizzonte culturale proprio dell'opera presa in esame. Il primo spunto viene sicuramente dalla totale assenza di soluzioni analoghe nell'arte croata coeva, il che rende da sempre più oscuro l'enigma sul monumento che qui ci interessa. Ê possibile, pertanto, che l'ispirazione per esso fosse giunta da un centro di maggior livello creativo e di più ampie conquiste intellettuali. A dire il vero, è difficile asserire che la miniatura sia stata utilizzata come modello diretto per l'opera scultorea di proporzioni maggiori, ma non doviemmo neppure escludere l'ipotesi di un incontro tra gli artefici del bassorilievo (ideatori piuttosto che esecutori materiali) e la miniatura, ò con opere analoghe. È generalmente dimostrabile, infatti, l'importanza dei piccoli manufatti nella progettazione di opere d'arte di dimensioni maggiori, e non solo nel Medioevo. ${ }^{97}$ Inoltre non è da escludere l'ipotesi che l'arredo scultoreo del presbiterio in una qualche importante chiesa della provincia dalmata potesse recare la riproduzione delle immagini di un libro sacro proveniente dal prestigioso centro benedettino.

In maniera del tutto comprensibile, paragonando le due opere si riscontrano tutte le possibili differenze tra l'alta esperienza di una delle migliori scuole di miniatura dell'Occidente e la prima rappresentazione di una figura umana nella scultura di un'officina nella cui attività i residui di stile preromanico furono causa di geometricità con accenti alquanto ingenui. La disposizione dei personaggi è regolata dalle leggi dell' inquadratura, mentre quella loro certa goffaggine è dovuta al linguaggio stilistico del primo romanico. Fra le analogie di cui siamo in cerca non sono da trascurare le discrepanze specifiche di realizzazione tecnica dell'una e dell'altra opera. A dire il vero, questo piano di osservazione è secondario, anche se non lo ritengo inutile nel caso serva a sostenere le conclusioni finali. Andando incontro a queste, bisogna notare che, rispetto al modello ideale, molti elementi del bassorilievo appaiono necessariamente trasfigurati dalla stessa tecnica di scalpello all'interno di un quadro determinato dalle esigenze architettoniche del pluteo, della lastra con il bassorilievo e del complesso di cui quest'ultima rappresenta solo una componente. I colpi della subbia affilata sul marmo duro non potevano raggiungere la morbida agilità della penna guidata dall'abile mano del miniaturista sulla pagina del libro. Nel disegno generale, però, come pure nella realizzazione plastica, sono dati i messaggi-chiave: la dignità imperturbata del re, l'indubbio carattere risoluto del funzionario e la compunzione e l'impotenza del supplice.

Fra i personaggi è definito, con mezzi dell'espressione figurativa e in modo chiaramente perspicuo, anche un equilibrio delle caratteristiche ponderatamente graduate dei personaggi all'interno dell'equilibrio tra il simbolico e il realistico, proprio dello spirito del tempo. ${ }^{98}$ Si ottiene così l'effetto di un giudice sobrio e intransigente e di un fermo esecutore della Giustizia, rispetto ai quali si stacca la figura esigua del terzo, disteso a terra in attesa del verdetto della legge. La disposizione ieratica è definita con tutti i mezzi disponibili, dalla posizione all'interno della composizione e dall'ordine di grandezza, sino all'ampiezza descrittiva ottenuta attraverso la variabile densità della lavorazione plastica. Nel complesso (malgrado l'espressione quasi primitiva) è esposto il programma temporale della fede nelle verità divine, per cui la supposta interdipendenza tra le due opere è determinata dalla comune subordinazione all'uffizio divino. ${ }^{99}$ Allo stesso scopo, nel primo esempio la morale è veicolata dal raffinato linguaggio iconografico del tomo

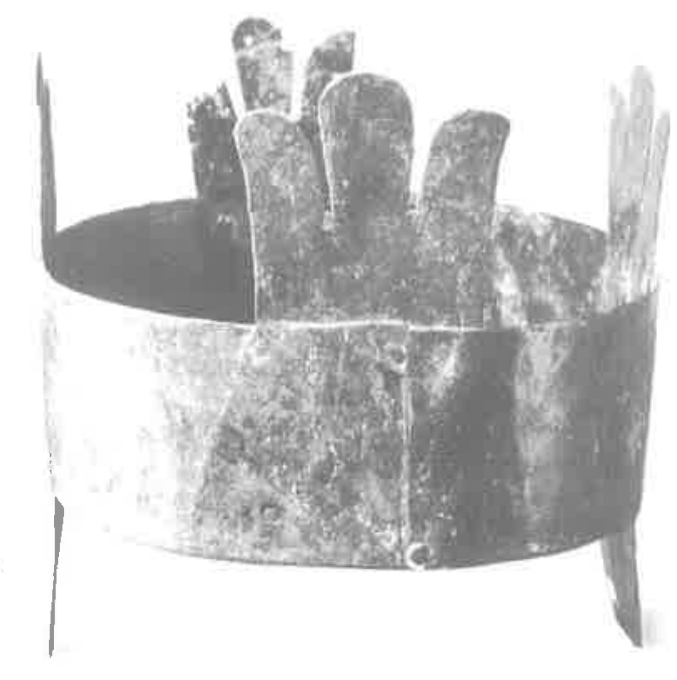

La corona di Enrico III della cattedrale di Speyer - 1056

consacrato, mentre nel secondo essa è esposta al pubblico in una forma più robusta all'interno di uno spazio sacro.

L'origine della miniatura indica inoltre che simili opere, in linea di principio, appartengono al genere delle donazioni regali alle istituzioni ecclesiastiche. I medievalisti sono d'accordo nell'attribuire alla miniatura del suddetto Evangeliario un primato di promozione politica in atto nella cultura cristiana del Medio Evo. ${ }^{100}$ Nel nostro caso, questo dato è per molti aspetti importante, nel caso in cui si accetti la corrispondenza di fatto tra la miniatura e il bassorilievo spalatino. In tal senso ciascuna delle due opere, con la sua specifica composizione dimostra di inscriversi fra i provvedimenti con cui l'Altissimo istituisce l'ordine sulla terra, evidentemente, mediante il tramite dell'autorità secolare che emerge a protagonista di entrambe le opere. Per questa ragione nella miniatura, di realizzazione antecedente, il re è sovrastato da una colomba, in posizione assiale. Nel bassorilievo, invece, lo stesso re leva in alto la croce che, come si è detto, è posta al centro con il probabile scopo di garantire l'inverarsi delle leggi della fede sotto quell'insegna. Grazie a questo fatto la rigidità cerimoniale della scena pare tradursi in un'azione drammatica, niente affatto a guisa di profezia, poiché la narrazione simbolica contribuisce a renderla più vicina agli spettatori.

Inoltre, anche il nostro bassorilievo, all'interno della recinzione dell'altare, si adeguava al piano della realtà terrena, allo scopo di una più piena affermazione del proprio contenuto di base: la fede nella verità che annunciava agli uomini. Del resto, già prima dell'XI secolo era diffusa in Dalmazia l'usanza di tradurre la saldezza della fede in plutei di pietra dal simbolismo eloquente, scolpiti su rilievo e accompagnati da iscrizioni a sfondo reale; si trasmetteva così anche la costanza di stati vitali iscritti nei monumenti ecclesiastici. ${ }^{101}$ Pertanto, non v'è motivo di non credere alla tesi secondo cui il bassorilievo figurale del pluteo spalatino dimostri la presenza politica di un re eletto per volontà di Dio. Serviva a rappresentare certe situazioni, a tal scopo riprendendo un'allegoria adottata già altrove con l'intento di denotare la sicurezza del persistere di un ordine sociale sotto il patrocinio del sovrano raffigurato.

Nel trarre conclusioni sul bassorilievo bisognerà quindi porre l'accento sul fatto che quest'ultimo, come sempre 


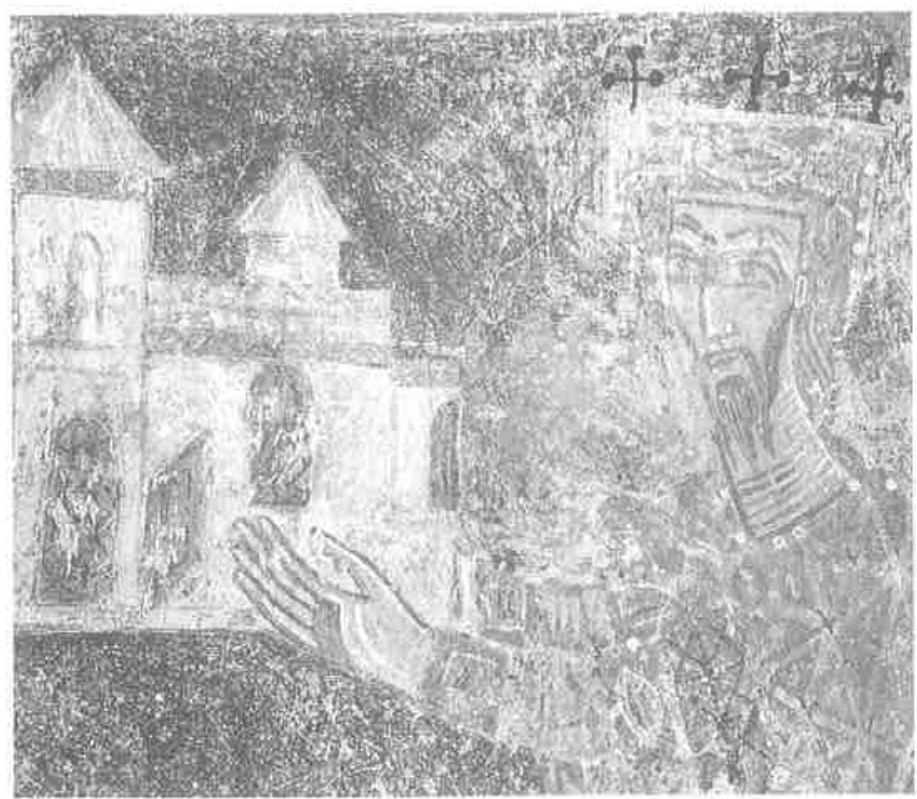

La figura del re nell'affresco a Ston: chiesa di San Michele-fine del sec. XI

nel Medioevo, è inteso come vicarius Christi: alter post Christum et secundus post dominum coeli, e in quanto tale rappresentato secondo il modello offerto dalle raffigurazione della gloria del Figlio di Dio. ${ }^{102}$ La stessa scelta della tipologia figurativa, niente affatto casuale, è ben motivata; ne esamineremo le motivazioni in seguito all'analisi iconografica. Non v'è dubbio che gli scultori dalmati, agli albori della ricerca volta a definire la rappresentazione della figura umana, si servirono di formule già esistenti per quanto riguardava sia il rispetto di regole morali che la diffusione di maniere di stile. Ricollegando questi due elementi, in un'espressione esemplarmente armoniosa delle convenzioni dell'epoca, al ruolo dell'onnipresente intermediario fra il cielo e la terra, fra Dio e l'uomo e, infine, fra la Chiesa e il popolo, risulta che nella struttura dell'altare poteva figurare solo l'effigie di tale intermediario - immagine vivente di Cristo sulla terra. ${ }^{103}$

Perciò, in realtà, è da supporre che il recinto altoromanico dell'XI secolo, con le lastre esistenti nel battistero spalatino, sia abbastanza completo, ovvero che non ci sia da aspettarsene necessariamente di altre figuralmente sviluppate all'interno della stessa tipologia iconografica. In relazione soprattutto ai caratteri dell'intera scena, si tratta evidentemente di una concezione della figura regale come lex viva: pater et filius Justitiae - volendo usare le formule di cerimoniale adottate nei testi medievali per designare il re. ${ }^{104}$ Secondo le concezioni del tempo sul suddetto ruolo intermediario, ciascun regnante era detentore e garante delle leggi divine nella sua sfera di dominio: Rex infra et supra legem, il che gli era anche riconosciuto dal diritto canonico. ${ }^{105}$ Con questa visione dell'opera, naturalmente, si apre la questione dell'identità di quel sovrano, il quale reca una corona che sulle coste orientali dell'Adriatico viene introdotta proprio nella seconda metà dell'XI secolo, senza dubbio il periodo a cui il nostro bassorilievo risale, dati i suoi tratti stilistici.

Il complesso di situazioni ed eventi verificatisi nell'Adriatico Orientale verso la metà dell'XI secolo introduce il problema della presenza sul bassorilievo spalatino di una figura regale nel contesto concreto della storia regionale.
In relazione a ciò, bisognerà escludere anzitutto ogni eventuale riferimento ai sovrani dei due imperi in cui all'epoca era diviso il mondo cristiano. Di fatto, essi non nutrivano in quel periodo alcun interesse verso la zona da cui proviene il nostro monumento, e ciò va sempre tenuto presente. L'influenza politica dei regnanti d'Occidente era già in precedenza inavvertibile in quelle regioni dove lo Stato croato aveva acquistato la piena indipendenza, dandosi un assetto teocratico per il resto organizzato principalmente in un territorio extraurbano. ${ }^{106}$ Proprio verso la seconda metà del XI secolo, la Croazia stava realizzando con maggior successo le sue aspirazioni allo sbocco sul mare, dove Bisanzio aveva ormai da gran tempo il predominio, concentrando la sua autorità nei centri urbani e tenendola formalmente unita entro il tema o "catapenato" imperiale, con un governatore amministrativo-militare avente sede a Zara. ${ }^{107}$ D'altro canto, però, con le lotte dinastiche nel cuore del grande impero e con l'impegno in difesa delle regioni fuori Dalmazia fortemente minacciate dal pericolo e che erano anche più importanti, il predominio bizantino, come si è detto, si allentò. ${ }^{108}$

Al crollo di quest'ultimo contribuì, naturalmente, anche lo scisma della Chiesa universale del 1056, con il quale venne ad annullarsi ogni influente presenza orientale nelle zone del confine, da secoli soggette alla giurisdizione di Roma. ${ }^{109}$ Il conseguente rinsaldarsi della Chiesa latina determinò lo sviluppo dei centri urbani, dovuto al fatto che nella gerarchia sociale di questi ultimi il rango più elevato spettava ai vescovi. ${ }^{110}$ I vescovi, dal canto loro, riconoscevano fermamente il primato dell'arcidiocesi di Spalato, istituitosi nella tarda antichità e consolidatosi con il procedere della riforma della chiesa che imponeva sopra ogni cosa il rispetto dell'ordinamento della vita terrena, formulato secondo la volontà di Dio, ${ }^{111}$ vale a dire definito e riconosciuto dalla Città Eterna. A ciò si sono aggiunte anche le tradizioni storicamente attestate del Cristianesimo in Dalmazia, dal momento che il centro ecclesiastico di Spalato aveva soppiantato quello di Salona dal periodo della tarda antichità. ${ }^{112}$

Nel quadro di tali circostanze generali, è da sottolineare il fatto che il movimento riformatore venuto da Occidente fu guidato dappertutto dall'ordine di S. Benedetto, che ne rappresentava il motore principale e che penetrò in maniera significativa in tutte le istituzioni ecclesiastiche, a partire dalla curia papale di Roma. ${ }^{113}$ A tale riguardo è noto il ruolo svolto dalla loro sede centrale di Montecassino, da dove si fecero strada verso la Dalmazia le antiche tradizioni di influssi e scambi spirituali. ${ }^{114}$ Nella diffusione delle nuove idee dimostrarono la loro efficacia anche altre abbazie, per cui, in seguito allo stabilirsi dei contatti tra le due sponde adriatiche, acquistò molta importanza il convento di S. Pietro a Ossero (Osor), sull'isola di Cherso, sorto in una cittadina del Quarnero fondata nell'antichità. ${ }^{115}$

Intorno alla metà dell'XI secolo fu tra i dignitari di quella cittadina il dotto abate Gaudenzio, prima di essere proclamato santo per la sua devozione all'austera religiosità di S. Romualdo. ${ }^{116}$ Egli educò un'intera generazione di monaci dediti ai suoi insegnamenti e pronti all'attuazione della riforma. ${ }^{117}$ Da quel centro di rinnovamento, colui che raggiunse il grado più elevato fu Lorenzo Dalmata (Lovro Dalmatinac), il quale assunse l'incarico vescovile per essere promosso di lì a poco, nel 1059, al rango di arcivescovo di Spalato. ${ }^{118}$ Come tale egli è menzionato negli scritti che testimoniano la fondazione o la donazione di una decina di conventi lungo il litorale su cui si estendeva l'autorità 
della sua cattedra. Con il titolo di primate della Dalmazia Lorenzo svolse evidentemente anche le funzioni di "abate maggiore", per cui non vi sono dubbi sulla sua fedeltà alle direttive di riforma avviata in Italia e attuata in una prima fase grazie soprattutto alla mediazione dei conventi. ${ }^{119}$ Sotto l'egida di questi ultimi, la riforma ebbe inizio oltralpe, per riversarsi in seguito come un'ondata compenetrando le idee della sacra città di Roma.

Insieme allo scopo generale di ripristinare la castità morale in seno alla Chiesa universale, tutti, secondo le intenzioni della curia papale, aspiravano al ritorno del vecchio ordine terreno, quello dei tempi degli apostoli, che riconosceva come suprema conquista l'unione ideale di fede e Stato. ${ }^{120}$ A ciò si aggiungeva, ovvero vi stava dietro, la tesi della Renovatio imperium romanum = Renovatio ecclesia romana e viceversa. ${ }^{121}$ Lorenzo, durante i quarant'anni del suo ufficio, fu infatti il più solerte promotore di questo indirizzo politico, intransigente nel rispetto della gerarchia presieduta dal Santo Padre seguace di S. Pietro. Dando appoggio all'idea guida del primato universale dell'istituzione ecclesiastica, l'arcivescovo Lorenzo è un modello di dignitario moderno, interamente dedicato a sovrintendere al proprio ufficio in una sfera in cui erano venuti meno qualsiasi autorità o potere centrali. Come e in quale misura egli riuscì a controbilanciare, se non proprio a supplire formalmente a questo vuoto, ${ }^{122}$ lo dimostrano le sue iniziative storicamente attestabili.

L'arcivescovo Lorenzo prese parte a quasi tutti gli avvenimenti più significativi che interessarono a quel tempo la costa dalmata, testimoniando la propria giurisdizione spirituale per quasi tutta la seconda metà dell'XI secolo. Probabilmente intraprendente di natura, temperante e sicuro di sè, egli compì frequenti viaggi, proprio come i regnanti suoi contemporanei. Partecipe attivo a diverse consulte ecclesiastiche, presiedette alla risoluzione di molte importanti questioni, relative ai più svariati ambiti; entrò nel seguito delle legazioni pontificie, conobbe dignitari delle autorità secolari; esortò a più riprese i fratelli d'oltremare a impegnarsi nel consolidamento delle istituzioni ecclesiastiche; ${ }^{123}$ fu consulente di uomini di potere e responsabile dei possedimenti dell'arcidiocesi. Formò intere generazioni di religiosi, fu amico di vescovi - alcuni dei quali furono poi canonizzati $-{ }^{124}$ nonché di alcuni regnanti stranieri. Se ne deduce che Lorenzo, con la sua fervida attività, si distinse ampiamente da tutti i suoi contemporanei in patria. Nella sede della sua arcidiocesi, volendo assestare la liturgia romana, incentivò l'arredo artistico dei santuari, dando inoltre impulso a svariate iniziative di estremo rilievo culturale. ${ }^{125}$ Riuscì soprattutto nel dare all'ordine ecclesiastico un'aspetto legale simile a quello dell'organizzazione statale, con il giudizio divino sovrastante, rappresentato, quest'ultimo, con equità ed efficienza dall'arcivescovo. Lorenzo divulgò, quindi, l'idea di una coesione tra regnum e sacerdotium - generalmente il fine ultimo dell'attività religiosa al suo tempo, del tutto congruente con le aspirazioni e le conquiste degli albori della riforma. ${ }^{126}$

Riflessi di tutto questo si manifestano d'altronde in particolar modo nel patrimonio artistico dell'intero territorio che all'epoca faceva parte dell'arcidiocesi di Spalato, nonché di un'area più ampia situata sulle coste orientali dell'Adriatico. Erano i tempi dell'introduzione dello stile altoromanico in scultura e in architettura, le quali offrono il maggior numero dei monumenti, ${ }^{127}$ ma anche in pittura, sia libraria che monumentale, sebbene in questo caso disponiamo di minori testimonianze. La creazione artistica era comunque generalmente guidata dall'idea di un ritorno agli ideali del primo Cristianesimo, piuttosto che dall'introduzione di qualche nuovo ed estraneo sistema o linguaggio estetico. Verso la metà dell'XI secolo prese così il sopravvento nell'architettura sacra lo schema della basilica a tre navate e con tre absidi, sul cui arredo scultoreo la figurazione fioriva in complessi cicli teologici e in realizzazioni monumentali. ${ }^{128}$ È importante sottolineare che con l'adozione di questi principi venne ad attuarsi l'unificazione dell'espressione artistica tra le regioni continentali dello Stato croato e le città costiere, appena in certa misura liberate dal dominio bizantino. Soltanto alle aspirazioni ed esperienze comuni a tutte le regioni croate può essere attribuita la costruzione di grandi chiese del tipo sopra menzionato, dall'Istria e dal Quarnero attraverso Zara e Zaravecchia fino a Salona e Spalato e ancora più a sud. Al contempo venivano sottoposte a importanti modifiche diverse basiliche del primo Cristianesimo, trascurate per molto tempo, come avvenne ad Arbe, Nona e Stagno, nonché sulle isole; subirono trasformazioni anche diverse chiese più piccole, sempre attraverso l'introduzione di una morfologia romanica piuttosto semplice. ${ }^{129}$ Numerose opere scultoree furono poste all'interno di queste chiese grazie allo sviluppo del lessico altoromanico, rivolto alla rappresentazione realistica, e grazie ai loro richiami ai modelli della tarda antichità. L'intreccio di tradizioni e innovazioni portò senz'altro a una sintesi di quella cultura figurativa alla cui base stavano le idee di modernità, accolte simultaneamente in tutto il resto d'Europa.

A partire dagli elementi citati, è possibile desumere quella spiritualità e quel clima politico che potevano incondizionatamente veicolare il contenuto del bassorilievo da me interpretato in base ai caratteri iconografici. Considerato che questo monumento si inserisce nel pieno XI secolo anche grazie alle sue qualità figurative, ovvero stilistiche, $\mathrm{e}$ considerato inoltre che esso è sicuramente legato al periodo dell'arcivescovado di Lorenzo, è interessante richiamare l'attenzione su altri punti di contatto tra il bassorilievo e la sua matrice ideale. Di fatto, tali punti di contatto si riferiscono a Montecassino, luogo d'irradiazione della riforma della Chiesa, riforma che in modo più che convincente rappresenta una solida base dei fenomeni che si verificavano all'epoca. ${ }^{130} \mathrm{Il}$ movimento per il rinnovamento della Chiesa prese l'avvio con la salita al soglio di S. Pietro, nel 1059, di papa Nicola II, il cui pontificato, durato un biennio, rappresenta un momento cruciale nei cambiamenti storici. ${ }^{131}$ Esiste a tale riguardo una copiosa bibliografia, ma noi, naturalmente, considereremo solo quegli aspetti che possono esserci d'aiuto, anche solo indirettamente, nella comprensione del nostro monumento.

Sarà perciò importante evidenziare che papa Nicola II fu in rapporti di amicizia con Desiderio, celebre abate di Montecassino dall'anno $1058,{ }^{132}$ (e in seguito papa egli stesso, con il nome di Vittorio III, negli anni 1086-1087) e che inoltre il primo legato pontificio inviato in Dalmazia con l'incarico di divulgare le nuove disposizioni circa l'organizzazione della Chiesa e il disciplinamento del clero, fu padre Mainardo, ${ }^{133}$ anch'egli benedettino e uomo distinto in quei circoli. Mainardo era presente al fianco di Lorenzo (all'epoca vescovo di Ossero) a Zaravecchia, allorchè re Petar Krešimir concesse privilegi al neoistituito convento benedettino di S. Giovanni Evangelista, ${ }^{134}$ il che induce a ritenere che ciò avvenne dietro consiglio di Mainardo. Da lì , l'insigne abate si recò a Spalato, ove presiedette il sinodo provinciale nella cui sede vennnero messe a punto, in base alle direttive della riforma, le condizioni della Chiesa dal- 
mato-croata. ${ }^{135}$ Egli era affiancato già da Lorenzo, il quale di lì a poco ricevette la delibera della sua nomina ad arcivescovo, consegnatagli nel 1059 da un altro legato, Acusone. Insieme firmarono il documento sulla consacrazione della chiesa di S. Giovanni Evangelista sull'Isola Lunga, di proprietà dei benedettini di Zara, ai quali il re Krešimir donò molti beni e le cui strade si incrociarono con quelle di Lorenzo. $^{136}$

L'intrecciarsi dei dati e dei nomi testimonia l'intensità delle attività in Dalmazia ai tempi della diffusione delle idee e direttive riformistiche. Poiché all'inizio della lotta per il rinnovamento etico, che riguardava la vita monastica e l'aumento di luoghi in cui questa veniva realizzata in modo esemplare, vi era fra le idee-chiave anche quella del legame tra il dominio religioso e quello secolare, per cui il coinvolgimento dei detentori di quest'ultimo appare significativo. Chiarito il ruolo dell'arcidiocesi di Spalato come centro di potere e di ricchezze, a questo punto ci restano ancora $\mathrm{i}$ rapporti da essa intrattenuti con il sovrano che le garantì il proprio appoggio e con il quale potè unirsi in ideologica armonia. La scettro e il dominio su tutto il territorio croato così come si delineava nel 1058 (il che coincide con l'entrata in carica di papa Nicola II, dell'abate Desiderio, nonché dell'arcivescovo Lorenzo!) furono assegnati a Petar Krešimir, in quanto figlio di re Stjepan I (Stefano) e della figlia del doge veneziano Pietro Orseolo II. ${ }^{137}$ La maggioranza degli storici nostrani concordano nel ritenere Petar Krešimir "il più importante dei re croati" poiché seppe estendere la sfera del suo dominio più di ogni altro sovrano suo conterraneo.

Il fatto che più conta è l'annessione delle città costiere al regnum Croatiae et Dalmatiae, un fatto che lo stesso re mette in rilievo in diversi documenti. ${ }^{138} \mathrm{E}$ poiché questi ultimi, di fatto, non fanno alcun riferimento alle questioni che riguardano la vita fra le mura cittadine, è lecito supporre che i comuni avessero preservato intatta la loro autonomia. Le città erano in pace con il re, il quale dal retroterra dava prova del proprio orientamento filo-occidentale sostenendo, persino fuori dei confini del proprio regno, quelle forze che si opponevano al dominio bizantino. Pare che egli si atteggiò con estrema prudenza verso gli ultimi residui meramente formali dell'amministrazione imperiale nell'Adriatico, tanto che, secondo l'antica consuetudine, gli fu concessa occasionalmente la precedenza protocollare. ${ }^{139}$ Krešimir, però, segnò chiaramente il suo sbocco sul mare con il trasferimento della capitale sulla costa, a Zaravecchia, e con la concessione alla città di Sebenico una delle ultime trasformatesi in un vero organismo urbano — dello status di libera città. ${ }^{140} \mathrm{Il}$ re croato, per altro, era legato alle autorità laiche zaratine da vincoli di parentela e proprio Zara era tradizionalmente il centro di organizzazione giuridica dei comuni urbani rimasti sino ad allora disgregati. ${ }^{141}$ Il re coltivava buoni rapporti soprattutto con le autorità di un' istituzione maggiormente integra, anzi la più compatta della regione, qual era la Chiesa dalmato-croata.

Queste sono tutte premesse importanti per la realizzazione del bassorilievo, che, oltre a permetterci di coglierne il significato storico e ideale ci consentono di stabilirne la datazione ai tempi del regno di Petar Krešimir. Questa tesi, però, è in contrasto con buona parte delle interpretazioni esistenti, che sogliono legare il monumento al regno di Dmitar Zvonimir (1076-1089), e che identificano qu est'ultimo nella figura regale di Spalato. ${ }^{142}$ Malgrado egli fosse in stretti rapporti con l'arcivescovo Lorenzo, al punto di considerarlo come suo "padre spirituale",143 la tesi che riconosce in lui il personaggio effigiato nel bassorilievo non è comprovata dai documenti scritti; probabilmente si è fatto leva, nel formulare la tesi, nella sola aura popolare di cui Zvonimir gode in quanto ultimo sovrano nazionale, la cui morte coincide con l'estinzione dello stesso regno croato. ${ }^{144}$ Pare, invece, che il regno, con Zvonimir ancora in vita, stesse già perdendo la propria forza di coesione, non provenendo più il sovrano dall'antica dinastia croata. ${ }^{145} \mathrm{Du}$ rante il suo regno egli dimostrò scarso interesse per i contatti con i centri urbani della costa e per le loro tradizioni, benchè si attribuisse ancora il titolo di rex Chroatorum et Dalmatorum, come pure Krešimir IV negli atti della cancelleria di corte. ${ }^{146}$

Inoltre, sotto il pontificato di papa Gregorio VII (10731085), contemporaneo di Zvonimir e accesissimo sostenitore della riforma della Chiesa, quest'ultima prese una direzione alquanto diversa che non in passato. ${ }^{147}$ Proprio da questo punto di vista vorrei sottolineare quanto fossero limitate le opzioni relative alla rappresentazione artistica di un sovrano secolare contemporaneo nell'ambito dei contenuti del bassorilievo, la cui interpretazione, basata sul riscontro di fatti storici, pubblico qui per la prima volta. Inflessibile nell'attuazione degli obiettivi riformistici finalizzati a un pieno consolidamento del primato della Chiesa latina, papa Gregorio antepose quest'ultima, nella maniera più rigorosa, a qualsiasi forma di potere temporale, e intese preservare le istituzioni ecclesiastiche da ogni influenza esterna nonché dal pensiero laico. ${ }^{148} \mathrm{Su}$ tale programma si basò la sua fede politicamente matura, dopo che ebbe trasferito la guida del movimento per il rinnovamento della morale cristiana dall'egida dei conventi e della spiritualità monastica alla dignità dei vescovi. ${ }^{149}$

La posizione dei vescovi, cioè, dipendeva molto di meno dall'amministrazione statale e, inoltre, con l'accrescimento dei loro poteri canonizzati, veniva trascurato il potere dei sovrani locali, ieraticamente soggetti alla cattedra di S. Pietro come primo apostolo di Cristo. ${ }^{150} \mathrm{La}$ "nuova Chiesa" di Gregorio significò l'attacco contro molti sistemi antichi e, quindi, a confronto con l'orientamento di Lorenzo ai tempi di Krešimir, sarebbe molto più difficile che sopportasse la raffigurazione di un sovrano secolare sull'arredo rappresentativo dell'altare. I cambiamenti nell'atteggiamento del principe della chiesa dalmato-croata sono visibili d'altronde in un ambito più ampio della sua attività. ${ }^{151}$ Con lo stesso rinvigorirsi dell' autorità assoluta del "vescovo romano" e dei suoi suffraganei, nell'ottavo decennio dell'XI secolo si ebbe, del resto, anche una separazione tra il papato el'ordine dei benedettini, soprattutto a Montecassino ${ }^{152}$ e si interruppero di fatto quei legami che, a mio giudizio, diedero impulso alla creazione del bassorilievo spalatino.

Sulla scia del presupposto che il sovrano raffigurato nel bassorilievo di Spalato possa essere prima di tutto Petar Krešimir IV, esistono anche altri elemeni a sostegno. Di questo re croato si è conservato, cioè, un sigillo, l'unico rimasto dall'epoca dello stato nazionale medievale. ${ }^{153} \mathrm{Nel}$ sigillo, il fiero dinasta è rappresentato in posizione seduta e circondato da un'iscrizione, mentre tiene il globo nella sinistra e lo scettro nella destra, con la dignità compassata e in una composizione sommamente chiara. Pur essendo assai simile a numerosi sigilli contemporanei dell'Alto Medioevo europeo, ${ }^{154}$ per noi ha un grande valore perchè dimostra che Petar Krešimir portava veramente le consuete insegne regali, facendosi anche ritrarre con esse. Trovano così una 

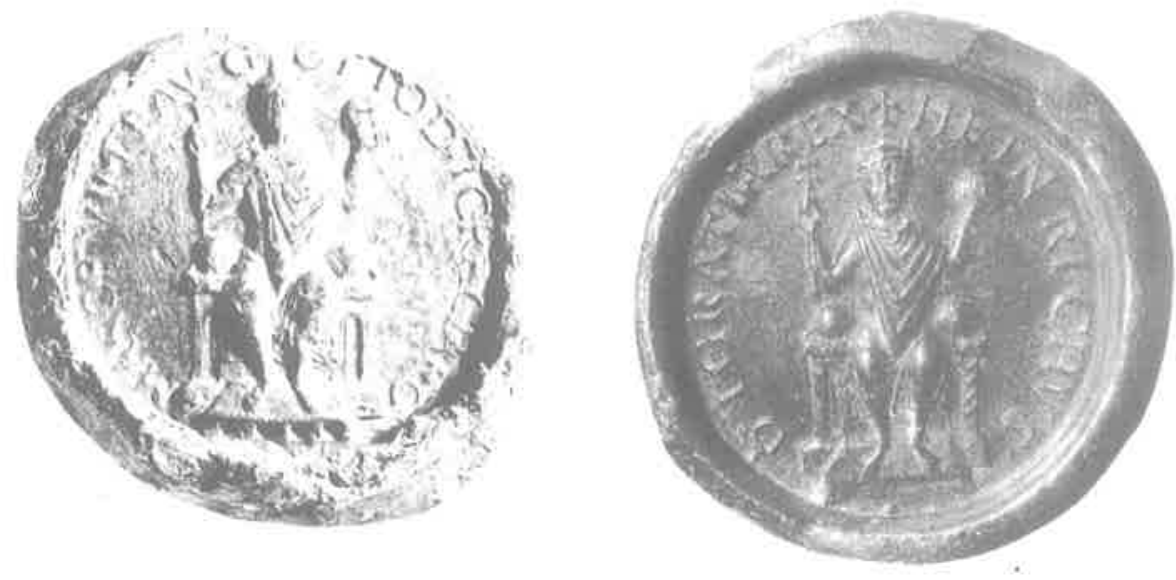

Il sigillo di Ottone III (996 - 1002)

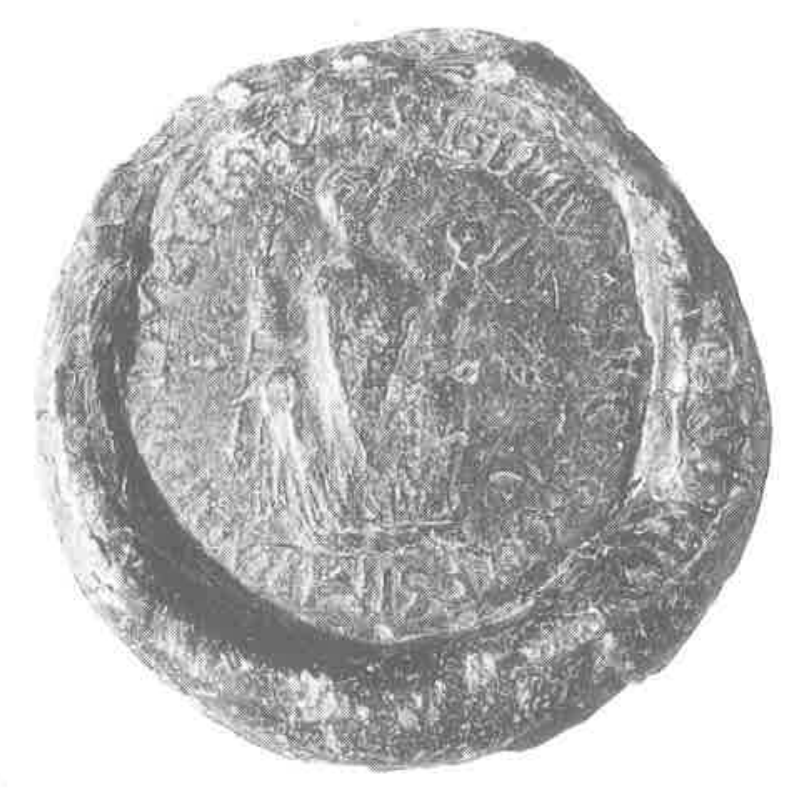

Il sigillo del re Petar Krešimir IV del 1066

soluzione anche gli invalsi interrogativi sul suo diritto identico a quello di qualsiasi altro sovrano incoronato, visto che non esistono dirette testimonianze scritte sulla data e sul modo in cui Krešimir ricevette le insegne regali. Perciò è stato occasionalmente messo in dubbio che queste gli fossero mai state consegnate e, di norma, doveva consegnargliele il papa. ${ }^{155}$ Invece, questo prezioso documento, che parla in maniera più chiara di qualsiasi documento scritto (presupposto che sia originale, come ritengo), è rimasto trascurato anche nella storia dell'arte.

Se dovessimo giudicare il sigillo niente di più che come una soluzione stereotipa, esso rimarrebbe un ottimo esempio a testimonianza dell'adozione di convenzioni moderne nell'espressione pubblica del potere con i mezzi dell'arte plastica e figurativa. A giudicare dallo schema ideale del sigillo, Petar Krešimir potrebbe anche essere il sovrano del bassorilievo marmoreo, a prescindere dal fatto che gli oggetti che reca nelle mani non sono identici nelle due opere. Nel piccolo calco in cera sono visibili d'altronde una corona a tre punte, un globo liscio e uno scettro cruciforme, come è da aspettarsi da una rappresentazione diretta di colui che con il suo titolo garantisce la validità legale di un atto o conferisce valori stabili a uno scritto. ${ }^{156} \mathrm{Il}$ carattere

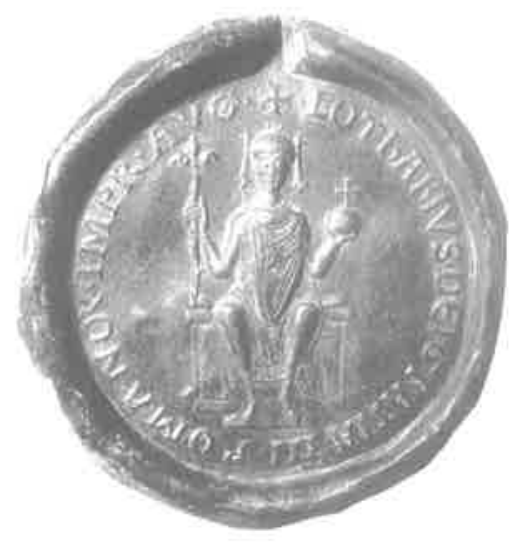

Il sigillo di Lotario III (1133)

alquanto differente delle insegne regali del bassorilievo è condizionato dal soggetto diverso della scena, ma il significato delle insegne in realtà non è diverso. Nel bassorilievo, cioè, il motivo simbolico-religioso con l'accento posto sulla croce è prevalso sulla volontà di rappresentare i pieni poteri del re vivente, che costituisce invece il motivo principale di ogni sigillo. A ogni modo, qualsiasi rappresentazione del sovrano secolare si poteva, se non addirittura si doveva riferire, nella coscienza delle popolazioni dell'Adriatico orientale, a colui che la gente conosceva direttamente per la sua dignità e per le sue azioni. Ciò conferisce al bassorilievo anche un adeguato significato politico.

Oltre al necessario richiamo sull'immagine di Petar Krešimir IV che figura nel sigillo trascurato e finora rimasto privo di un'analisi degli studiosi, il calco in cera non offre spiegazioni immediate circa il bassorilievo. Dai dati disponibili, le due opere risultano coeve, ma spiegabili ognuna all'interno della propria tipologia, non essendo condizionate l'una dall'altra. Appare più significativo, sotto ogni aspetto, il parallelismo tematico tra il bassorilievo e l'evangeliario di Montecassino con l'immagine dell'imperatore occidentale che assume le prerogative del Signore dei cieli in un simbolismo studiato dai caratteri generali. Quanto lo stesso tipo di simbolismo potesse essere applicato alle condizioni politiche e alle tendenze sociali della Dalmazia e in particolare di Spalato, rimane da appurare con un'analisi approfondita della storia della Chiesa, il che, evidentemente, non intendo fare in questa sede, non ritenendolo affatto un compito semplice.

Vorrei soltanto accennare, allo scopo di rendere più consistente il legame rilevato, che non è del tutto casuale se il bassorilievo prende a modello la miniatura antecedente. Questa considerazione è dovuta al fatto che Arrigo II, effigiato nella miniatura, fu il primo insieme al papa suo contemporaneo a perorare la causa del movimento riformistico avviato a Cluny, ${ }^{157}$ così come Petar Krešimir IV si unì allo zelo dell'arcivescovo Lorenzo ai tempi del papa Nicola II, ancor più fermo del suo predecessore nell'attuazione della riforma, con il contributo significativo dei benedettini. Inoltre, non sarà superfluo ricordare che in quello stesso periodo si verificarono eventi di estrema importanza e almeno in parte di aspirazioni scismatiche con il centro a Spalato. ${ }^{158}$ Seguendo la linea generale della politica pontificia, nel 1059 ebbe luogo il sinodo provinciale, sotto la guida del già citato Mainardo (abate pomposiano e più tardi cardinale) nelle vesti di legato pontificio e di Lorenzo Dal- 
mata, a quel tempo appena assunto alla dignità arcivescovile. ${ }^{159}$ Lo scopo del sinodo era di far rispettare nelle regioni dalmate le disposizioni del concilio lateranense che segnò la svolta, tenendo conto della posizione sempre assai delicata di quella regione ai confini degli influssi occidentali. Pare che il sinodo non ebbe pieno successo, vale a dire che le sue conclusioni furono meno rigide rispetto alle delibere romane sulla simonia e sull'uso della lingua latina nella prassi liturgica. ${ }^{160}$ Eppure, provocarono scontri nell'intera società della regione, causando eventi particolari in cui si riconoscono segni di scisma; di conseguenza, fu necessario convocare, già nel 1064, un secondo sinodo a Spalato a riconferma dei canoni del primo. ${ }^{161}$

A giudicare dalle testimonianze dei cronisti e da altre fonti scritte o documenti diretti, era in atto un ampio schieramento tra due fazioni: l'una, riformista, composta da membri di classi alte, cioè da vertici ecclesiastici e laici, da vescovi cittadini alla corte del re; l'altra eretica, che difendeva le antiche tradizioni del clero croato sulle questioni della morale privata e degli uffizi divini. ${ }^{162}$ I disordini si diffusero anche nelle città, ed è difficile discernere quel che si celasse dietro le singole correnti o dietro gli eventi tumultuosi la cui cronologia è ancor oggi da stabilire. Appare persino un falso vescovo, tale Ceded, il quale riuscì addirittura a essere ricevuto in udienza da papa Alessandro II, grazie all'intercessione del missionario Wulf, uno straniero forse venuto da Aquileia. ${ }^{163}$ Questa linea eretica viene giustamente valutata da alcuni alla luce della lotta che l'antipapa Onorio II condusse per acquisire i diritti di spettanza papale, e non vi è dubbio che anche qui si riflettessero le ondate provocate dalla riforma in tutta l'Europa, assumendo però caratteri specifici in un'area che per molto tempo si era trovata sotto il dominio bizantino. Mentre tanti fatti rimangono offuscati da leggende e privi di spiegazioni storiografiche, per il nostro discorso è importante sapere che Petar Krešimir indubbiamente appoggiò l'arcivescovo Lorenzo e che questi in certe occasioni fece altrettanto nei confronti del re. Anzi, per via del suo orientamento filooccidentale, il re dovette affrontare forti resistenze persino tra le file dei suoi diretti sudditi delle regioni continentali e ancor di più tra le file del clero croato, sostenitore di tradizioni antiche che all'epoca trovavano la loro espressione più manifesta nella liturgia in lingua nazionale croata, vietata da Roma. ${ }^{164}$

Avendo considerato sin dall'inizio il bassorilievo spalatino come risultato di un determinato programma storico, anche nella politica governativa di Petar Krešimir IV si potrà trovare, senza troppe difficoltà, il motivo che ne ispirò la realizzazione, nonché le successive modifiche. È importante, a tale proposito, il fatto che il re croato si mostrò molto abile nell'approfittare del declino di potere bizantino nell'Adriatico orientale, estendendo il dominio alle città del tema imperiale. ${ }^{165}$ Si ritiene che all'inizio di questo processo il re ebbe il consenso della suprema casa imperiale, ma è altrettanto vero che ne divenne nemico allorchè sostenne militarmente la rivolta dei bulgari nell'entroterra e l'avanzata dei normanni oltremare. Tenendo conto di tutti questi elementi, la possibilità che della sua presenza più che simbolica a Spalato fosse lasciato segno non è da escludere, specialmente intorno al 1069, considerato anche che il personaggio più influente a Spalato dell'epoca fu l'arcivescovo Lorenzo. ${ }^{166}$ Tutto quel che è successo in segvito con il monumento, sembra altrettanto andare a pari passo con gli eventi storici. Con l'avvento al trono di Zvonimir, Bisanzio riprese con più forza le sue posizioni in Dalmazia, mentre si iniziava a sentire l'influenza di Venezia. ${ }^{167}$ I diversi partiti d'interessi trovavano adepti nel patriziato e in altri ceti cittadini e in questa situazione di contesa fra varie fazioni, predominio ora di gruppi anticroati, ora di quelli filocroati, per di più in un centro urbano di orientamento romano-latino, troveremo sicuramente elementi per spiegare le sorti successive di quel monumento. Quest'argomento, credo, potrà essere affrontato con maggiori certezze dopo che avremo esaminato più in dettaglio le direzioni di sviluppo dell'amministrazione comunale spalatina, senza trascurare l'insieme delle circostanze createsi intorno al bassorilievo e cui abbiamo accennato finora nelle nostre analisi.

Dopo aver offerto un quadro sommario degli eventi storici, si presenta la necessità di altre spiegazioni in linea con le precedenti, volendo proseguire nella ricerca di una risposta circa la datazione del bassorilievo all'epoca di Petar Krešimir IV oppure di Dmitar Zvonimir. Le spiegazioni necessarie si riferiscono alle tesi in larga misura radicate e a più riprese sostenute, che il monumento fosse situato nella nota basilica dei SS. Pietro e Mosè, nei pressi di Salona. ${ }^{168}$ Queste tesi erano fondate, come ho già accennato, sul ritrovamento archeologico dei frammenti marmorei di un pluteo recante figure scolpite in bassorilievo e manifestamente simili a quelle di Spalato, per cui si è cercato di unirli in un unico insieme che, però, mancava di troppi elementi per poterne ricostruire la forma ipotizzata dagli studiosi. ${ }^{169}$ Visto che nel 1075 re Zvonimir fu incoronato proprio in quell'edificio monumentalmente strutturato e splendi-
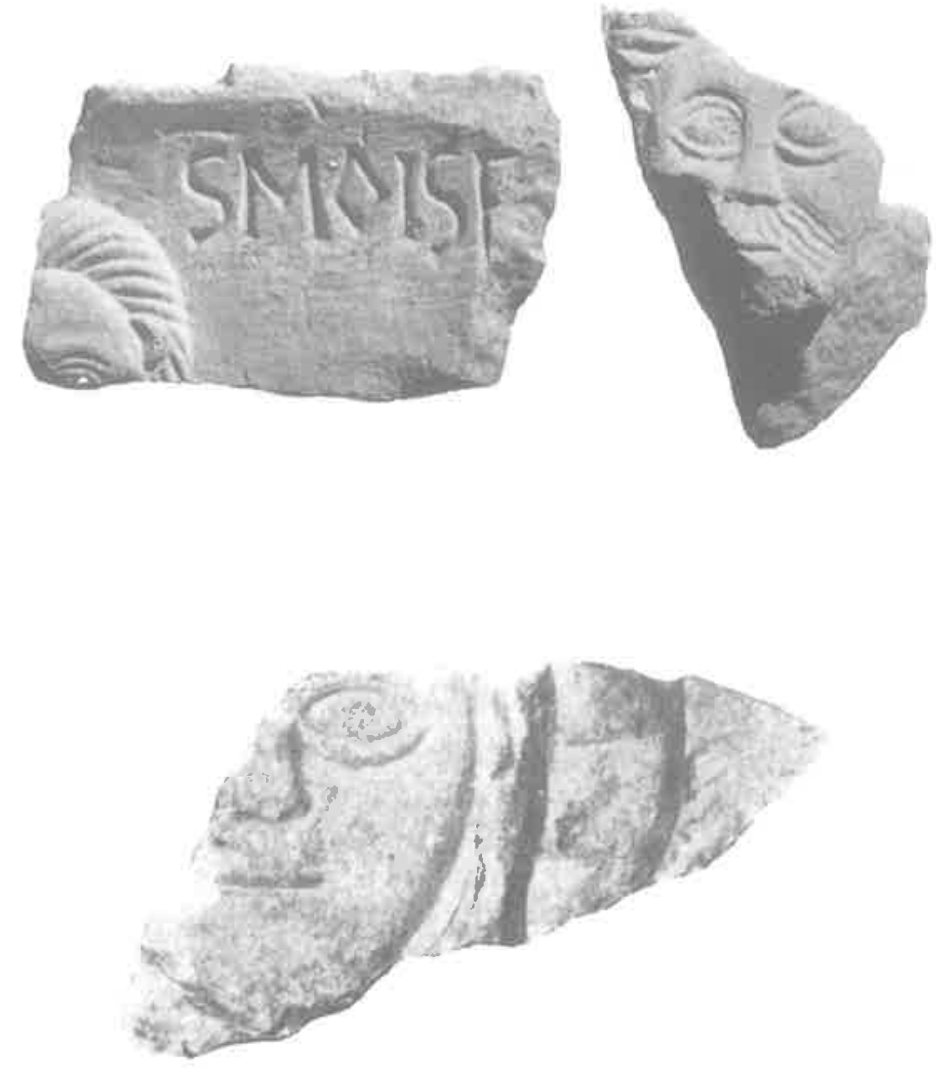

I frammenti del cancello della chiesa di SS. Pietro e Mosè a Salona terzo quarto del secolo XI 


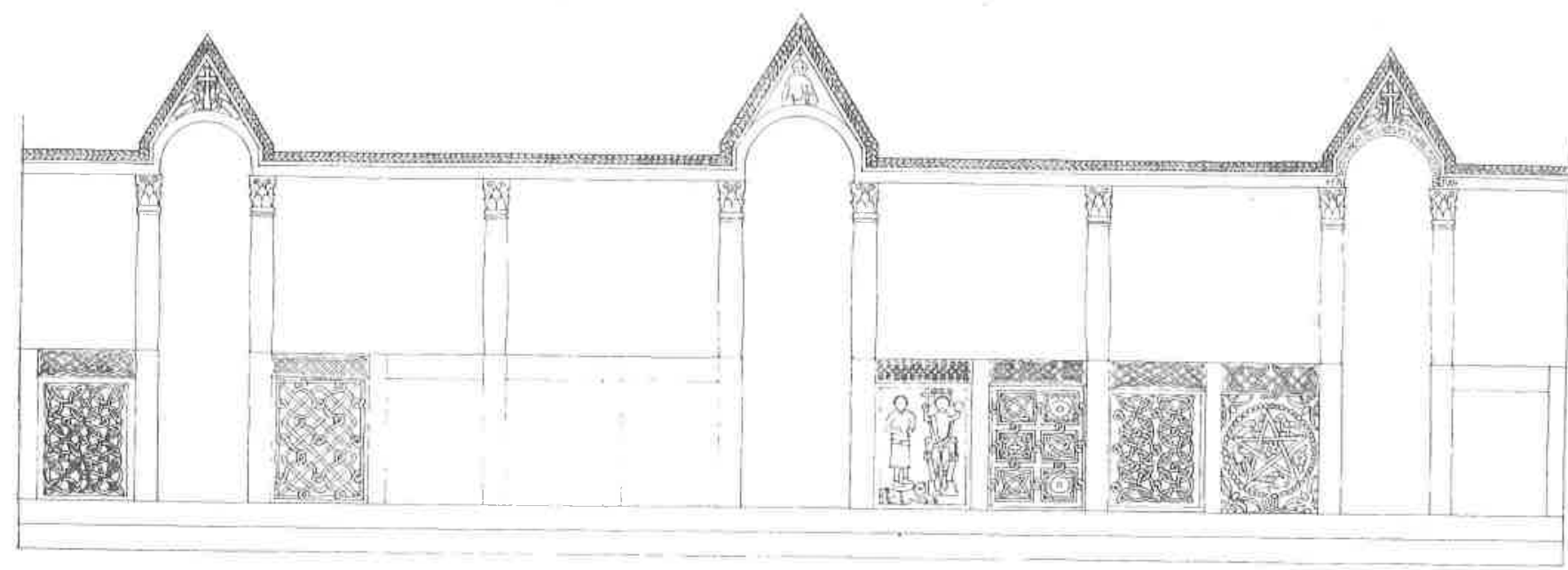

Ricostruzione ipotetica della recinzione presbiteriale della basilica si SS. Pietro e Mosè a Salona (E. Dyggve, 1951)

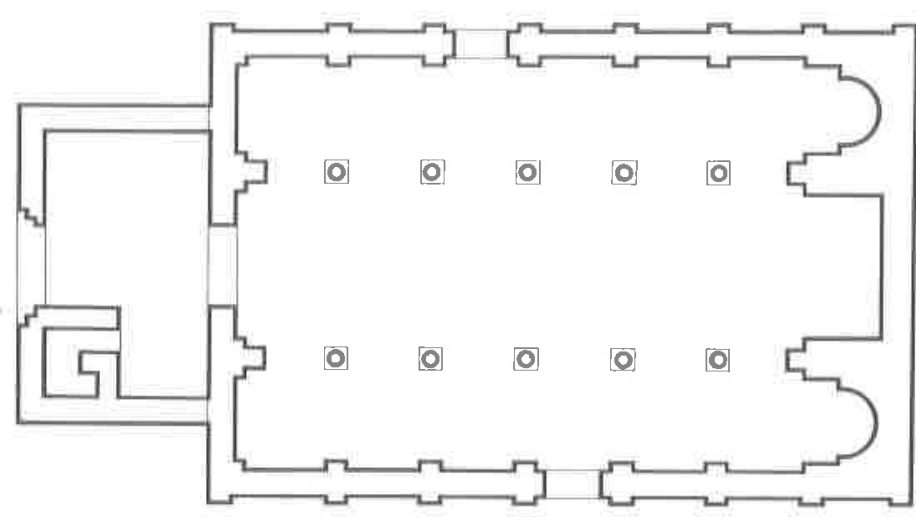

La pianta della basilica di Ss. Pietro e Mosè a Salona

damente arredato, la costruzione della basilica dei SS. Pietro e Mosè veniva attribuita al re, per cui anche il bassorilievo veniva spiegato con l'atto di incoronazione. ${ }^{170} \mathrm{E}$ evidente, invece, che la basilica fu costruita prima, durante il regno di Petar Krešimir IV, ed essendone già terminata la costruzione, servì allo scopo in occasione dell'incoronazione del re successivo. Sarebbe difficile credere che la recinzione dell'altare fosse realizzata solo in seguito, in memoria dell'evento di incoronazione, dal momento che essa è stilistiçamente conforme ad altre parti dell'arredo del presbiterio. Tenendo conto di questa definizione stilistica, è più facile accettare le prove dei legami che si possono stabilire tra i frammenti ritrovati nella basilica e la produzione scultorea di un'officina attiva a Zara nel quarto decennio dell'XI secolo. ${ }^{171}$ Il repertorio dei motivi decorativi non è comunque decisivo per l'inserimento di altri plutei spalatini nella produzione della bottega zaratina, quand'anche l'eccellente realizzazione della principale scena figurale si possa attribuire al fatto di essere condizionata dal modello grafico.

Nel nostro tipo di approccio a questo problema non si può prescindere dal fatto che la lettura dell'azione compiuta nel bassorilievo dal sovrano e dal suo seguito non richiede un ciclo iconografico più ampio in cui avrebbero il loro ruolo altre scene successive con figurazioni umane. Perciò riteniamo che non sia necessario un concatenamento diretto del bassorilievo con i frammenti di Salona che, a quanto pare, raffigurano i SS. Pietro e Mosè; lo riteniamo ridondante rispetto al contenuto dei monumenti in questione, nonché storicamente errato. Anzi, le sei lastre conservate nel battistero di Spalato bastano a formarne, in maniera ragionevole, un cancellum di altare idealmente integro, in cui le due lastre a soluzione figurale-simbolica sono sufficienti a creare fra di loro un insieme armonico, se non anche ideale.

Ciò nonostante ritengo che il contenuto del bassorilievo con il tema del Rex iustusfosse completato da un'altra lastra di lavorazione più rigorosa, l'unica con una descrizione che includa la figurazione. ${ }^{172}$ Su questa lastra troviamo, com'è noto, una composizione a figura di pentagramma, eseguita sullo stesso piano di superficie e in un sistema coincidente a quelli del bassorilievo figurale, tanto più che la superficie elaborata ponderatamente è sovrastata da una cimasa a

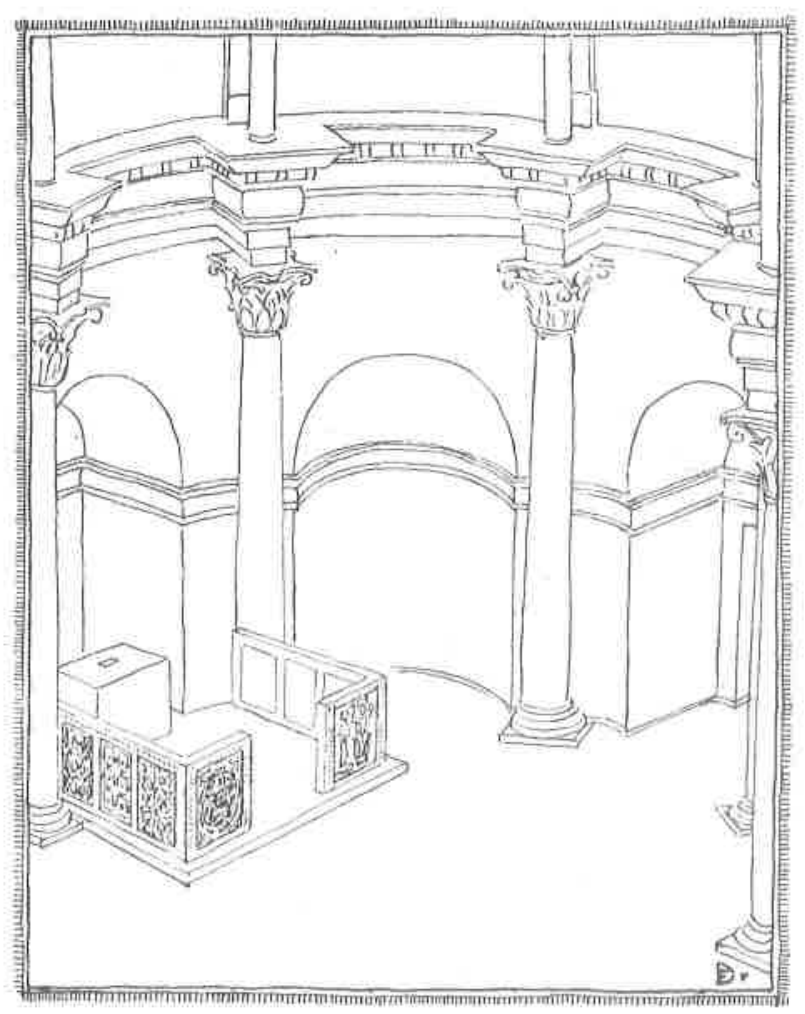

Ricostruzione ipotetica della recinzione nella cattedrale a Split (M. Abramić, 1925) 


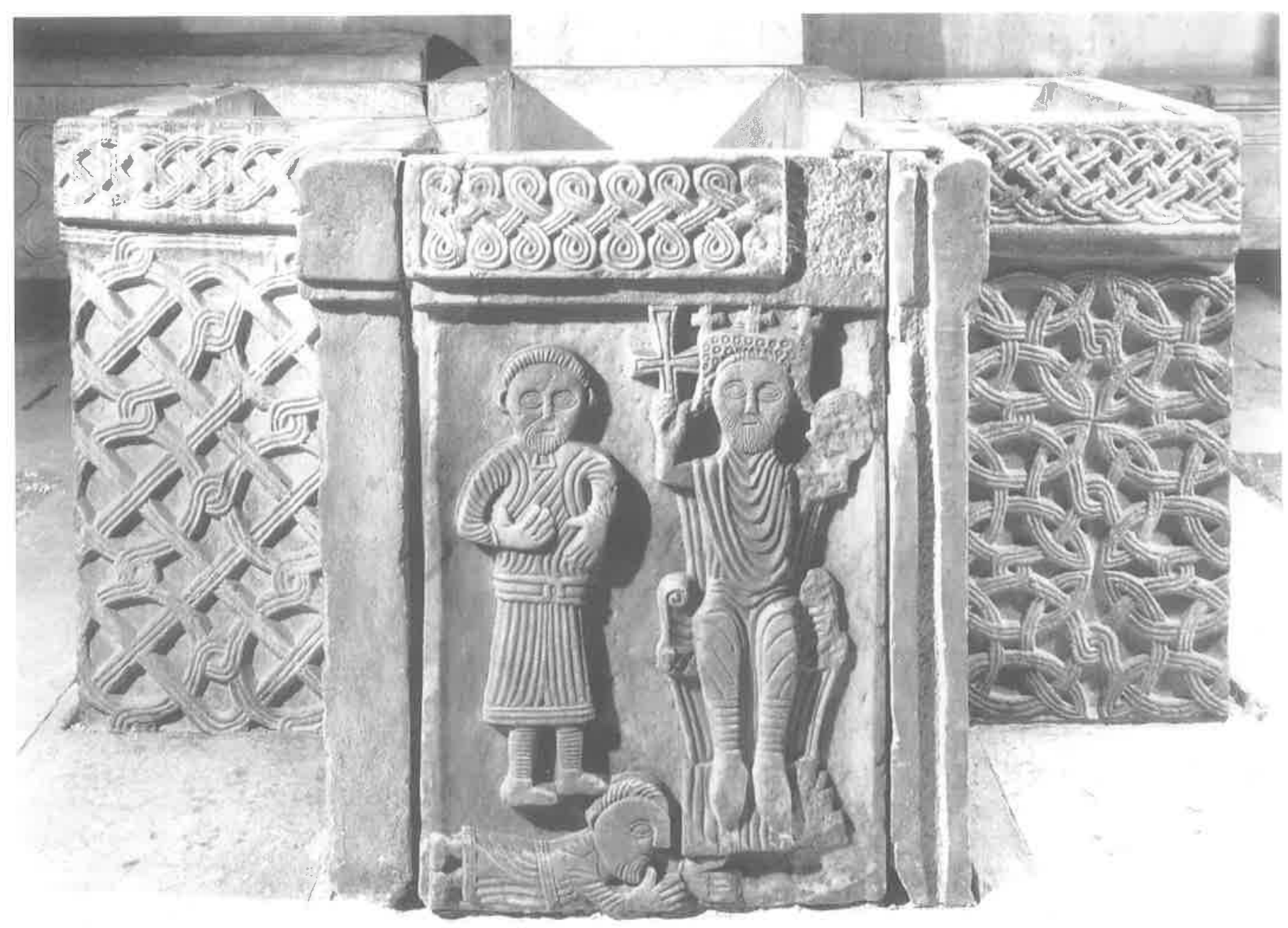

L'insieme del fonte battesimale visto dalla facciata

(foto Živko Bačić)

intreccio. Il motivo principale della lastra stava di solito a rappresentare il Cristo, partendo da un significato più antico del simbolo, dove questo stava per l'idea perfetta, ovvero per l'avverarsi dell'unità del microcosmo composto di elementi ineguali. ${ }^{173}$ Come la stella a cinque punte realizzata sulla lastra di Spalato, il pentagramma è l'emblema di Figlio del Sole o del moto perpetuo, sacro indizio della Fonte della Vita Eterna che è il seme universale di tutti gli esseri. ${ }^{174} \mathrm{Nel}$ contesto religioso il simbolo appare a garanzia della conoscenza, anzi come il mezzo di acquisizione e di restituzione del potere, che è il significato ripreso dal Cristianesimo rispetto al destino del Figlio di Dio e alla sua missione sulla terra. In particolare, nell'esempio di Spalato viene confermato quest'ultimo significato, mediante l'inserimento di piccole figure di uccelli fra le punte della grande stella, poiché gli uccelli sono i segni primevi del legame fra il cielo e la terra, testimoni spirituali del divino, con allusione alla beatitudine paradisiaca e alla vita eterna. ${ }^{175}$

La stessa idea dell'eternità è trasmessa anche dalle altre lastre del battistero, ricoperte esclusivamente di ornamenti a intreccio, ma in una disposizione delle superfici determinata dalle due lastre principali. Nonostante vi fossero applicati differenti motivi a intreccio del ricco patrimonio di geometria astratta tipica del preromanico dalmata, ${ }^{176}$ nell'insieme essi creano un effetto di successione dinamica, con un'impressione globale di vibrazione ottica. Si nota sulle lastre la totale assenza di motivi vegetali e altri motivi des-

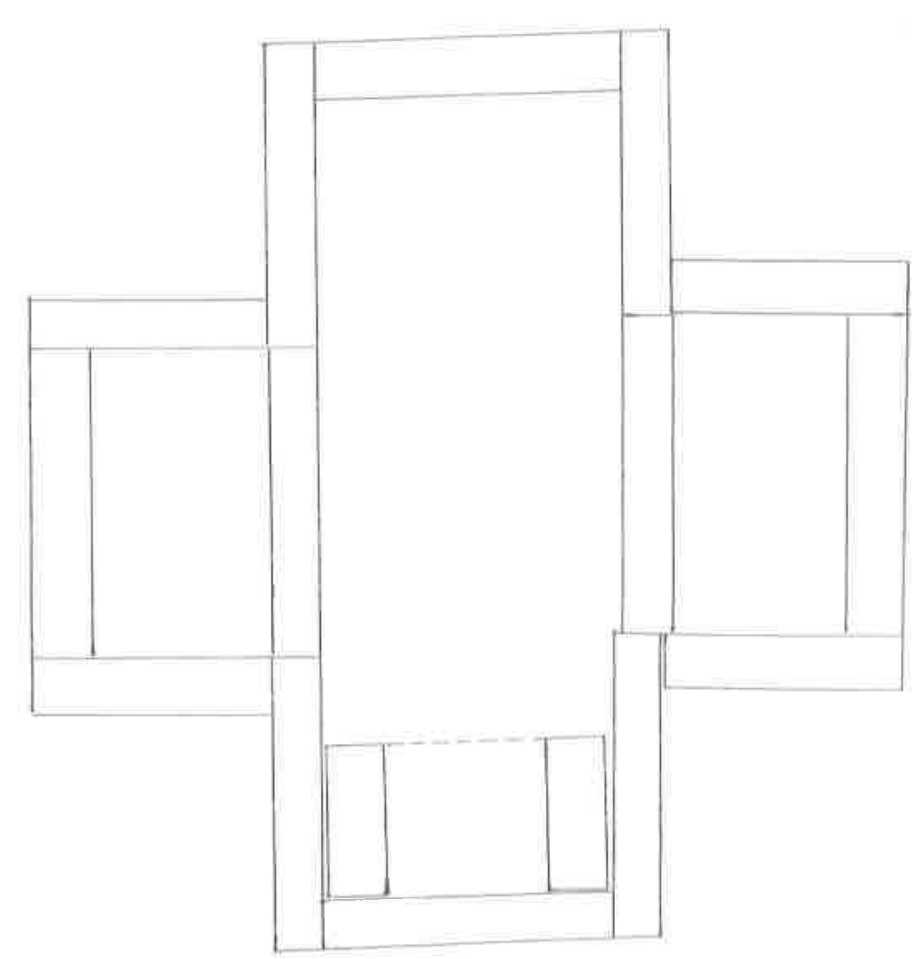

Pianta del fonte battesimale 


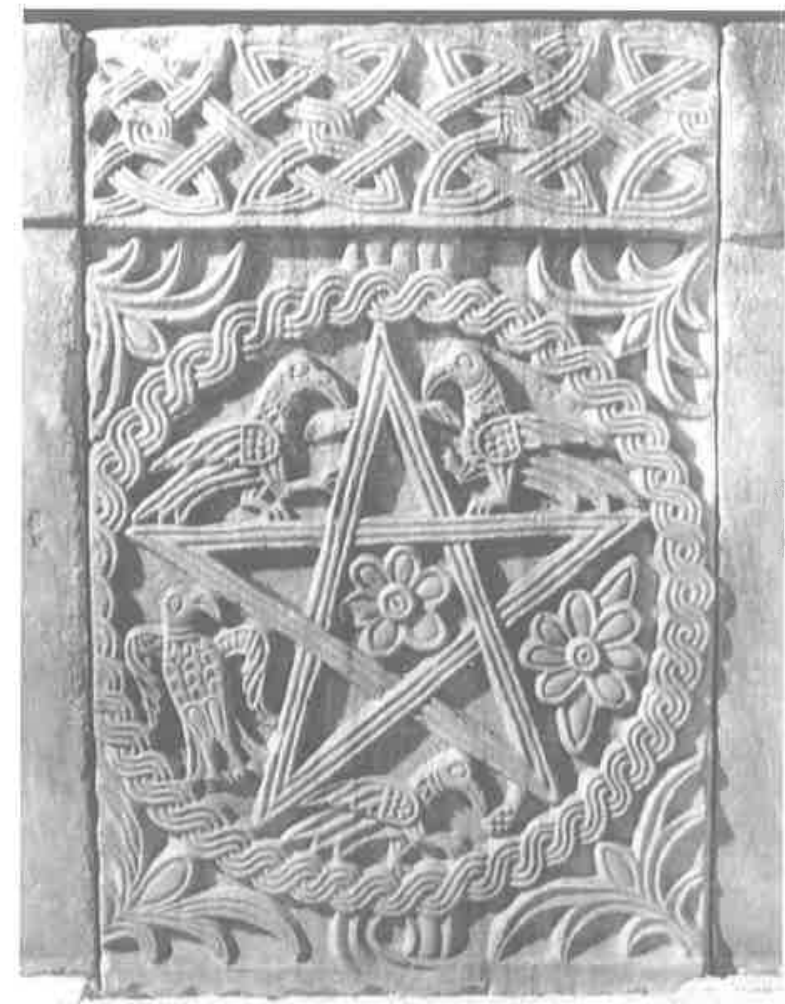

La lastra del pluteo con il rilievo del pentagramma

critivi dell'epoca, in una limpida rete di nastri a tre fili che, considerando il carattere protoromanico dell'espressione scultorea, sta a testimoniare la consapevolezza dei significati di quella rete. Per la stessa ragione, l'ornamento non è inqua- drato architettonicamente, però la sua bellezza figurativa è sostenuta da un'esecuzione precisa che dimostra la volontà di ordine nell'elaborazione ritmica di moto infinito o di intrecciatura lineare dello schema interconnesso. Il simbolismo, quindi, è chiaro, perchè spiega l'energia di tutta quanta l'esistenza e il mistero del mondo con l'inconoscibile natura divina. ${ }^{177}$ Bisogna perciò comprendere la concordanza complessiva e anche ideale tra le lastre ornate a intreccio e le altre due che probabilmente occupavano la posizione centrale nell'insieme composto da un numero pari di componenti. Nella simmetria dell'insieme, su due bassorilievi centrali è espressa l'idea fondamentale: l'equilibrio di $\mathrm{Sa}$ cerdotium, con i suoi simboli di Cristo e del paradiso, eil Regnum con l'allegoria narrativa che si riferisce al legittimo re.

Il contenuto e così pure la forma armoniosa di tutte le lastre corrispondono a una loro destinazione alla recinzione di qualche punto importante della liturgia, all'interno di una chiesa senz'altro rinomata. Questa tesi è confermata dal materiale usato, che è il marmo, nonché dall'eccellenza di lavorazione figurativa e tecnica; inoltre, la compattezza plastica delle componenti, tutte di identiche proporzioni e slanciate in alto, fa pensare piuttosto a una loro collocazione in uno spazio ristretto, oltre a rivelare un fondamentale rispetto dello spirito stilistico. Perciò sembra in gene rale persuasivo il collegamento delle lastre con Spalato, poiché è quasi certo che nell'XI secolo inoltrato il Duomo avrebbe dovuto essere sottoposto a interventi di rimodernamento con arredo sfarzoso, questo perchè teatro di più d'un sinodo ecclesiastico e perchè proprio in quel periodo si ebbe un rinvigorimento di attività scultorea legata a tutta una serie di importanti lavori architettonici in tutta la città e nei dintorni. Senza alcun dubbio, quindi, verso la metà dell'XI secolo esisteva nella metropoli ecclesiastica dalmata
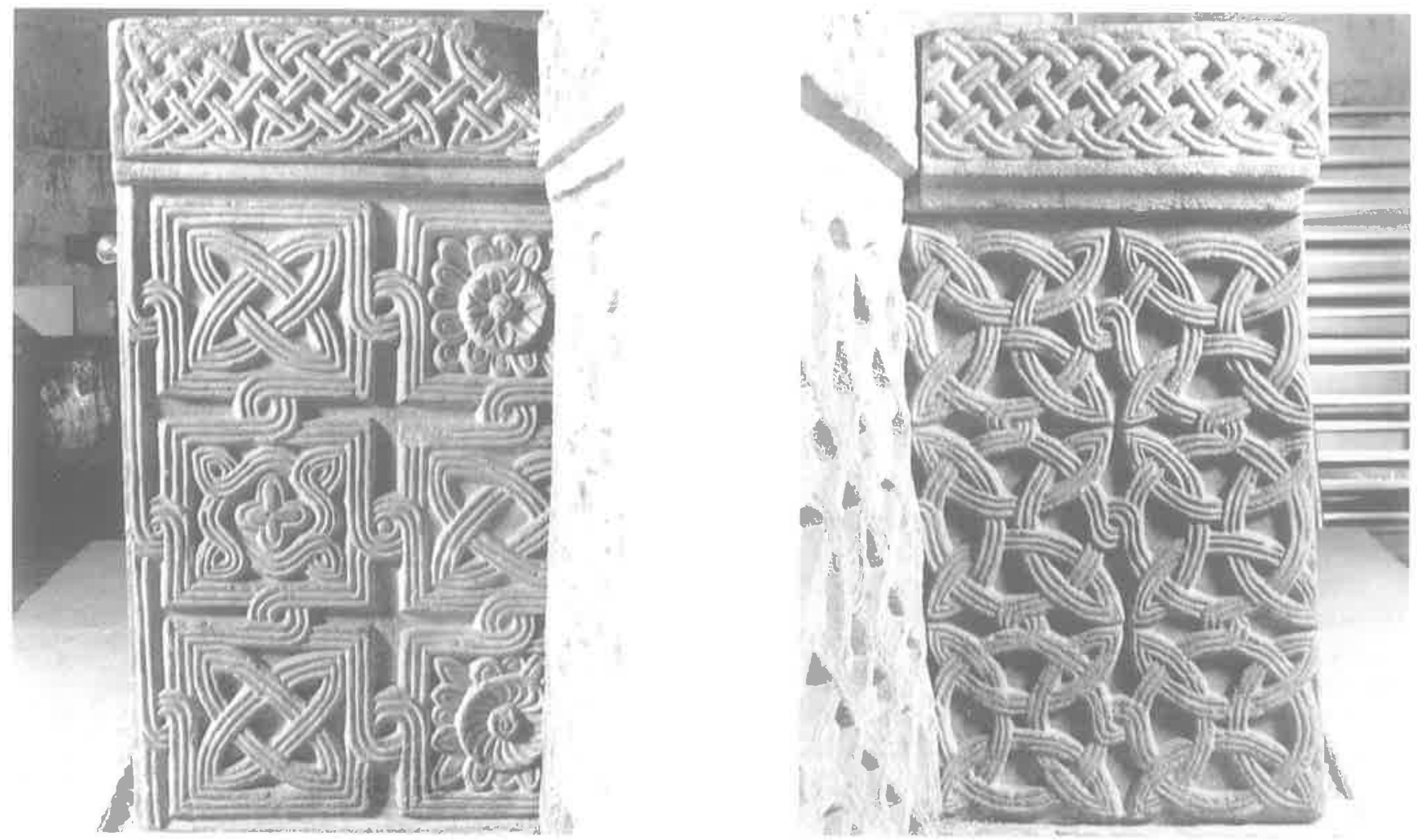

Le lastre del pluteo con l'ornamento d'intrecciatura 
un'officina scultoria in cui maestri abili ed esperti sopperivano ai bisogni dell'arcidiocesi che allora era presieduta dal più che efficiente Lorenzo. Bisogna dire, però, che le opere rimanenti che si trovano oggi nel Duomo e che potrebbero venire da quell'officina, non sono sufficienti per poter trarre conclusioni di maggiore portata sull'arredamento completo del santuario. Questo forse potrà essere chiarito da un'analisi, ancora tutta da fare, di una moltitudine di frammenti plastici decorativi che si trovano nell'area cittadina. In ogni caso, è più che significativo il fatto che i plutei tanto discussi dagli studiosi siano conservati, grazie a un loro uso secondario, proprio nel battistero che si trova una distanza di circa cinquanta metri dal Duomo.

Non si è riusciti a capire finora soprattutto le ragioni per cui parti di cancellum siano state riutilizzate per l'arredo del battistero, in mezzo a una città in cui di scultori abili non ne sono mai mancati. ${ }^{178}$ Sei delle lastre di cui sopra sono state semplicemente utilizzate nella costruzione del fonte battesimale a forma di croce greca, cioè con quattro bracci uguali cui si addiceva bene la dimensione delle lastre, e che anzi ha determinato la larghezza e l'altezza dei bracci. Per di più, i lati decorati sono posti ai bracci anteriori, proiettati in modo che li si possa abbracciare con lo sguardo immediatamente, appena entrati nell'ambiente. La parte posteriore del fonte, al contrario, è fatta di piatti rettangoli in marmo, di fabbricazione nuova, ma di dimensioni identiche a quelle delle lastre decorate. ${ }^{179}$ La lastra con la stella a cinque punte - il pentagramma è posta sul principale braccio frontale, verso l'entrata, il che sta a dimostrare la considerazione del suo significato originario, mentre il bassorilievo con l'effigie di sovrano è trascurato, collocato di lato sul braccio settentrionale del fonte cruciforme, eseguito in corrispondenza con il piedistallo. ${ }^{180}$ Malgrado il montaggio eseguito con cura, sono stati staccati piccoli pezzi di alcune lastre, inclusa l'unica che reca una scena figurale, e questo al fine di far aderire la lastra successiva ad angolo retto. Due lastre sono state addirittura un po' raccorciate per essere inseririte nella nuova entità di grande importanza rituale. Intanto si ha l'impressione che tutte le componenti del vecchio cancellum siano state prelevate nelle vicinanze per consentire l'assestamento del battistero del Duomo ai tempi quando l'originaria collocazione del cancellum aveva ormai perso la sua attualità.

Da una parte è lecito supporre che si trattasse dell'ordinario riammodernamento del santuario nel cui interno il cancellum altoromanico non trovava più il suo posto per via del cambiamento del gusto o delle esigenze liturgiche. Questo, ovviamente, sarebbe potuto avvenire in un arco di tempo incerto, ma non poco dopo il terzo quarto dell'XI secolo, a cui il cancellum risale. Però già nel XII secolo veniva fabbricato intorno al Duomo dell' arredo in pietra di caratteri stilistici differenti. ${ }^{181}$ Nello stesso tempo, dobbiamo tenere a mente che un fonte della stessa tipologia di quello in cui sono state inserite le lastre non si sarebbe potuto realizzare dopo il XIII secolo, perchè il battesimo per immersionem, previsto dalla forma di quel tipo di fonte, cade in disuso proprio in quel periodo. Esistono, d'altronde, altre prove indirette che l'assestamento completo del battistero risalga al XII secolo e che sia dovuto alla trasformazione del tempio principale

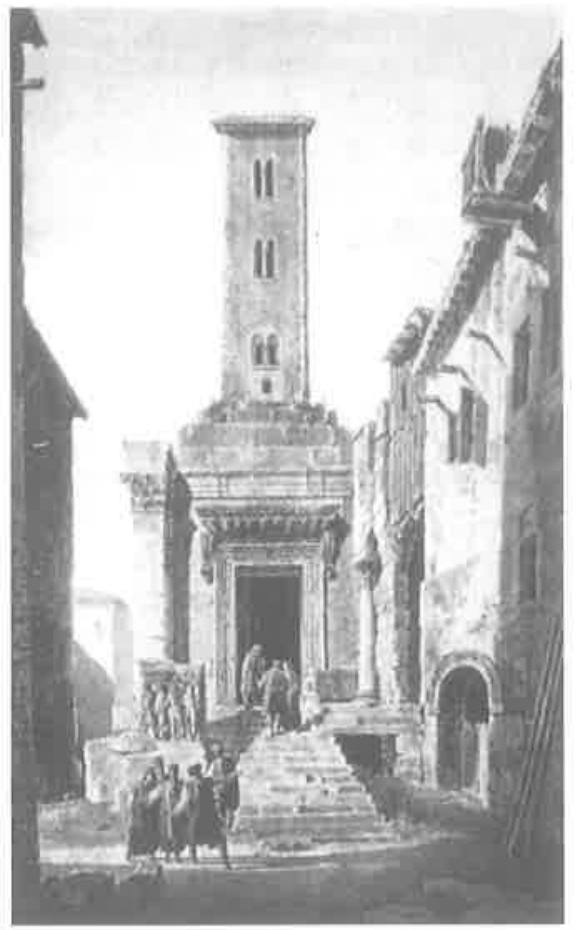

Il disegno del tempio-battistero con il campanile : L. F. Cassas; 1782.

del palazzo di Diocleziano in un santuario cristiano dedicato a S. Giovanni in Fonte. ${ }^{182}$ Sopra l'edificio esistente è stato eretto un piccolo campanile che molto probabilmente risale allo stesso periodo (XII sec.). ${ }^{183} \mathrm{In}$ ogni caso, il campanile elegante era stato eretto prima che si iniziasse, accanto al vicino Duomo, la costruzione di un grande campanile dallo stile romanico molto maturo, di struttura molto più plastica accompagnato da una scultura figurale altamente sviluppata. ${ }^{194}$

A partire dalle prove di tali successi nell'evoluzione artistica a Spalato, sorprende il riuso del pluteo che nella sua collocazione originaria non doveva esser durato più di un secolo e mezzo. Che sia stato rimosso, non dovrebbe sembrare strano, se prendiamo questo fatto a indizio che la collocazione originaria del cancellum fosse particolarmente esposta, ma, semmai, sembra più unica che rara la decisione di spostarlo e riutilizzarlo ad altri fini. Il carattere di eccezione che questo atteggiamento assume, induce a prendere in considerazione le specifiche condizioni che avrebbero potuto determinare il significato storico del pluteo nel l' ambiente in cui si trovava. Tanto più appare incomprensibile e ingiustificata la tesi del suo trasferimento dalla lontana basilica di Salona, ${ }^{195}$ dato che non esistono prove di tale trasferimento e dato che la suddetta basilica, a giudicare dai dati disponibili, rimase intatta nella sua forma originaria e senza particolare bisogno di modifiche almeno fino alla metà del XV secolo. Possedimento dell'arcidiocesi di Spalato in una località esposta, la basilica di Salona fu distrutta solo con l'avanzata dell'esercito ottomano. Gli archeologi vi hanno trovato numerosi frammenti di arredo altomedievale in pietra, fra cui ve ne sono alcuni stilisticamente molto vicini al nostro bassorilievo. ${ }^{186} \mathrm{La}$ conformità stilistica dei frammenti e del bassorilievo ne fa risalire la realizzazione allo stesso periodo, ma i frammenti di Salona rivelano la presenza di più componenti di arredo di un grande presbiterio, fra cui anche un cancellum composito. ${ }^{187}$ Significa che in quel luogo solitario fuori dall'abitato, tutto fu distrutto con violenza in una sola volta, 
mentre le lastre spalatine, al contrario, spiccano nella molteplice integrità dell'insieme da cui traggono origine. In questo modo viene riconfermata l'intensa attività durante il regno di Petar Krešimir IV di un'eccellente officina scultoria dall'area spalatino-salonitana, le cui opere sopra individuate ne garantiscono da una parte la stessa attività e dall'altra che questa si svolgesse fra i due centri politici, proprio a quell'epoca assai collegati tra di loro.

In ordine di analisi, è importante riconoscere che il fonte battesimale del Duomo di Spalato, situato all'interno del battistero arredato nel XII secolo, è composto da sei lastre provenienti da un cancellum realizzato una quarantina d'anni prima dell'inizio della sistemazione del battistero. Tutto sta a indicare che le lastre si trovavano a Spalato sin dall'inizio, anche se non esistono dati sulla loro precisa collocazione. A ogni modo, tutte insieme dovevano costituire un unico e autosufficiente ciclo programmatico all'interno di qualche chiesa importante, ${ }^{188}$ vista la rappresentatività delle forme e dei contenuti del monumento. Proprio quel soggetto del bassorilievo, qualcuno a un certo punto doveva averlo trovato scomodo, perchè si cercò di modificarlo ovvero offuscarlo in maniera premeditata proprio nella sua parte più significativa e più facilmente leggibile. Dal bassorilievo figurale, il cui significato di narrazione simbolica siamo arrivati a comprendere, è stato rimosso attraverso un intervento scultoreo posteriore l'oggetto che il personaggio dritto teneva all'altezza del petto, ed è stata cancellata, inoltre, l'iscrizione che sovrastava la scena. Siccome gli altri due personaggi sono rimasti intatti e questo terzo si è conservato integro a parte l'oggetto toltogli dalle mani, l'azione originaria rappresentata è stata in realtà neutralizzata e ne è stata mutilata la narrazione. L'intervento è stato eseguito in un periodo in cui le scene figurali stavano diventando sempre più attraenti, perchè generalmente comprensibili. Comunque, non è stato modificato nè tanto meno eliminato nessuno degli attori della scena, ma essendo stato soppresso l'oggetto che doveva pur significare qualcosa, è stato offuscato il senso del legame fra i personaggi e annullato il significato complessivo del bassorilievo. A questo scopo era in particolare mirata la cancellazione dell'iscrizione sovrastante che necessariamente rivelava altri elementi importanti per la comprensione del documento figurativo. ${ }^{189}$ In questo modo il bassorilievo è stato sradicato dal suo contesto storico, perchè è stata mutilata la realtà cui esso si riferiva e che in origine avrebbe dovuto immortalare.

Tutto ciò è stato fatto con estrema attenzione, in maniera quasi impercettibile. Della fascia che recava l'iscrizione è stato eliminato con cura soltanto lo strato superficiale, fino al punto di profondità raggiunto dall'intaglio delle lettere; tutta la superficie è stata poi lisciata, come se non ci fosse mai stato niente. Allo stesso modo, sul petto dell'uomo barbuto che sta in piedi sono stati abilmente connessi i panneggi stilizzati rispettando le stesse linee e le stesse incurvature delle parti circostanti che in questo modo sono state collegate fra di loro. Nonostante gli sia stato strappato qualcosa dalle mani, quest'uomo sta nella sua posizione irrigidita come se non avesse mai portato nulla. La superficie situata tra le sue mani e nel prolunga- mento di quel piccolo rettangolo allungato appare comunque un po' incavata, in conseguenza al lavoro di rifinitura eseguito dallo scultore nell'intervento posteriore alla realizzazione originaria del monumento. ${ }^{190}$ Un certo intento è stato quindi mandato a effetto in piena consapevolezza, senza però mutilare l'integrità estetica del bassorilievo e dell'insieme a cui apparteneva. È stata creata in realtà un'immagine nuova del re, al quale non è stato sottratto nulla, e dei due suoi sudditi, in una composizione che potrebbe addirittura avere altri significati di generico carattere teologico. Un eventuale significato teologico della scena non trova però giustificazioni nell'insieme iconografico del cancellum e non ha fondamenti storici anche se non rinnega la presenza del re. D'altronde, i dilemmi e gli errori delle interpretazioni esistenti, insieme alle divergenze delle opinioni espresse dagli studiosi, sono dovute alle imprecisioni intorno all'identità del personaggio a fianco del re e intorno alla natura dell'azione che egli svolge.

Tenendo conto dei fatti sopra esposti e ponendo l'accento sulla consapevolezza e sulla perfezione dell'intervento, bisogna riconoscere che esso abbia avuto luogo mentre il bassorilievo si trovava ancora nella sua collocazione di provenienza. Il fatto è che il bassorilievo è stato preparato per l'inserimento nel fonte battesimale in un modo completamente diverso, quando gli è stata ritagliata a scalpello la verticale fascia terminale posta a sinistra, per creare il supporto della lastra successiva. Le parti plastiche sono qui gravemente danneggiate da colpi di uno scalpello acuminato che partivano dall'alto e che dovevano lasciare ruvida la superficie per permettere una migliore adesione con la malta nel braccio del fonte cruciforme. ${ }^{191}$ Si sapeva esattamente che la lastra successiva posizionata ad angolo retto avrebbe coperto quella parte e oggi, in effetti, riusciamo appena a scorgerla. È evidente, inoltre, che quella fascia laterale doveva essere ritagliata solo dopo e non insieme alla cancellazione dell'iscrizione dalla fascia superiore, poiché nei due casi sono state adottate due tecniche di lavorazione diverse. Nel corso del secondo intervento al re è stato tolto il globo dalla mano, senza alcuno scrupolo, il che significa che ormai non si aveva più rispetto per la sua effigie, come invece era stato il caso precedentemente, quando era rimasto intatto. Si trattava, evidentemente, di due interventi diversi con scopi diversi e a una certa distanza di tempo.

La politezza tecnica del primo intervento testimonia il compito di questo nella modifica del significato della scena, ma non della destinazione del pluteo, mentre il secondo intervento ha avuto luogo in condizioni alterate di rapporto nei riguardi del monumento e della sua funzione. Evidentemente, anche il soggetto del bassorilievo aveva ormai perso la sua attualità e solo l'aspetto ornamentale esercitava ancora un certo fascino. L'unica scena figurale aveva perso l'importanza a tal punto che nella recinzione del fonte gli è stata assegnata una posizione laterale, mentre la lastra con il pentagramma spicca invece in posizione frontale. Tutto ciò significa che ai tempi dell'arredamento del battistero il senso dell'insieme originario del bassorilievo era ancora e almeno in parte ricordato e che ne veniva ancora riconosciuto il valore estetico, visto che è comunque stato riutilizzato in un punto di grande importanza rituale. Perchè invece non si sia ricorsi alla fabbricazione di una lastra nuova, sarà il 
fatto più difficile da comprendere e la possibile urgenza dei lavori può essere adottata solo come giustificazione provvisoria. Niente, però, contraddice la tesi secondo cui l'arredo dell'intero battistero risalga agli inizi del XII secolo, dato che esso non denota improvvisazioni casuali.

In questo contesto è fondamentale, naturalmente, arrivare a comprendere le condizioni di esecuzione del primo intervento che ha intenzionalmente modificato il senso del bassorilievo con il re. Malgrado gli sforzi per arrivare a leggere l'iscrizione, non siamo riusciti a scorgervi niente più di quello che vi hanno visto gli studiosi un'ottantina d'anni fa, quando è stata rilevata l'importanza dell'iscrizione; ${ }^{192}$ essa, quindi, resta un enigma. La recente scoperta dell'eliminazione a scalpello dell'oggetto che il personaggio a seguito del re teneva nelle mani, ha conferito però una maggiore importanza alla cancellazione dell'iscrizione, aprendo la via a nuove riflessioni, sempre in direzione del pragmatismo politico a cui si ispirava l'intervento. A mio avviso, si trattava di un rotolo piuttosto corto e non di una spada, come si riteneva al momento della scoperta dell'atto di eliminazione. È una considerazione di carattere essenziale, perchè la spada poteva essere usata nell'iconografia regale come un attributo generico, utilizzato spesso, infatti, per indicare coloro che prendono parte all'azione passivamente e rimanendo in disparte, ${ }^{193}$ a mo' di indicatori simbolici, se non addirittura decorativi, della dignità del personaggio principale. Nella composizione asimmetrica del bassorilievo, dove il re non è posto al centro del ri quadro, probabilmente era più importante rappresentare la presenza del sovrano all'evento anzichè semplicemente raffigurarne la persona, il che ci fa presupporre la volontà di mettere in rilievo soprattutto la dimensione storica e reale dell'evento. In linea di massima, si può pensare alla consegna di un qualche documento o concessione regale, in conformità con il ruolo di Rex iustus - vicarius Christi, in cui, vista la datazione dell'opera, riconosciamo Petar Krešimir IV.

Dall'analisi della composizione artistica che abbiamo affrontato da diversi punti di vista, sarebbe difficile arrivare a credere che il bassorilievo spalatino fosse un memoriale. Esso mostrava direttamente e con la sua struttura sobria testimoniava sinteticamente un'azione che doveva avere una base storica, ne contesto della vita cittadina, perché i protagonisti della scena sono persone laiche. ${ }^{194}$ Questa base storica non doveva avere un carattere generale e neanche meramente simbolico, perchè altrimenti non si spiegherebbe il fatto che vi fosse bisogno di modifiche del suo contenuto già mentre l'intero cancellum era ancora situato in qualche spazio sacro di grande importanza. Specialmente più tardi non vi sarebbe stato motivo di apporre modifiche al monumento e tutto nello stesso tempo fa capire che il periodo intercorso tra la realizzazione e il trasferimento fosse piuttosto breve. Le sorti del bassorilievo definite in questo modo confermano la nostra tesi iniziale che si trattasse di un monumento a carattere politico, tesi cui abbiamo trovato sostegni indiretti, indicandone il possibile modello, nonché le circostanze storiche che la rendono più persuasiva e giustificano letteralmente la realizzazione del bassorilievo.

Nella stessa misura siamo arrivati a stabilire che esistevano condizioni storiche che avrebbero potuto causare pri- ma l'occultamento di significato del bassorilievo e poi la sua totale eliminazione dall'ambiente originario. Evidentemente, cambiavano le circostanze in cui era stato realizzato e così anche le conseguenze della sua esposizione in chiesa. Basterà in questa sede ricordare che con l'avvento al trono del re Zvonimir, dopo il re Petar Krešimir IV, a partire dal 1075 cambiò la dinastia regnante, nonché il globale orientamento politico dello Stato croato. ${ }^{195}$ Questi cambiamenti furono accompagnati da altri significativi nell'ambito della Chiesa, in seguito alle nuove leggi stabilite dal papa Gregorio VII in quegli anni. ${ }^{196} \mathrm{~L}$ 'arcivescovo Lorenzo manteneva la sua assoluta lealtà a Roma, nonostante coltivasse nello stesso tempo buoni rapporti con la casa regnante croata. ${ }^{197}$ Dopo la scomparsa di questa, a partire dall'ultimo decennio dell'XI secolo, Bisanzio e Venezia aumentarono per di più le loro pressioni sulle città dalmate. Forse potrebbero risultare utili ai fini di una definizione più precisa del bassorilievo, ma sono purtroppo meno note, le circostanze legate ai fenomeni scismatici nella stessa regione, e non, sono ancora stati analizzati con esattezza i rapporti giuridici della città e della sua amministrazione comunale con i regnanti dei territori circostanti. Infatti, a partire dagli inizi del XII secolo, l'Ungheria ha un controllo sempre più forte, sui territori croati, per impadronirsene poi definitivamente, per cui l'ingerenza degli interessi stranieri raggiunge il culmine. In questo campo di indagine forse si potrà arrivare a spiegazioni più precise sulle sorti del bassorilievo, dalla sua realizzazione fino al periodo in cui è stato definitivamente collocato laddove rimane ancor oggi, dopo più di otto secoli.

Per ora, in base alle argomentazioni esposte, non possiamo riconoscere nel bassorilievo altro che l'immagine di un contemporaneo sovrano croato. Per molti aspetti l'opera, intesa come monumento politico di prima qualità, sta a testimonio di quel legame che si ebbe fra le autorità ecclesiastiche e laiche a partire dalla metà dell'XI secolo, quando queste erano rappresentate dall'arcivescovo di Spalato Lorenzo e dal a lui vicinissimo re Petar Krešimir IV della casa regnante nazionale. La loro concordia ideologica, guidata da criteri spirituali e politici, è visibile a tutti i livelli; ha lasciato segni decisivi anche nello sviluppo armonioso dell'espressione artistica su tutto il territorio sotto le competenze religiose e politiche dei due uomini. A testimonianza dei loro legami concorre, d'altronde, anche la congruenza delle loro attività e doveri di carattere formale-giuridico, che per loro doveva essere un motivo di orgoglio. Il titolo di arcivescovo attestava il ruolo e la dignità di capo religioso della chiesa croato-dalmata ed era in perfetta corrispondenza con il titolo di sovrano secolare della Croazia e della Dalmazia, titolo annotato, con varianti, in più di un documento scritto. ${ }^{198}$

Il rapporto che vi era fra l'arcivescovo e il re appare chiaro anche in un monumento spalatino storicamente definito meglio del bassorilievo e che si trova alla distanza di appena duecento metri dal Duomo e dal battistero, di fronte alla porta settentrionale del palazzo di Diocleziano, che costituisce il nucleo storico della città medievale. Lo stesso arcivescovo vi fondò il convento femminile di S. Benedetto che più di una volta ricevette doni dal re croato. ${ }^{199}$ Sopra l'ingresso della chiesa di S. Eufemia - studiata a fondo ${ }^{200}$ stava un'iscrizione, anch'essa cancellata poi per chiari 
motivi politici di soppressione di ogni traccia che potesse testimoniare la partecipazione del re croato alla vita della città dalmata. Il contenuto dell'iscrizione è rimasto però annotato nell' archivio, ${ }^{201}$ per cui ne conosciamo con certezza le parole:

\section{DALMATICAS REGERET DUM CRESIMIRUS ABENAS HOC TE LAURENTI PRAESULE SURGIT OPUS:}

$$
\text { A.D.MLXIX }
$$

("Mentre in Dalmazia regnava Krešimir, o Lorenzo, quest'opera fu eretta - Nell'Anno del Signore 1069.")

Non vi è dubbio che il nostro bassorilievo recasse un contenuto simile, poiché era il risultato unitario di circostanze storico-politiche all'epoca di quei due uomini, potenti e importanti, veri signori spirituali e politici della sfera in cui il bassorilievo si trova. ${ }^{202}$ Soltanto il capo della chiesa regionale non è raffigurato nel ciclo scultoreo, perchè la sua presenza era garantita dall'uffizio divino e istituzionalmente contrassegnata dal pentagramma che faceva parte dello stesso monumento. La dimensione programmatica

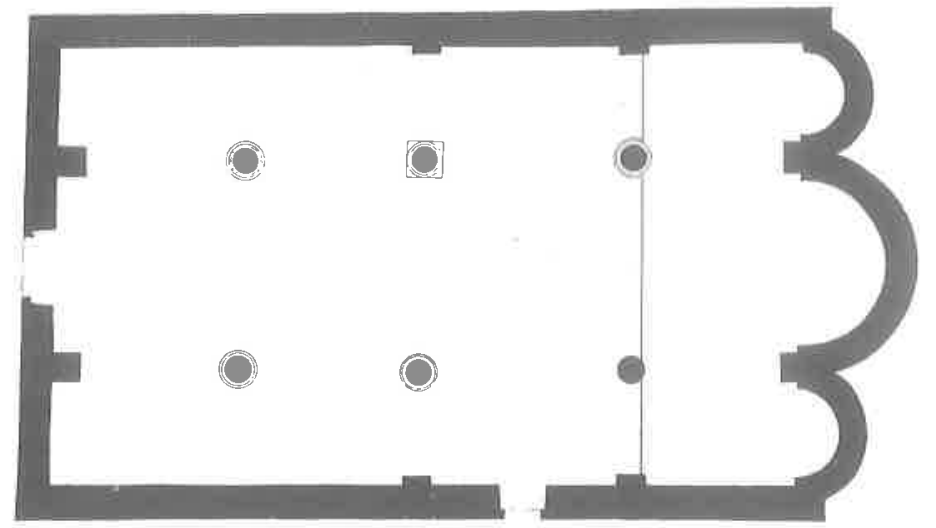

La pianta della chiesa di Santa Eufemia a Spalato - XI sec.

è stata conferita al cancellum dalla rappresentazione simbolica del re Petar Krešimir IV, per molteplici aspetti degno di essere effigiato in un monumento antologico del primo romanico spalatino.

Traduzione: Snježana Husić

${ }^{1}$ R. EITELBERGER, Die Mittelalterischen Kunstdenkmale Dalmatiens, Wien 1861, p. 123; T. G. JAKSON, Dalmatia - the Quarnero and Istria, vol. II. London 1887, p. 68.

${ }^{2}$ Agli aspetti politici del monumento ha già accennato LJ. KARAMAN, Basrelijef u splitskoj krstionici (Il bassorilievo nel battistero di Spalato). Prilog Vjesniku za arheologiju i historiju Dalmatinsku - (Bulletino di archeologia e storia dalmata). 1924 / 1925. pp. 1 - 27.; IDEM, Potječe li ploča s likom hrvatskog kralja u splitskoj krsitionici iz splitske katedrale ili solinskog sv. Mojsija? (La lastra con la figura del re croato nel battistero di Spalato proviene dalla cattedrale di Spalato o dal San Mosè di Salona?) Disertationes V. Lubiana 1966, pp. 111 - 129. - che controbatte il rifiuto, da parte italiana prima, e serba poi, della possibilità di rappresentazione di un re croato del secolo XI in un luogo pubblico.

${ }^{3}$ La nuova tesi sulla rappresentazione di Cristo è di S. RADOJČIĆ, di Belgrado, (1983) e, pur rimanendo senza risposta, ha acquistato i suoi seguaci. Prescindendo anche da questo, nel 1993 Ž. JIROUŠEK ha cercato di riproporre la sua vecchia convinzione che il rilievo era stato eseguito nel secolo IX e che rappresenta un monumento di prima classe della sovranità nazionale dei croati all'inizio dello sviluppo statale. V. note 77 - 79.

"I. FISKOVIĆ, Prikaz vladara iz 11. st. u splitskoj krstionici (La rappresentazione del sovrano del secolo XI nel battistero di Spalato). Kulturna baština 30 - 31. Split 1996.

${ }^{5}$ Sul re del paese senza o con il segno nazionale cominciarono a scrivere i ricercatori più antichi, quali I. KUKULJEVIĆ-SAKCINSKI (1857) di Zagreb o gli stranieri come C. CATTANEO (1889) di Venezia e E. A. STUCKELBERG (1896) di Zurigo. Il primo ad esporre la tesi su Cristo fu il famoso F. BULIĆ negli stessi anni, e sotto la sua autorità la tesi si è mantenuta a lungo, ma nel 1931 lui stesso l'ha riconosciuta come sbagliata. Per lo sviluppo più preciso dell'opinione V. op. cit. nota 4.

${ }^{6}$ Mentre la maggior parte dei ricercatori antichi datava il rilievo nel secolo IX - X, il primo a sostenere il secolo XI fu L. JELIĆ di Split - del resto il fautore più forte della tesi su Cristo. La datazione fu in seguito accettata dai ricercatori più eminenti quali LJ. KARAMAN, M. ABRAMIĆ, E. DYGGVE nei loro studi, nonché dalla maggior parte degli altri, mentre I. PETRICIOLI ne ha dato anche una spiegazione stilistica più completa nel contesto della presentazione della figura umana come conquista della prima arte romanica nella scultura in Dalmazia.

${ }^{7}$ Questa tradizione è stata registrata da chi scrisse per primo sull'opera e la sua origine esatta non è nota. In base ai ritrovamenti più recenti delle simili suppellettili scalpellate nella cattedrale di Spalato, a partire dagli anni venti di questo secolo, M. ABRAMIĆ e LJ. KARAMAN sostenevano la tesi che le lastre provengono di là. Però, negli anni cinquanta E. DYGGVE ha pubblicato i reperti dalla basilica di Salona dell'incoronazione del re Zvonimir, che morfologicamente sono molto simili al rilievo, cosicché I. PETRICIOLI si è applicato a trovare le prove ancora più fondate alla tesi che le lastre provengono di là. Le convinzioni sono finora divise.

${ }^{\text {8}}$ Al Simposio del 1996 ho esposto i punti di vista fondamentali, ma la discussione tenutasi in quell'occasione mi ha stimolato a effettuare le ricerche che riferisco adesso in una forma più integrale.

${ }^{9}$ Per la problematica della scultura croata contemporanea V. in: LJ. KARAMAN, Iz kolijevke hrvatske prošlosti (Dalla culla della storia croata). Zagreb 1930.; J. STRZYGOWWSKI, Die Altslavische Kunst. Augsburg 1923.; Ž. RAPANIĆ, La costa orientale dell'Adriatico nell'Alto Medioevo : Considerazioni storico-artistiche. Settimane Spoleto, 30 / 1982.; I. PETRICIOLI, La scultura preromanica in Dalmazia. Antichità Alto Adriatiche, 26 / 1986. nonché nelle nuove sintesi sommarie di N. JAKŠIĆ e J. BELAMARIĆ nel libro Tisuću godina hrvatskog kiparstva (Mille anni della scultura croata), Zagreb 1996. — ed. I. Fisković, cap. I-II.

${ }^{10}$ Per le comparazioni con i monumenti scultore i contemoranei, in modo particolare: I. PETRICIOLI, Pojava romaničke skulpture u Dalmaciji (L'apparizione della scultura romanica in Dalmazia) Zagreb 1960.

${ }^{11}$ Insieme con gli altri motivi ornamentali li ha classificati E. STÜCKELBERG, Die langobardische Plastik. Monaco di Baviera 1909 - benché con l'attribuzione erronea. Anche più tardi 'è stata la tendenza a spiegare il patrimonio preromanico croato attraverso l'arte longobarda, tendenza superata grazie alle scoperte analitiche della sua particolarità durante $\mathrm{i}$ vari periodi.

${ }_{12}$ Menzionato per la prima volta nel 1144 : "S. Johannis de Fonte" - I. KUKULJEVIĆ, Diplomatički Zbornik kraljevine Hrvatske (Atti diplomatici del regno di Croazia)... vol. II. Zagreb 1875. p. 37.

${ }^{13}$ Una completa descrizione tecnica è offerta da D. DOMANČIĆ, O krsnom zdencu splitske krstionice (Sul fonte battesimale del battistero di Spalato). Kulturna baština 5-6 / IV. Split 1976. pp. 17-22. nell'occasione del restauro del monumento. Grazie allo smontaggio dell fonte si è riusciti ad allontanare 
il dubbio che al di sotto del fonte ci fossero le tracce di un battistero più antico, secondo un'affermazione non provata che il battistero fosse stato fondato quando il mausoleo di Diocleziano venne trasformato in cattedrale.

${ }^{14}$ L. JELIĆ, Interessanti scoperte nella fonte battesimale del Battistero di Spalato. Bullettino di archeologia e storia dalmata, 6 - 7 / XVIII, Split 1886. pp. 81 - 137. In questo testo, l'autore fu uno dei primi a stabilire la datazione precisa del rilievo, parlando persino dell'influenza della riforma della Chiesa, benché ritenesse che si trattasse di un paliotto d' altare oppure di un antependio.

${ }^{15} \mathrm{~V}$. le opere citate alle note 9, 10, 11; Il motivo appare nella Croazia del sud anche prima, mentre qui spicca senz'altro per una perfetta lavorazione. Tuttavia, per un'attribuzione precisa manca ancora un corpus analitico della plastica preromanica dalmata, nonché un chiarimento delle fasi del passaggio della scultura allo stile romanico.

${ }^{16}$ Un buon panorama dello sviluppo più recente è stato offerto da N. JAKŠIĆ nel catalogo della mostra Starohrvatski reljefi (I rilievi paleocroati), Zagreb 1995. Per informazioni più ampie V. il testo dello stesso autore in Enciklopedija Hrvatske umjetnosti (Enciclopedia dell'arte croata) : Predromanika (L'arte preromanica). vol. II. Zagreb 1996. pp. 90 - 97; V. anche Ž. RAPANIĆ - la nota 179.

${ }^{17}$ Oltre al fatto che il monumento viene molto spesso menzionato nella nostra bibliografia - - V. op.cit. no. $4 e 9-$ lo indica e lo riproduce anche $\mathrm{H}$. GLÜCK, Die Christlische Kunst der Ostens. Berlin 1923. tab.14. — datandolo nel secolo VIII. Sono molto frequenti tali constatazioni sbagliate sui monumenti della Croazia, sebbene nella bibliografia nazionale molti problemi fossero risolti in precedenza, ma grazie all' ignoranza della nostra lingua queste soluzioni non vennero conosuite scienza europea.

${ }^{18}$ Due ricostruzioni grafiche di tutta la recinzione dell'altare furono disegnate da E. DYGGVE, che situò il complesso dapprima nella cattedrale di Spalato, secondo lo studio di M. ABRAMIĆ del 1929, e poi nella basilica di SS. Pietro e Mosè a Salona, secondo i reperti personali. Dandogli un'importanza uguale, in merito alla documentazione, le pubblico tutte e due come illustrazione al testo presente insieme al commento del problema più ampio della collocazione originaria del monumento.

${ }^{19} \mathrm{Cfr} .:$ M. F. HEARN, Romanesque Sculpture - The Revival of Monumental Stone Sculpture in the Eleventh and Twelfth Centuries. ed. 1981 Corbell Univ. Press. ; C. L. RAGGHIANTI, L'arte bizantina e romanica, Roma 1968, cap. V-VII.

${ }^{20}$ Finora, è stato trattato in un modo sistematico soltanto il materiale archeologico: "Salona I, Sculpture architecturale." Recherches Archéologiques Franco - Croates dir. par N. DUVAL et E. MARIN. Coll. de l'école française de Rome 194 — Split 1994.

${ }^{21}$ Z̆. RAPANIĆ, Predromaničko doba u Dalmaciji (L'età preromanica in Dalmazia), Split 1987; N. JAKŠIĆ, Predromaničko kiparstvo (La scultura preromanica). Tisuću godina hrvatskog kiparstva (Mille anni della scultura croata) Zagreb 1996.

${ }^{22}$ Cfr.: Chiesa e riforma nella spiritualità del secolo XI : Convegni del Centro di studi sulla spiritualità medievale VI. Todi 1968. etc.

${ }^{23}$ I. PETRICIOLI, op. cit. 1960. pp. 28 - 32.

${ }^{24}$ IBID. pp. 15 sg. V. anche : I. PETRICIOLI, Reliefs de l'église salonitaine de St-Pierre. Disputationes Salonitanae 1. Split 1975. pp. 111 - 117.

${ }^{25}$ I. PETRICIOLI, op.cit. 1960. p. 8 - in relazione alla possibile datazione dei rilievi di Spalato e di Zara, confrontandoli ritiene che questo rilievo sia "una opera ritardataria un po' rustica” rispetto alla qualità e allo stile della bottega dei monumenti di Zara, il che non trovo accettabile perché i plutei di Santa Domenica, nonché il ciborio del proconsole Gregorio (verso il 1033) mi sembrano più semplici e più arcaici quanto alla forma.

${ }^{26} \mathrm{~J}$. BELAMARIĆ ha recentemente presentato la proposta di chiamare l'autore anonimo di questo rilievo "il maestro del re Zvonimir" probabilmente con l'intenzione di sottolineare le sue capacità artistiche di carattere individuale e di datare il rilievo nell'ultimo quarto del secolo XI.

${ }^{27}$ A. GRABAR, Cristian Iconography - A study of its Origins, Princeton 1968. pp. 38 e sg. ; E. KITZINGER, The Portraits of Christ. ed. Penguin 1940, passim. ${ }^{28}$ P. BESCOW, Rex Gloriae - The Kingship of Christ in the Early Church. Stockholm 1962. - Sui processi di sviluppo più ampiamente : A. GRABAR, op.cit. cap. II. ; L. R. TAYLOR, The Divinity of Roman Emperor. London 1931. p. 35 e sg.

${ }^{29}$ S. G. MAC CORMAC, Arte e cerimoniale nell'antichità. Torino 1995. passim.

${ }^{30}$ A. GRABAR, L'empereur dans l'art byzantin. London 1971.

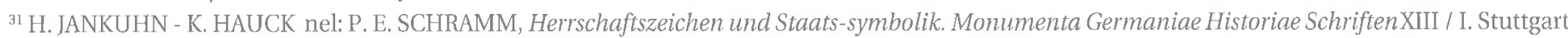
1954. pp. 101 sg. ; In modo particolare A. GRABAR, op.cit. 1971. nel cap. I. — mette in rilievo lo schema dei sovrani sul trono: pp. 24 - 26.

${ }^{32}$ R. DESHMAN, Cristus rex et magi reges: Kingship and Christology in Ottonian and Anglo Saxon Art. Frühmittelalterliche Studien 10 / 1976. pp. 381 - 390.

${ }^{33}$ A. ALFÖLDI, Die monarchische Repräsentation in römischen Kaiserreiche. Darmstadt 1977. pp. 40 - 45 sg.

${ }^{3}$ Il panorama generale : C. R. DODWELL, Painting in Europe 800 to 1200. London 1971.; E. W. ANTHONY, Romanesque Frescoes. Princeton 1951,; M. AVERY, The Exultet Rools of South Italy. Princeton 1936. ed altro.

${ }^{35}$ Cfr.: H. SWARZENSKY, Monuments of Romanesque Art. London 1954 ; P. DELBRUECK, Consulardiptichen und verwandte Denkamler. Berlin 1927.; L. GRODECKI - F. MÜTHERICH, Le siècle de l'an Mil. ed. Gallimard 1973.

${ }^{36}$ Uno degli esempi di collegamento di personaggi sacri e laici nelle rappresentazioni simboliche in pietra per l'arredo ecclesiastico, oltre al rilievo di Spalato, è offerito anche dalla transenna di Biskupija, anch'essa dell'XI sec. ; S. GUNIAČA. Reconstitution d'une dalle avec representation du "dignitaire croate". Archeologia Jugoslavica II. / 1956. pp. 111 - 117.

${ }^{37}$ La discussione tenutasi al Simposio a Montona nel 1996 è stata presentata dalla giornalista e storica dell'arte V. KUSIN, Krist ili kralj? Obavijesti lirvatskog arheološkog društva (Le informazioni dell'associazione degli archeologi della Croazia), XXVIII/2. pp. 60-62.

${ }^{30}$ M. HARTIG, Die Christuskönig in der Kunst - Eine ikonographische Studie. Die christlische Kunst XXIII / 1926-27. pp. 291-312. ; R. BERGER, Die Darstellung des thronenden Christus in der Romanischen Kunst. Reutlingen 1927. estratto da "Tübinger Forschungen zur Archäologie und Kunstgesschichte V."; J. KOLLWITZ, Das Bild von Christus den Könige in Kunst und Liturgie der christlichen Frühzeit. Theologie und Glaube $38 / 1947$. :9a La prima valutazione corretta è offerta da LJ. KARAMAN in "Strena Buliciana" 1925. p. 463. ; Su questo per esteso I. PETRICIOLI, op.cit. 1960. pp. 18-27. ${ }^{40} \mathrm{G}$. B. LADNER, Ad Imaginem Dei - The Image of Man in MedievalArt. Latrobe 1965.; A. KATZENELLEBOGEN, L'immagine di Cristo nell'Alto Medioevo. "Vita e pensiero nell'Alto Medio Evo". Napoli 1977. pp. 75-94.; Cfr. F. van der MEER, Images du Christ dans la sculpture... Paris 1980. cap. I-IV.

${ }^{4 l}$ F. RAČKI, Cfr.; F. PAUVINI-ROSATI, Monetazione Bizantina in Italia. Milano 1982. passim.

${ }^{42}$ In ordine delle illustrazioni e teorie : C. R. DODWELL, op.cit. ; O. DEMUS, Romanesque Painting in Europe. Londra 1970 ; A. GRABAR, L'art du Moyen Age en Occident - influences byzantines et orientales. Londra 1980 ; G. GAMES, Byzance et la peinture Romane de Germanie. Parigi 1966 ; O. PACHT, Book Illumination in the Middle Ages. Oxford 1986; Von dem Jahr 1000 - Abenlandische Buchkunst zur Zeit der Kaisern Theophanu, Colonia 1991passim, etc.

${ }^{43}$ V. "Christusbild" in: Lexicon der christlicshen Iconographie I/ 1968. p. 355 sg. e in: Reallexicon zur byzantinischen Kunst I/ 1966. p. 966 sg.

"Nello schema iconografico della "Maiestas Domini": K. NIEHR, Lexicon der Mittelalters VI/ 1993. p. $112 \mathrm{sg}$.

${ }^{45}$ O. TREITINGER, Die oströmische Kaiser und Reichsidee nach ihrer Gestaltung in höfichen Zeremoniel ... Darmstadt 1956. 
${ }^{46}$ A. R. BELLINGER, Catalogue of the Byzantine Coins in the Dumbarton Oaks Collection. Washington 1966 - introduzione nel Libro I. - Il significato storico dei singoli sovrani dovrebbe forse essere esaminato secondo le varianti delle rappresentazioni.

${ }^{17}$ Secondo A. ALFÖLDI, op.cit. 1977 p. 275. sg. - proprio per mezzo di tali "imagines lauratae" i re si facevano valere nel ruolo di "triumphator - victor". A confermarlo, tra le altre, è anche la rappresentazione di Enrico II del Sacramentario di Monaco di Baviera con la stessa iscrizione : P. E. SCHRAMM, Denkmale der deutschen Könige und Kaiser ( ed. 1981 ), tab. 329. — ${ }^{*}$ Questo ci é interessante riguardo al fatto che accanto alle sue rappresentazioni, il nostro rilievo viene presentato anche con le altre caratteristiche - V. più avanti. Del resto, lo schema iconografico non si ripete spesso : IDEM, Die deutschen Kaiser und König in Bilder ihrer Zeit. - I. Lipsia 1928 - Abb. 28, 68.c, 74. a-b, 79.a-b. etc.

${ }^{4 y}$ A. R. BELLINGER, op.cit. - Inizialmente è importante l'affermazione che a partire dal secolo VI la figura allegorica di Victoria sulle monete tiene una croce e una sfera. Per di più, A. GRABAR, op.cit. 1971. - osserva che la via dei tipi iconografici va da Roma a Bisanzio da dove torna alla verso l'Occidente nel Medioevo. Dunque, sono numerose le condizioni favorevoli all'apparizione e concezione di una tale opera nell'Adriatico orientale, soprattutto a Spalato, una città viva a partire dall'Antichità che promuoveva il rinnovamento del culto dei sovrani con tutti i simboli relativi.

${ }^{49}$ Poiché questo testo riguarda soprattutto d'identificazione dei caratteri specifici del rilievo di Spalato, ho limitato i confronti con altre opere consimili, anche in altri "media". Anche per la bibliografia relativa, mi riferisco solo ai testi fondamentali, omettendo talora anche citazioni precise. Oltratutto, alcuni testi non sono referibili in Croazia, e i miei soggiorni all'estero sono stati limitati. Per un'esame più ampio del problema dal senso di vista teorico rimane essenziale : D. BULOUGH, "Imagines Regum" and their Significance in the Early Medieval West, pp. 223-276.

${ }^{50}$ J. DEER, Der Globus des spätromischen und byzantinische Kaisers : Symbol other Insignie? Bysantinischen Zeitschrift 54 / 1961 . pp. 53 - 85.

${ }^{51}$ J. L. NELSON, Symbols in Contexsts : Ruler's Inauguration Rituals in Byzantium and West. Studies in Church History - 13. Oxford 1976. pp. 91 - 119.

${ }^{52}$ P. E. SCHRAMM, Sphaira - Globus - Reichsapfel. Stuttgart 1958. - E' attuale la citazione del 1080. Solo qui è citato anche il rilievo di Spalato - p. 133. Abb. 23.: benché indicato come Dmitar Zvonimir — perché corrisponde alle importanti constatazioni dell'autore, non solo di questo libro.

${ }_{53}^{53}$ J. DEER, Der Keiser und der Kreutz. Jahrbuch des römische-germanischen Zentralmuseums 12. Mainz 1965. pp. 167 - 180.

${ }^{54}$ La croce di metallo con i rami viene generalmente considerata d'origine bizantina ma la conosce tutta l'Europa già a partire dalla Tarda Antichità Parte di una tale croce è stata trovata di recente in Dalmazia vicino a Dubrovnik.

${ }_{55}$ La corona è stato l'elemento più discusso nella nostra letteratura, spesso in modo superoficiale, se non sbagliato, finchè LJ. KARAMAN non ha abbiato gli elementi che ne definiscono il carattere relativamente autoctono.

${ }^{56}$ Già prima, in modo particolare LJ. KARAMAN e M. ABRAMIĆ, hanno richiamato l'attenzione sulle corone press'a poco analoghe nell'arte europea dell'Alto Medioevo e su questo non mi trattengo. E' invece opportuna la domanda sul suo ornamento, poiché dalla lavorazione plastica del rilievo non si può vedere se si tratti di gemme più grosse o di collane di perle, che si presenta in diverse varianti nel corso del secolo XI : H. FRITZ, Die Krone als Symbol der Monarchischen Herrschaft im ausgehenden Mittelalter. Berlin 1944. - V. specialmente : F. RADEMACHER, Eine Krone Kaiser Ottos II. Zeitschrift des deutschen Vereins für Kunstwissenschaft I / 1934.pp. 79 - 94, 89 - 90. a favore delle nostre osservazioni. Il quadro delle corone disegnate graficamente è offerto da P. E. SCHRAMM, Die deutschen Kaiser und Könige ... 1983. pp. 142 - 143. e si può constatare che, quanto alla forma, non è completamente identica a nessun altra, ma quanto al tipo corrisponde alle varianti conosciute. Inoltre, la tecnica di scalpellatura ha per certo creato le differenze maggiori rispetto alle corone disegnate. Cfr. anche : IDEM, Herrschaftzeichen : gestiftet, verschenkt, verkauf, verpfäkt aus dem Mittelalter. Gottingen 1957 .

${ }^{57}$ E. EICHMANN, Die Kaiserkrönung im Abenland. Würzburg 1942 ; H. DECKER-HAUFF, Die Kronen des frühen Mittelalters. Stuttgart 1955. Tutti e due danno un quadro piuttosto ampio del materiale artistico in cui viene confermata la frequenza del tipo e la somiglianza delle varianti. Tuttavia, la corona con tre croci in punta non appare molte volte : la più sicura sembra quella sulla testa di Corrado II del codice di Echternach all' Escurial (1050). Poiché P. E. SCHRAMM nel catalogo menzionato (No. 11 - 17) presenta più corone, si può presupporre una certa libertà dei pittori ed artisti antichi. ${ }^{58}$ C. FISKOVIĆ, Ranoromaničke freske u Stonu. (Gli affreschi protoromanici a Stagno) Prilozi pov. umjetnosti u Dalmaciji 12. Split 1970. pp. 33 - 49.

${ }^{59}$ LJ. KARAMAN, Crkvica Sv. Mihajla kod Stona. (La chiesetta di San Michele vicino a Stagno) Vjesnik Hrvatskog arheološkog društva u Zagrebu. N. S. XV / 1928. pp. $81-116$.

${ }^{60}$ C. FISKOVIĆ, Dalmatinske freske (Gli affreschi di Dalmazia). Zagreb 1962. tab. 2,3; I. FISKOVIĆ, Romaničko slikarstvo u Hrvatskoj (La pittura romanica in Croazia). Zagreb 1986. pp. 28 - 31.

${ }^{61}$ Scrive del trono in tal modo: P. E. SCHRAMM, Herrschaftszeichen und Staatsymbolik, Stuttgart 1954.; IDEM, Die Throne und Bischoffstuhle des frïhen Mittelalters. Monumenta Germaniae Historica Schriften XIII/1. Capt. 14. pp. 316 sgg. Cfr. figs. 27-38.

${ }^{62}$ In questo senso li cita: P. E. SCHRAMM, Kaiser, Rom und Renovatio. Leipzig 1929 ; anche: J. K. EBERLEIN, Apparitio Regis - revelatio veritatis. Studien zur Darstellung des Vorhangs in der bildenen Kunst von der Spätantike bis zum Ende des Mittelaters. Wiesbaden 1982.

6.3 O. TREITINGER, op.cit. 1956. pp. 84-93. scrive su questo, nonché sulla prosternazione davanti ad ogni persona a cui si riconosce la santità. I re medievali ne avevano il diritto secondo la regola "Rex - Sacerdos". Più ampiamente sulla dualità di Cristo o del re in : R. BRILLANT, Gesture and Rank in Roman Art. New Haven 1963. pp. 31 sg. ; J. C. SCHMITT, Il gesto nel Medioevo. Torino 1991. p. 278 sg ; S. G. MAC CORMAC, op.cit. 1981.

${ }^{64} \mathrm{Si}$ deve anche richiamare l'attenzione sulla spiegazione della sfera nella mano sinistra del re che d'obbligo "in sinistra habet pillam auream", cioè "portans in sinistra pomum aureum quod significat monarchiam" - P. E. SCHRAMM, Der "Salische Kaiserordo" un Benozo fon Alba. Deutschen Archiv I / 1937. p. 394, ; IDEM, op.cit. 1958, pp. 78, sg. — su questo e sulla sistemazione dei personaggi secondari, cioè quelli che fanno parte della scorta del re, a destra secondo il protocollo.

${ }^{65}$ Sulla prosternazione nel Bisanzio : C. MANGO, The Art of the Byzantine Empire, New Jersey 1972 pp. 169 - 174.; V. anche: A. GRABAR, op. cit. 1931. cap. III.; The Oxford Dictionary of Byzantium - 3. New York 1991. p. 1738.

${ }^{\text {fis }}$ P. E. SCHRAMM, Sphaira... 1958. pp. 62-63;

${ }^{67}$ Rispetto alla figura dell'imperatore secondo le abitudini delle rappresentazioni medievali, al nostro incoronato manca la fibbia sulla spalla sinistra : $\mathrm{O}$. M. DALTON, Byzantine Art and Arheology. Oxford 1911; L. BREHIER, La sculpture et les Arts mineurs Byzantine. Paris 1936 etc.; G. P. GALAVARIS, The Symbolisme of the Imperial Costume as display on Byzantine Coins. Museum Notes - American Numismatic Society, 8/1958. pp. 99-117.; Delle particolarità della corona ha scritto soprattutto LJ. KARAMAN, op.cit. 1925 - sintetizzando in genere le varie opinioni e comparandola con le rappresentazioni artistiche dell'Europa. (Bisogna aggiungere che la forma principale del diadema in antiquita significava la sovranità, mentre la corona era assegnata ai vincitori e ai festeggiatori in varie occasioni : C. DAREMBERG - E. SAGLIO, Dictionnaire des antiquités. Paris 1910. pp. 1532 - 1535.)

${ }^{68}$ Le opinioni su cui si ritorna costantemente dall'Ottocento - V. : I. FISKOVIĆ, op. cit. no. 4. - e nei tempi più recenti si cerca invano di riviverle.

${ }^{{ }^{6} 9} \mathrm{C}$ 'è un numero uguale di coloro che dubitano che questa sia infatti la figura di un re croato - p. e. N. KLAIĆ, Povijest Hrvata u ranom srednjem vijeku (La storia dei croati nell'Alto Medioevo). Zagabria 1971. p. 444.; Al contrario, J. BAUM, Die Malerei und Plastik des Mittelalters - II. Handbuch des Kunstwissenschaft. pp. 28 - 29. Abb. 23. - gli riconosce il contenuto e riporta la fotografia, evidentemente rendendosi conto della qualità antologica del rilievo. Si decide per il re Petar Krešimir IV nonostante i dilemmi aperti dai nostri autori. 
${ }^{70}$ Cfr.: F. S̆IS̆IĆ, Povijest Hrvata u vrijeme narodnih vladara (La storia dei croati nei tempi dei sovrani popolari). Zagreb 1925. libro III. cap. IV-VI. ${ }^{71}$ Sulla posizione della Dalmazia nell'ambito della talassocrazia bizantina al Mediterraneo e nell'Adriatico : G. NOVAK, Prošlost Dalmacije (Il passato della Dalmazia) I / 1936. pp. 98 sg.

${ }^{72}$ Benché su questa domanda si trattenessero moltissimi scrittori - più dettagliatamente su questo : I. FISKOVIĆ, op.cit. no. 4. - la maggior parte di loro si è abituata pure di menzionare nello stesso tempo tutti e due i sovrani della seconda metà del secolo XI : Petar Krešimir IV e con le convenzioni uguali Dmitar Zvonimir.

${ }^{73}$ E. DYGGVE, History of Salonitan Christianity. Oslo 1951. Fig. 17./ VI.; IDEM, Oltarna pregrada u krunidbenoj crkvi kralja Zvonimira (La transenna dell'altare nella chiesa d'incoronazione del re Zuonimir). Vjesnik za arheologiju i historiju dalmatinsku (Bulletino dell'archeologia e della storia dalmata) LVI - LIX. Split 1957. pp. 238- 243. T.XXVII-XXXII.

${ }^{74}$ I. PETRICIOLI, op.cit, 1975 ; All'opposto dei frammenti di Salona spiegati scientificamente già a più riprese, sembra che quelli di Spalato, a cui si riferiscono LJ. KARAMAN e M. ABRAMIĆ - op. cit. 1925, 1929 - non siano stati identificati con esattezza e probabilmente neanche tutti conservati;

${ }^{75}$ Così, allo studio in apparenza rivoluzionario di S. RADOJČIĆ, del 1983 una risposta breve e assai indecisa è stata offerta solo da J. BELAMARIĆ, op.cit. 1996, mentre in un modo sostenuto l'ha appoggiato I. PETRICIOLI, Od Donata do Radovana. Spalato 1990. p. 58.

${ }^{76} \mathrm{Su}$ questo esiste solo un rapporto di stampa di V. KUSIN su "Vjesnik" — Zagreb. V. date del Convegno. In questo momento nessuno non si ricordava che già F. BULIČ ha visto l'intervento sull'rilievo.

${ }^{77}$ Soprattutto si riferiva alla lastrina frontale di un elmo del tempo del re Agilulfo, che si conserva al Bargello a Firenze : J. HUBERT - J. PORCHER - W. F. VOLBACH, L'Europa delle invasioni barbariche. Milano 1980. fig. 272.

${ }^{78}$ Con questo ha infatti rinnovato una sua vecchia affermazione esposta in modo assai breve nell'articolo: Karolinška umjetnost (L'arte carolingia) Enciklopedija likovnih umjetnosti (Enciclopedia delle arti figurative) III / 1964. p. 151. — che è stata presto rifiutata da LJ. KARAMAN nel 1964.

${ }^{79}$ L. JELIĆ, op.cit. 99 - 101. Le sue interpretazioni erano in genere considerate poco convincenti e come tali erano rifiutate, direi principalmente perché egli non riconosceva il re croato e perché, cercando di provare Cristo, si sviava nelle spiegazioni contraddittorie. Tuttavia, non si deve dubitare della giustezza della sua lettura dell' iscrizione staccata il cui ordine delle lettere è seguente : ... O ... E .. UFEMIE ... LEGEM .... S .. DA ....-; IDEM, Zvonik spljetske stolne crkve (Il campanile del Duomo di Spalato). Split 1895. pp. 79-81. Alla verificazione di questo si deve continuare a lavorare con i migliori mezzi tecnici, il che non sono ancora riuscito a fare, ma ci prevedo una possibilità di consolidare la struttura delle riflessioni che espongo alla fine del testo.

${ }^{\text {в0 }} \mathrm{Al}$ simposio a Montona nel 1996 ho esposto questa variante che è stata registrata nei rapporti di stampa - V. no. 37. - La stessa opinione è stata pubblicata più tardi anche da M. PEJAKOVIĆ, Omjeri i znakovi (Proporzioni e segni). Dubrovnik 1996. pp. 278 - 291. e mi sembra accettata benché la consideriamo nei contesti diversi. Però, per ragioni storiche rifiuto la sua interpretazione fantasiosa sull'origine salonitano del rilievo - V. più avanti.

${ }^{81}$ Di questo ho parlato al XXIX Congresso internazionale della storia dell' arte ad Amsterdam, nell' autunno 1996 : I. FISKOVIĆ, "Damnatio Memoriae" in the Medieval Sculpture of the Southern Croatia, e il testo sara publicato negli Atti del Congresso..

${ }^{82}$ Cfr. : H. P. L. ORANGE, Apotheosis in Ancient Portraiture. Oslo 1947.

${ }^{83}$ H. BLOCH, Monte Cassino, Byzantium and the West in the Earlier Middle Ages. Dumbarton Oaks Papers 3 / 1946. pp. 165 - 224.

${ }^{84}$ H. JANTZEN, Ottonische Kunst. Hamburg 1959; La descrizionee riassunta da P. E. SCHRAMM — F. MUTHERICH, Denkmale der Deutschen Könige und Kaiser, München 1962. Cat. No. 141, e altri.

${ }^{85}$ A. CAMPANA, Per il "Textus Evangelii" donato da Enrico II. a Monte Cassino. Miscellanea Mercati 1959.

${ }^{86}$ Accanto alle spiegazioni dirette offerte dagli autori che hanno descritto l'opera e le circostanze della sua creazione : H. BLOCH, A. CAMPANA — risulta forse interessante anche l'affermazione dello stesso Giovanni che designa il personaggio del re con l'attributo: "Cultor Dei, deffensor ecclesiae" - V. KATH, Biblijski leksikon (Dizionario biblico) Zagreb 1986.

${ }^{87}$ Oltre alle designazioni "Prudentia" e "Sapientia", seguono all'interno dei campi della composizione simmetrica ancora "Justitia", "Pietà", "Lex" e "Ius" con i significati che spiega particolarmente H. BLOCH, op.cit. pp. 177 -186. I fondamenti storici dei concetti per il periodo dal secolo X fino al secolo XI sono presentati da P. E. SCHRAMM, op.cit. 1928. pp. 138 - 211.

${ }^{88}$ Dopo l'elaborazione monografica anche H. KANTOROWITZ, Les Deux Corps du Roi. Paris 1989. pp. 95 - 97.

${ }^{89}$ Secondo la consuetudine della maggior parte dei sovrani del Sacro Romano Impero: P. E. SCHRAMM, op.cit. 1958. ; Anche : D. BULLOUGH, op.cit. con una rassegna di rappresentazioni simili che risalgono a tempi precedenti.

${ }^{90}$ Cioè, il re fu designato come "Dominus et Deus" ancora dai Romani e nel Medioevo, in seguito a questa consuetudine veniva designato tra l'altro come "summus mundi rector" e sim. nel ruolo di "vicarius Christi". Di questo scrivono molti autori sopraccitati, offrendo la base più solido a per la nostra interpretazione.

9' Su questo per esteso H. BLOCH, op.cit. cap. II-III. E indicativa l'apparizione e la spiegazione della frase "in tyrannos" diretta contro l'amministrazione bizantina che, in merito all'accettazione dello schema, potrebbe essere approfondita dalle corrispondenze relative allo stato in Dalmazia, che ancora non sono chiarite con esattezza grazie alle bordeggiate possibili e all'atteggiamento del popolo del paese rispetto ad un potere straniero. Dall'altra parte, per gli orientamenti generali della politica contemporeanea del mondo cattolico: C. W. PREVTE-ORTON, The Shorter Cambridge Medieval History - I / 1971. XVI : 5. The Revival of Imperial Power. pp. 449 - 456. che in una certa misura si riflette anche in Croazia.

${ }^{92}$ H. BOECKLER, Das Goldene Evangelien Buch Heinrichs III. Berlin 1933 ; Più ampiamente con il commento della scuola : F. BANGE, Eine bayerische Malerschule des 11. und 12. Jahrhunderts. München 1923.

${ }^{93}$ H. JEDIN, Velika Povijest Crkve (La grande storia della Chiesa) III / I. Zagreb 1971. parte II : pp. 1046 - 1124.

${ }^{94}$ Cfr. G. DUBY, Adolescence de la chretienté occidentale 980 - 1140. Ginevra 1967.

${ }^{95}$ A. J. CARLYLE, A History of Medieval Political Theory on the West. Edimburg 1930 - istruttivo anche per le tesi della nota 103-105.; M. FUMGALLI - M. PARODI, Storia della filosofia medievale. Bari 1989. Capt. VI : Il pensiero politico nel XI e XII secolo.

${ }^{96} \mathrm{~V}$ : : R. MORGHEN, La concezione dell'Impero romano-germanico e la tradizione di Roma da Carlo Magno a Federico II. Atti della Reale Accademia dei Lincei - Classe di Scienze morali 1938 ; Cfr. : M. BRANDT, Opća povijest srednjeg vijeka (La storia generale del Medioevo). Zagabria 1980. pp. 80 sg.

${ }^{97}$ Cfr. : J. EVANS, Cluniac Art of the Romanesque Period. Cambridge 1950, part. IV. capt. 3.; J. BECKWITH, Early Medieval Art. London1964.

${ }^{9 \pi}$ Su questo : H. JEDIN, op.cit. pp. 389, 522 etc; Più ampiamente sulla concezione hierocratica che su quella teocratica dell'organizzazione del mondo cattolico di allora, con l'accento al ruolo del titolare dell'autorità spirituale per il mantenimento di pax e di iustitia nella società: P. BREZZI, op.cit. 1972. pp. $142-143$.

${ }^{99}$ Su questo in modo particolare : E. H. KANTOROWITZ, Deus per naturam - Deus per gratam. A Note on Medieval Political Theology. Harward Theological Review, XLV - 1952. pp. 253 277. - in seguito alla tesi indicata da: A. GRABAR, op.cit. 1971. p. 7. — con l'affermazione che l'introduzione della figura del re nell'ambito della liturgia è anche un segno giuridico. 
${ }^{100}$ E. H. KANTOROWITZ, The King's Two Bodies - A Study in Medieval Political Theology. Princeton 1957. cap. IV. pp. 80. sg.

${ }^{101}$ Il nuovo libro di V. DELONGA, The Latin Epigraphic Monuments of Early Medieval Croatia, Split 1997.

${ }^{102}$ Oltre alle opere citate di E. H. KANTOROWITZ - note 99 e 100, e - P.E. SCHRAMM, 1960 vol. III : A. GRABAR, op.cit. 1971 . pp. 24 - 26 ; IDEM, op. cit. 1968, pp.60-86. S. G. MAC CORMAC, op.cit.pp.51, 187 etc, - accennano all'origine nell'iconografia antica imperiale cosicchéla reciprocità nella ricomparsa diventa più chiara. Di particolare importanza è per noi ì fatto che alla consuetudine si da il vigore di legge proprio nell'Impero Franco: P. E. SCHRAMM, Der König von Franchreich - Das vessen der Monarchie vom 9. bis zum 16. Jahrhunderts. Darmstadt 1960. vol. I. - perché non c'è dubbio che i re croati ne adottarono la maggior parte delle consuetudini culturali e cerimoniali, il che ha lasciato tracce anche nell'architettura del periodo.

${ }^{103}$ Secondo la spiegazione di E. H. KANTOROWITZ, op.cit. 1957, p. 401.; sulla natura sacra della sovranità nell'Europa d'allora V. anche : M. ELIADE, Storia delle credenze e delle idee religiose III. Firenze 1983. pp. 103. sgg.

${ }^{104}$ A. KATZELLENBOGEN, Allegorie of the Virtues and Vices in Medieval Art. Studies of Warburg Institutes 10. London 1939. pp. 36, 104, 118.

${ }^{105}$ IDEM p. 118. secondo la massima : "Ubi est fiscus, ibi est imperium." — Cfr. : E. KANTOROWTTZ, Kingship under the Impact of Scientific Jurisprudence. Selected Studies. New York 1965.; H. MORDEK in "La Giustizia nell'Alto Medioevo." Settimane di Studi da Spoleto, XLII - 1995. pp. 1008 - 1009 etc. ${ }^{106}$ F. RAČKI, Hrvatska prije XII. vieka glede na zemljišni opseg i narod (La Croazia prima del secolo XII, quanto all'estensione del territorio e il popolo) Rad JAZU 56 - 57. Zagreb 1881. pp. 63 - 140, 102 - 149; I. GOLDSTEIN, Vrhunac hrvatskog ranosrednjovjekovlja (Il culmine dell'Alto Medioevo croato) - op.cit. 1995. pp. 406 412.; A favore di questo è anche il regno di Enrico II, come un periodo di scarsa presenza dell'impero nei territori marginali dell'Europa : M. BRANDT, op.cit.p. 508 sg.

${ }^{107}$ J. FERLUGA, Vizantinska uprava u Dalmaciji (L'amministrazione bizantina in Dalmazia). Beograd 1957. - offre il panorama più ampio dello sviluppo e dello stato dell'amministrazione bizantina sulla costa odierna della Croazia. Per le nostre domande specialmente pp. 120 - 123;V. anche I. GOLDSTEIN, O naravi bizantinske prisutnosti na istočnojadranskoj obali 6 - 12. st. (Della natura della presenza bizantina sulla costa adriatica orientale dal Vi. al XII. sec.). Radovi zavoda za hrvatsku povijest 24 /1991. p. 5 sg.

${ }^{108}$ G. OSTROGORSKI, Istorija Vizantije (La storia del Bisanzio). Cap. V / 1 - 2. Beograd 1959.

${ }^{109}$ F. ŠIŠIĆ, op.cit. 1925. pp. 497 sg. ; I. GOLDSTEIN, Hrvatski rani srednji vijek (L'Alto Medioevo croato). Zagreb 1995. pp. 364 -366.

${ }^{110} \mathrm{~J}$. LUČIĆ, Komunalno uređenje dalmatinskih gradova u 11. st. (L'organizzazione comunale delle città dalmate nel secolo XI.) Zbornik radova za povijesne znanosti JAZU - 10 / 1980. pp. 209-235.

${ }^{11}$ R. MORGHEN, Gregorio VII e la riforma della chiesa nel sec. XI. Palermo 1974.

${ }^{112}$ F. ŠIŠIĆ, op.cit. 1925. pp. 418 sg.

${ }^{113}$ F. KEMPF - in Velika povijest crkve; op.cit. No. 94 - pp. 356 - 372 ; B. HAMILTON, Monastic Revival in tenth-century Rome. Studia Monastica IV / 1962. pp. 35 - 68 ; A. FLISCHE, op.cit. cap. VIII, ; M. BRANDT, op.cit.pp. 514 - 520.

${ }^{124}$ I OSTOJIĆ, Benediktinci u Hrvatskoj (I Benedettini in Croazia). I - III. Split 1965. - passim, specialmente secondo indice.

${ }^{115}$ M. SUIĆ, Antički grad na istočnom Jadranu. Zagreb 1976. pp. 26, 35; I. OSTOIÍ, op. cit. vol. II. pp. 145 - 156.

116 “Vita B. Romualdi” : G. TABACCO, Fontes Storiae Italianae - 94 / 1957.; P. RICEPUTI, Acta s. Gaudentii I. p. 120 - 131., II. p. 371. etc.

${ }^{117}$ I. OSTOJIĆ, op.cit. spiegando la storia del monastero sottolinea che lo chiamavano "episcoporum seminarium" e lo consideravano il semenzaio "sanctorum et preclarissimorum virorum". - V. anche D. FARLATI, vol. V. p. 617.

${ }^{118}$ D. FARLATI, Ilyricum sacrum. Venezia 1800. vol. III. pp. 128 - 131.

${ }^{119}$ A. FLISCHE, Reforme gregorienne. Louvain 1924 ; M. JURKOVIĆ, Crkvena reforma i ranoromanička arhitektura na istočnom Jadranu (La riforma della chiesa e l'architettura della prima arte romanica all'Adriatico orientale). Starohrvatska Prosvjeta 20/1992.

${ }^{120}$ E. D. THEISEDER, L'idea imperiale di Roma nella tradizione del Medio Evo. Milano 1942.; G. MICCOLI, "Chiesa gregoriana": Ricerche sulla Riforma del secolo XI. Firenze 1966, - passim.

${ }^{12 t}$ W. ULLMAN, The Growth of Papal Government in the Middle Ages. London 1955; P. E. SCHRAMM, Kaiser, Könige un Papste. Stuttgart 1960. vol. IV. cap. C. ; P. IGNEO, Studi sull'età Gregoriana. Studi Storici per Medio Evo. Roma 1960. fasc. 40 - 41.

${ }^{122}$ Perciò anche I. GOLDSTEIN e gli altri storici croati parlano giustamente del "regno di Lorenzo". Lo sottolinea, del resto, anche lo stesso arcivescovo nel suo epitaffio “... quam ego dum rexi.." - l'analisi dell'iscrizione insieme alla traduzione viene offerta da Ž. RAPANIĆ, op. cit. 1987. pp. 145 - 146.

${ }^{123}$ I. OSTOJIĆ, op. cit. - secondo indice, riferendosi alle fonti e alla bibliografia più antica. In questo senso il ruolo di Lovro è quasi corrispondente a quello del grande Oddone di Cluny - R. W. SOUTHERN, The Making of the Middle Ages, 1953. pp. 158-159. - o a quello di Desiderio di Monte Cassino - H. E. COWDREY, op.cit. 1986. - quando si impegna dappertutto per la costituzione dello spirito monastico.

${ }^{124}$ I. OSTOJIĆ, op.cit. vol. II. pp. 320 sgg. - particolarmente nei monasteri di Santo Stefano e di San Benedetto di Spalato. Oltre ai collegamenti iniziali con : San Romualdo e San Gaudenzio di Ossero, sono importanti anche i contatti con il suo contemporaneo, il vescovo di Traù — Giovanni Ursini, proclamato beato - C. FISKOVIĆ, Legende i kronike, Split 1977. pp. 59-121. commentari di M. IVANIŠEVIČ, cap. III.

${ }^{125}$ Di questo riferisce il cronista di Spalato TOMA ARHIDAKON nel secolo XIII. : Kronika (Cronaca), ed. Split 1977. pp. 47 - 48 - riportando la notizia che mandava gli artisti a studiare in Anatolia, che aveva arricchito il tesoro della cattedrale, che badava alla musica e che aveva invitato il dotto Adamo di Parigi a scrivere le biografie dei santi protettori e martiri locali : F. RAČKI, Documenta ... pp. 446 - 447. ; N. KLAIĆ, op.cit. 1971 . p. 493.

${ }^{126}$ T. KEMPF, Unutrašnji pokret kršćanskog zapada u vrijeme reforme (Il movimento interno dell'Occidente cristiano nel tempo della riforma): Regnum e sacerdotium. Velika povijest crkve III / I. ed. H. Jedin, Zagreb 1971. cap. 49 - 50.

${ }^{127}$ LJ. KARAMAN, Pregled umjetnosti u Dalmaciji (Il panorama dell'arte in Dalmazia). Zagreb 1956. ; M. PRELOG, Hrvati - Umjetnost (ICroati - L'arte). Enciklopedija Jugoslavije (Enciclopedia Jugoslavica) IV / 1959. pp. 90 - 92.

${ }^{128}$ M. JURKOVIĆ, Pojava romaničke arhitekture u Hrvatskoj (L'apparizione dell'architettura romanica in Croazia). Rađanje hrvatskog kulturnog pejsaža (La creazione del paesaggio culturale della Croazia). Zagreb 1996. pp. 325 - 338 ; J. BELAMARIĆ, Pojava hrvatske romaničke skulpture (L'apparizione della scultura romanica in Croazia). Ibid. pp. 357 - 370.

${ }^{129}$ I. FISKOVIĆ, Apport des reconstructions d'églises de l'antiquité tardive dans la formation du premier art romane sur le littoral croate. Hortus Artium Medievalium I / 1995. pp. 14 - 27.

${ }^{130}$ A. FRANZEN, Pregled povijesti crkve (Il panorama della storia della chiesa). Zagabria 1983.pp. 143 - 158; C. H. LAWRENCE, Il monachesimo medioevale. Milano 1993. cap. VI.

${ }^{131}$ G. GAY, I papi del secolo XI e la Cristianità. Firenze 1968. pp. 128 sg. ; F. JAFFE, Regesta pontificum Romanorum I. : Nicholas II. Graz 1956.

${ }^{132}$ H. E. COWDREY, L'abbate Desiderio e lo splendore di Monte Cassino. Milano 1986; H. JEDIN, op.cit. 1971. pp. 405 - 407. Bisogna tener presente che a partire dal tempo di Leone IX (1048 - 1057) un'influenza straordinaria nella curia romana, nonché in tutta l'Europa, era esercitata dal monaco Ildebrando che più tardi diventerà papa Gregorio VII. V. più avanti le note 148 - 152. 
193 Su questo FARLATI, op.cit. vol, II. pp. 128 - 130. - Denomina Majnard come "Montis Cassinis monachus", benché si affondi nell'incertezza quanto alla sua identità. Da F. JAFFE, op.cit. pp. 557, 566 - è registrato come vescovo di Silva Candida, e bibliotecario della biblioteca Vaticana, Cfr. : F. ŠIšśC, op.cit. pp. $502-505$.

${ }^{134}$ Per i dati originali menzionati in precedenza e più avanti V. Codex Diplomaticus Regni Croatiae, Dalmatiae ... I / 1967. Doc. 64. l'anno 1060, poi 68, 74, 77. 98 etc. V. anche F. RAČKI, Documenta historiae Chroaticae periodum antiquam. Zagreb 1977. Doc. No. 83, 99 - 100.

${ }^{135}$ J. ŠIDAK, Historijska čitanka (Letture storiche). Zagreb 1936. pp. 19 - 21.

1:36 I. OSTOJIĆ, op. cit. vol. II. pp. 75, 217 - 218 etc. - scrive dei monasteri singolarmente.

${ }^{137}$ F. ŠIŠIĆ, op.cit. Cap. IV. - suppone giustamente che fosse nato ed educato a Venezia e che avesse avuto il nome di ambedue i nonni. Da tutta la sua biografia risulta evidente che si impegno per la legalità della chiesa universale e che si oppose al potere straniero nel suo paese; era dunque fautore dei principi di governo che ezano in vigore in tutta l'Europa proprio dal tempo di Enrico II. - Cfr. H. JEDIN, op.cit. pp. 375 - 387.

${ }^{138}$ Come, insieme a V. KLAIĆ, Regnum Croatiae et Dalmatiae. Sveslavenski zbornik, Zagreb 1930. pp. 79 - 89, sottolineano F. ŚIŠIĆ, J. FERLUGA e altri, con l'osservazione che in questi documenti i rappresentanti dell'autorità di Bisanzio appaiono irregolarmente. Cfr. F. RAČKI, Documenta ... — dal 1058 al 1067. Doc. No. 40, 41, 53, 57 etc.

${ }^{139}$ Su questo in modo particolare F. ŠŠŠĆ, op.cit. pp. 530. sg. e N. KLAIĆ, Povijest Hrvata u ranom srednjem vijeku (La storia dei Croati nell'Alto Medioevo). Zagreb, 1971. Cfr. : M. BRANDT, op.cit. 1980. pp. 462, $514 \mathrm{sgg}$.

${ }^{140}$ Anche I. GODSTEIN, op.cit.

${ }^{141}$ N. KLAIĆ, Zadar u srednjem vijeku do 1409.(Zara nel Medioevo fino al 1409). Prošlost Zadra (La storia di Zara) I / 1976. pp. 77 - 105.

142 Fino ai tempi più recenti: M. ZEKAN, King Zvonimir - Documents and Monuments. Zagabria 1990. (Catalogo della mostra), e gli altri studi citati degli autori più moderni.

${ }^{143}$ F. ŠANJEK, Crkva i kršćanstvo u Hrvata (La chiesa e il Cristianesimo dai Croati). Zagreb 1988. pp. 136 - 142. ; il rilievo di Spalato designa invece "La figura di un dignitario croato" - p. 7.

${ }^{144}$ Fra gli altri : N. BUDAK, Prva stoljeća Hrvatske (Primi secoli di Croazia), Zagreb 1996. pp. 41-45.

${ }^{145}$ F. ŠIŠIĆ, op.cit. cap. VI. ; N. BUDAK, Hrvatska društva u 11. st. (Le società croate nel secolo XI). Zbornik "Zvonimir kralj hrvatski", Zagreb 1997. pp. $207-212$.

${ }^{146}$ Codex diplomaticus, doc. 124. ecc.

${ }^{147}$ A. FLISCHE, La reforme gregorienne. I - III, Louvain 1924 - 1937 ; P. BREZZI, op.cit. 1972. cap. V/ 3. Biografia di Ildebrando, la sua personalità, il suo programma. pp. $153-159$.

${ }^{148}$ R. MORGHEN, op.cit. pp. 457 sg.; G. SORANZO, Aspetti del pensiero e dell'opera di Gregorio VI e lo spirito dei tempi. "Aevum" 22 / 1948. pp. 309 - 322. I principi concreti della teocrazia pontificia sono stati spiegati dettagliatamente in più luoghi, in consegvenza dell'atto "Dictatus Papae" del 1075 : J. LE GOFF, Il Basso Medioevo. Milano 1967. Papato e Impero : la lotta per il Dominum Mundi, pp. 92 - 97. etc.

${ }^{149}$ F. KEMPF, Grgurouska reforma (La riforma gregoriana). Velika povijest crkve III / I. part. II / I. pp. 393 - 451, 474 - 485.

${ }^{150}$ E. VOOSEN, Papauté et pouvoir civil à l'époque de Gregoire VII. Gembloux 1927. pp. 7 - 157 ; K. HOFMANN, Die "Dictatus Papae" Gregors VII. Paderborn 1933 ; F. KEMPF, op.cit. Cap. 50. pp. 486 - 495.

${ }^{151}$ N. KLAIĆ, Pobjeda reformnog Rima na Jadranu za pape Grgura VII. (La vittoria della Roma riformista nell'Adriatico all'epoca del papa Gregorio VII.). Vjesnik historijskog arhiva Rijeka, 28 / 1981, pp. 147 - 202.

${ }^{152}$ R. MORGHEN, Gregorio VII e la riforma della chiesa nel secolo XI. Palermo 1974.

${ }^{153}$ LJ. KARAMAN, Deux portraits de souverains yugoslaves sur des monuments dalmates du haut Moyen age. Byzantion IV/ 1929. pp. 321 - 386. fig. 2. Ringrazio il collega A. Gulin per la fotografia del sigillo.

1 .54 "Ornamenta Ecclesiae" - Kunst und Künstler der Romanik - II. Colonia 1985. pp. 15 - 61; Cfr: W. EWALD, Siegelkunde. Wien 1972.

${ }^{155}$ N. KLAIĆ, Izvori za hrvatsku povijest do 1526. god. (Fonti della storia croata fino al 1526). Zagabria 1972. pp. 68 - 69. ; Però tutti hanno trascurato il fatto che Zvonimir ebbe del papa "vexillum, ensem, sceptrum et coronam" - F. RAČKI, Documenta... No. 87, pp. 103 - 104. - mentre nel rilievo ci sono insegne differenti: la croce e la sfera, che secondo le disposizioni di Gregorio VII nessun sovrano secolare doveva più portare — erano insegne riservate esclusivamente al Santo Padre : P. E. SCHRAMM, Sacerdotium und Regnum im. Austach ihrer Vorrechte. Studia Gregoriana II / 1947. pp. 403 - 407. e altri.

${ }^{156}$ H. FILLITZ, Die Insignien und Kleinodien des Heiligen Romischen Reiches. Wien 1954.

${ }^{157}$ H. JEDIN, op.cit. pp. 330. ; M. BRANDT, op.cit. pp. 499 - 500. ; Sulla fermezza della seconda fase della riforma diretta soprattutto da parte della curia romana : G. BARONE, La riforma gregoriana. in "Storia dell'Italia religiosa" - I. ed. Laterza 1993. pp. 242 - 256.

${ }^{154}$ R. MORGHEN, Medioevo cristiano. Bari 1951.pp. 212 - 286 ; IDEM, Movimenti religiosi popolari nel periodo della Riforma della Chiesa. Relazioni III Internazionali di scienze storiche. Firenze 1955. pp. 333 - 356.

${ }_{159}$ N. KLAIĆ, op.cit. 1971, con il panorama più ampio delle circostanze: cap. VII - VIII.

${ }^{160}$ I. GOLDSTEIN, op.cit. pp. $366-368$.

${ }^{16 i}$ F. ŠIŠIĆ, op.cit. p. 516. sg. ; T. MACAN, Povijest hrvatskog naroda (Storia del popolo croato), Zagreb 1992. pp. 41-43.

${ }^{162} \mathrm{~F}$. ŠIŠIĆ, op.cit.pp. 510. sg. - Si può osservare senz'altro che l'atteggiamento del re rispetto ai problemi religiosi, soprattutto in relazione all'esistenza della diocesi croata, non fu costante, cioè presento delle oscillazioni. Perciò anche le nostre tesi andranno verificate più dettagliatamente attraverso lo studio della storia della chiesa dell'Alto Medioevo in Croazia.

${ }^{163}$ N. KLAIĆ, op.cit. 1971. p. 373. ; I. GOLDSTEIN, op.cit.

${ }^{i 61}$ F. ŠIŠIĆ, op.cit. ; Il ruolo nell'interruzione dell'influenza bizantina in Dalmazia viene attribuito a P. Krešimir anche dal "Dictionnaire d'histoire et de géographie ecclesiastiques" - 14/1960. p. 33.

165 J. FERLUGA, op. cit.pp. 123 - 126.

${ }^{166}$ Cioè, in quell'anno la Dalmazia e Spalato passano alla Croazia, con il consenso di Bisanzio - F. ŠIŠ́Ć, op.cit. pp. 522 - 524 . - e allo stesso anno rísale anche l'iscrizione con la menzione di Lovro e P. Krešimir nella chiesa di S. Eufemia, della quale parlo alla fine del testo. Si menzionò allora per la prima volta il reggente, lo stratego della Dalmazia: J. FERLUGA, op.cit. p. 105.

${ }^{167}$ J. FERLUGA, op.cit. 1957. pp. $120 \mathrm{sg}$.

${ }^{168}$ Su questo più ampiamente nella rassegna delle opinioni sul rilievo. La tesi è infatti stata definita da E. DYGGVE, - V. nota 73 - ed ha avuto molti sostenitori dei quali nessuno ha offerto un'argomentazione più approfondita, provando soltanto la somiglianza approssimativa della lavorazione di quei rilievi con quelli di Spalato. 
${ }^{169}$ Dopo la relazione sui ritrovamenti, su questo insiste particolarmente I. PETRICIOLI - op.cit. 1960 - e nello studio speciale : op.cit. 1975 - V. note 23, 24. - attenendosi soprattutto alla valutazione morfologica.

${ }^{170}$ N. KLAIĆ, op.cit. 1972. pp. 67 - 69. ; Per chiarire le circostance della costruzione della chiesa risultano importanti le osservazioni circa l'iscrizione sulla transenna, perché rivelano la dedicazione dell'abbate benedettino, superiore del monastero reale di quel luogo, il monastero di SS. Pietro e Mosè : V. DELONGA, Ranoromanički natpisi u latinskoj epigrafici kraljevske Hrvatske (Le iscrizioni della prima arte romanica nell'epigrafia della Croazia reale), ed. Hrvatsko arheološko društvo Ediz. (L'associazione arheologica della Croazia) - 15 / 1992. p. 81.

${ }^{171}$ Sembra che un'analisi morfologica più dettagliata, insieme alle ragioni storico-culturali, separerà inevitabilmente "le sculture preromaniche di Zara e quelle Spalato, che I. Petricioli collega in un'unica bottega artistica - V note 23-25.

${ }^{172}$ Di essa hanno scritto in modo particolare gli autori più antichi - V, nota 17 . ecc.

${ }^{173}$ J. CHEVALIER - A. GHEERBRANT, Rječnik simbola (Il dizionario dei simboli). Zagabria 1983 pp. 494.; F. BULIĆ, Hrvatski spomenici u kninskoj okolici iz doba narodne dinastije (Monumenti croati negli intorni di Knin...). Zagreb 1888. pp. 41 - 43.

${ }^{174}$ Ibid, pp. 540 - 542.; F. BULIĆ, op. cit., 1888. pp. 41-43

${ }^{175}$ IDEM, Rječnik... pp. 814 - 816.

${ }^{176}$ LJ. KARAMAN, Iz kolijevke Hrvatske prošlosti. Zagreb 1930. e le altre opere da J. STRZYGOWSKI a N. JAKŠIĆ.

${ }^{177}$ J. CHEVALIER ... op.cit. no. 20. pp. 514 - 515. con i commenti più nuovi dei monumenti in Croazia.

${ }^{178} \mathrm{Cfr}$. Ž. RAPANIĆ, Kamena plastika ranog srednjeg vijeka u Arheološkom muzeju u Splitu (La plastica di pietra dell'Alto Medioevo nel Museo archeologico a Spalato). Bulletino d'archeologia e la storia dalmata 60 / 1957 - 1963. pp. 98 - 124.

${ }^{179}$ Per il momento sembra che non esistano opere che possano essere più direttamente collegate con le lastre del battistero - Cfr. Ž. RAPANIĆ, Predromaničko doba u Dalmaciji (L'età preromanica in Dalmazia). Spalato 1987. pp. 176 - 177. - con l'esame teorico dei prinicipi della formazione dei plutei.

${ }^{180}$ La descrizione più dettagliata in L. JELIĆ, op.cit. 1886. e le nozioni sulla costruzione della fonte in D. DOMANČIĆ, op.cit. 1976. Le osservazioni più ampie anche nei testi sul rilievo di LJ. KARAMAN, 1925 e 1964, e la descrizione di tutti i plutei in I. PETRICIOLI, op.cit. 1960.

${ }^{181}$ E' rilevante senz'altro che il complesso della cattedrale già nel secolo XII, e poi nel secolo XIII si procurava nuove suppellettili in pietra, con ricche decorazioni, ma stilisticamente più moderne. Su questo T. BURIĆ, Arheološki tragovi kasnobizantske epohe na istočnoj obali Jadrana. Diadora 16 - 17. Zadar 1996. pp. 377 - 380 .

${ }^{102}$ Su questo per esteso in LJ. KARAMAN, op. cit. 1925. - Vedi anche nota 12 - Tuttavia rimane da trattare più dettagliatamente, nonché catalogare necessariamente un numero considerevole delle sculture dell'Alto Medioevo della città di Spalato.

${ }^{183}$ Il primo ad accennare alla sua esistenza è stato C. FISKOVIĆ, grazie al incisione di L. F. CASSAS del 1782 : dopo il campanile fu abbattuto e dimenticato benché venga menzionato negli archivi : Visitationes Spalatenses - 1604 - p. 11; 1682 - p. 28; 1714 etc. Dall'altra parte, il fatto che sulla sua facciata, su un'asse si succedono tre bifore come le sole aperture del cubo snello, dice che il campanile è stato costruito dopo quello simile ma molto più chiuso della piccola chiesa della Vergine sopra la vicina Porta Ferrea, nel centro medievale di Spalato costruito verso la fine del secolo XI: J. BELAMARIĆ, Gospa od zvonika u Splitu (Vergine del campanile a Spalato). Monumenta croatica 1. Zagreb 1991.

${ }^{184}$ D. KEČKEMET, Figuralna skulptura romaničkog zvonika splitske katedrale (La scultura figurativa del campanile romanico della cattedrale di Spalato). Prilozi povijesti umjetnosti u Dalmaciji, 9. Split 1955.

${ }^{185}$ La chiesa medievale a tre navate, dalle dimensioni monumentali, fu dedicata a San Pietro, il che è indicativo per la sua datazione nella prima fase della riforma, a cui appartiene tutta una serie di chiese con lo stesso nome in Dalmazia. Interpolata nella basilica molto più grande del primo Cristianesimo, era collocata infatti proprio sul confine tera la Dalmazia veneziana e quella turca, e fu esposta alle distruzioni anche prima delle guerre del Seicento.

${ }^{186}$ Oltre ai frammenti dei plutei, sono state riconosciute anche le parti del ciborio, cosicché l'arredo presbiteriale è press'a poco completo, benché si tratti di frammenti : I. PETRICIOLI, op.cit. 1975. pp. 113-117. figs. 2 - 10.

${ }^{187}$ Si può supporre che la cattedrale nell'edificio del mausoleo imperiale della Tarda Antichità richiedeva necessariamente l'arredamento sontuoso, quanto riguardo ai bisogni litturgici da una parte, tanto alla concezione del rinnovamento dello splendore e della stima della Roma antica che era il modello della cultura del secolo XI : P. E. SCHRAMM, op.cit. 1958. - la teoria "Renovatio imperii Romanorum" : pp. 62 - 63 etc. Inoltre, sul pavimento della chiesa si vedono le tracce delle suppellettili medievali, che, purtroppo non sono conservate sufficentemente da dar luogo a una ricostruzione coerente dell'eventuale posizione simetrica degli elementi del presbiterio arredato.

${ }^{188}$ Su molte recinzioni di pietra nell'antica arte croata si usavano mettere iscrizioni di carattere votivo o simile, importanti per la datazione, nonché per l'identificazione dei donatori: V. DELONGA, op.cit. 1996.

${ }^{189}$ Queste tracce sono infatti notate molto tempo fa, ma non vennero considerate importanti fino a quando non vi accennò Ž. JIROUŠEK, che neanche per mezzo delle indagini più dettagliate è riuscito ad ottenere più informazioni di quante abbiamo a disposizione.

${ }^{190}$ La tecnica dell'installazione della fonte è stata esposta da D. DOMANČIĆ, op.cit.

${ }^{19]}$ Come lo descrivono L. JELIĆ e LJ. KARAMAN, accennando alle molteplici modificazioni nella struttura del monumento fino al secolo XVI.

${ }^{192}$ Le interpretazioni di L. JELIĆ del 1886 sembrano pure troppo libere, ma nessuno dopo di lui ha trattato i problemi epigrafici del battistero, benché in genere si sia dubitato sulla correttezza della sua affermazione. - V. nota 80.

${ }^{193}$ Su questo: G. CAMES, op.cit. ; A. CAMERON, Images of Authority, Birmingham 1981. - con tutta una serie di esempi nella bibliografia citata specialmente per quanto concerne le miniature: J. K. EBERLIN, Apparitio Regis - revelatio veritatis. Wiesbaden 1982.

${ }^{194}$ Della natura laica di tutte le figure testimoniano in un certo modo i costumi, e soprattutto i visi coperti di barbe, che ai preti in Croazia e in Dalmazia aveva esplicitamente proibito il sinodo ecclesiastico di Spalato nel 1059, con la tendenza evidente ad interrompere alcune usanze della chiesa greca che sopravvivevano da queste parti attraverso le tracce dell'influenza bizantina : I. GOLDSTEIN, op.cit.

${ }^{195}$ Sulle questioni dinastiche dell' XI sec. : N. KLAIĆ, op. cit. 1971. pp. 478-485.

${ }^{196}$ Storia della chiesa - VII. Torino 1976. p. 457. e sg. S. 3. "Scomparsa del Dominium secolare."

${ }^{197}$ F. ŠŠSIĆ. op.cit. cap. III/3. - presenta in un modo più ampio la situazione della chiesa, nonché i conflitti tra le città e i territori dello Stato croato, accennando all'orientamento del re Petar Krešimir IV verso le correnti progressiste. Aperto rimane a sua volta ie questo se motivo principale dei conflitti posse la libertà di mantenere la liturgia slava, come spiega in genere la storiografia nazionale fino ai tempi più recenti.

${ }^{198}$ Petar Krešimir portava il titolo "rex Croatiae et Dalmatiae", come anche Lovro era chiamato "primas Dalmatorum et Chroatorum" - F. ŠIŠIĆ, op.cit. 1925. Anche V. KLAIĆ, op. cit. nota 139. etc. 
${ }^{199}$ Cfr. : Codex Diplomaticus I - doc. 80 fino al 1068 ... "regnante Cressimiro re Chroatorum et Dalmatinorum ... ego Laurentius, nuper ecclesae presul divina ministrante clementia ... Spalatine sedis electus et ordinatus arhiepiscopus ..." etc.

${ }^{200}$ C. FISKOVIĆ, Iskopine srednjovjekovne crkve sv. Eufemije u Splitu (Gli scavi della chiesa medievale di Santa Eufemia a Spalato). Historijski zbornik, I / 1948. pp. 201 - 211. - con tutti gli altri ritrovamenti archeologici che hanno messo in luce anche i frammenti in pietra. Essi mostrano la possibilità che la chiesa abbia cambiato a più riprese le sue suppellettili ornamentali.

${ }^{201}$ L'iscrizione era stata incisa sull'architrave del portale che non mostra le caratteristiche del primo stile romanico e sembra essere più tardo, sebbene non si escluda la possibilità che fosse modificato. E' evidente anche che l'iscrizione di due linee fu cancellata - V: I. FIŚKOVIĆ, op. cit. no. 81. - e si sa che questo fu eseguito nel 1736 su ordine delle autorità della Serenissima, mentre la nota sul suo contenuto è giunta da noi in maniera indiretta : D. FARLATI, op.cit.

${ }^{202}$ Già prima ho scritto sulla misura in cui la chiesa di Santa Eufemia era anche nel corso dei secoli successivi un luogo di confluenza dei nobili croati del retroterra, intesa probabilmente come un luogo sacro collegante i portatori del pensiero nazionale e la tradizione del paese con la società comunale della capitale di Dalmazia: I. FISKOVIĆ, Nadgrobna plastika humanističkoga doba na našem primorju (La plastica sepolcrale dell'età umanistica nel nostro litorale). Dometi XVIII / 1-3. Rijeka 1984. pp. 85-87. ; IDEM, Dalmatinski prostori i stari majstori (Le terre dalmate e $i$ maestri antichi). Spalato 1990. pp. 56, $67-72$.

\section{HRVATSKI KRALJ NA RANOROMANIČKOME RELJEFU U SPLITU}

Višestranom analizom znamenitoga reljefa na kojem glavnu ulogu ima kralj na prijestolju i uz njega dva pobočna lika, autor uz široku valorizaciju tumači sadržaj kompozicije kako najzanimljivije mramorne ploče tako čitave oltarne ograde kojoj ona bijaše sastavni dio. Ujedno dokumentira današnje njeno stanje sa sekundarnim smještajem u krstionici splitske katedrale iz čega posredno izvlači konačne zaključke o sudbini djela neodvojivog od sredine južnohrvatske metropole. Svakako otklanja tvrdnje o prikazu Krista u bilo kojem vidu te daje razloge za spoznavanje ikonografske tematike svjetovnog ili zemaljskog vladara s temeljnom političko-propagandnom nakanom. U tom smislu razlistava analogna rješenja iz drugih medija likovnog stvaralaštva zapadne Europe uočavajući sličnosti na razini simboličnih pojedinosti a sa ciljem otkrivanja idejnih ishodišta djela u vezama otonske umjetnosti i benediktinskih matica Italije.

Ključ čitanju reljefa iznalazi u jednoj minijaturi njemačkog podrijetla iz evanđelistara cara Henrika II, radenog za Monte Cassino 1022. god. Ističući pak antologijsku vrsnoću splitskog spomenika kao uopće najmonumentalnijeg ostvarenja među umjetninama regalnog značaja u prostoru srednjovjekovne Europe, uz prepoznavanje stilskih značajki kiparske obrade, nastoji dokazati da bijaše namijenjen nekoj važnoj crkvi u središnjem gradu srednjovjekovne Dalmacije, tj. Splitu umjesto Solinu kako se prije uglavnom mi- slilo. Podrobnije tumači povijeśne uvjetovanosti nastanka djela u vrijeme vladavine kralja Petra Krešimira IV (treća četvrtina 1l. st.), koji je najvjerojatnije tu i predočen prema uopćenom predlošku Rex iustusa. Mogućnosti osmišljenja takvog figuralnog prikaza nastoji raskriti unutar prve faze velike reforme univerzalne Crkve s naglaskom na ulozi nadbiskupa Lovre, kao učenog i poduzetnog primasa Dalmacije koji se iz Splita uspješno zalagao za povezivanje svoje ustanove s hrvatskim kraljem. Zbrajajući ostale sve podatke iz tijeka crkvene reforme i hrvatske povijesti, uglavnom odbija mogućnosti postanku djela u kasnijem dobu vladavine kralja Dmitra Zvonimira, što se navodi kao gotova činjenica u mnogim recentnim tekstovima, čak uz tvrdnje da reljef izravno njega i predočuje.

Takva se obrazloženja slijedom povijesnih mijena podgrađuju s utvrđivanjem čina "damnatio memoriae" kojem reljef bijaše podvrgnut malo poslije izvorne izrade a potom premješten u krstionicu prije 13. st. Ocrtavanjem idealnog njegovog značenja u kontekstu kulturnog razvoja i političkih zbivanja iz razdoblja prve romanike na Jadranu, najopširnije dosad se predlaže razriješenje slojeva zagonetke što se odavno plela oko mnogostruko važnog spomenika. $\mathrm{Na}$ kraju otvara mogućnost o podrijetlu reljefa iz crkve sv. Eufemije uz prvi samostan splitskih benediktinki koji su udruženom djelatnošću podigli nadbiskup Lovro i kralj Petar Krešimir 1069. godine. 